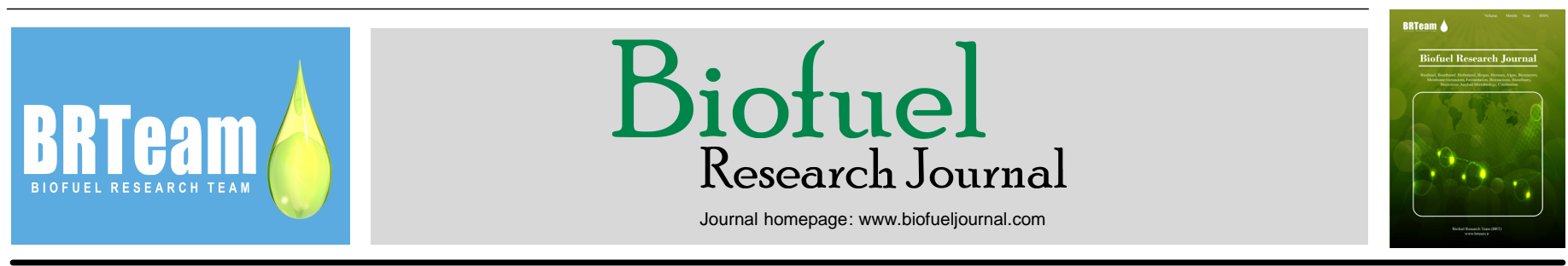

Review Paper

\title{
A comprehensive review on biodiesel purification and upgrading
}

\author{
Hamed Bateni ${ }^{1,2}$, *, Alireza Saraeian ${ }^{1}$, Chad Able ${ }^{2}$ \\ ${ }^{1}$ Department of Chemical and Biological Engineering, Iowa State University, Ames, IA 50011, USA. \\ ${ }^{2}$ Department of Chemical and Biomolecular Engineering, Ohio University, Athens, OH 45701, USA.
}

\section{HIGHLIGHTS}

$>$ Various biodiesel purification methods, i.e., equilibrium-based, affinity-based, and reaction-based separation techniques along with membrane technology and solid-liquid separation processes were reviewed.

$>$ Deoxygenating process via hydrodeoxygenation and decarboxylation/decarbonylation pathways is a common way to upgrade bio-based oils to produce biorenewable diesel with excellent fuel properties. $>$ Catalysts and operating conditions, i.e., pressure, temperature, and contact time, are the most important variables in biodiesel upgrading discussed herein.

\section{GRAPHICAL ABSTRACT}

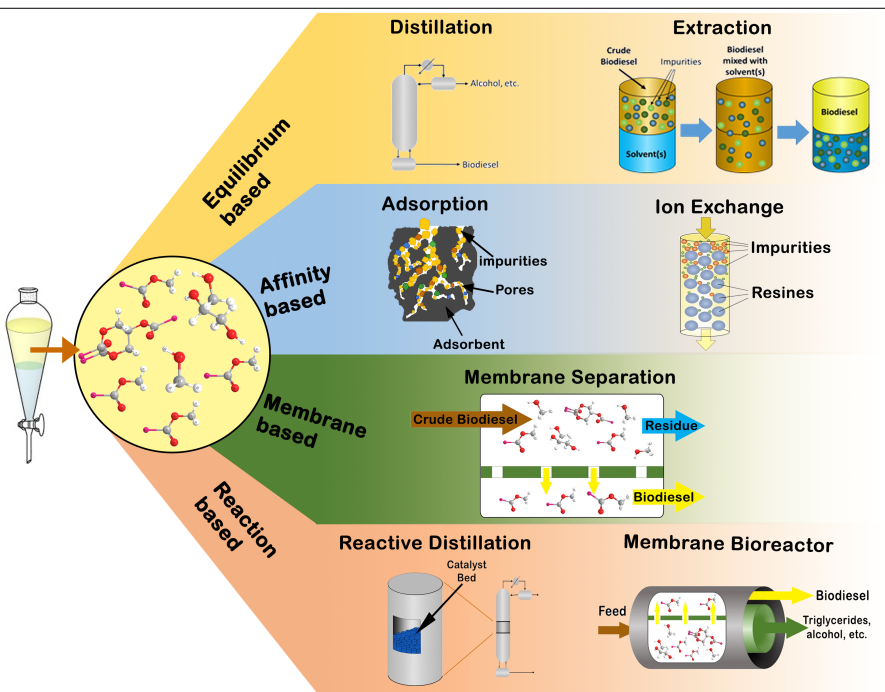

\section{ARTICLE INFO}

\section{Article history:}

Received 1 July 2017

Received in revised form 13 August 2017

Accepted 13 August 2017

Available online 1 September 2017

\section{Keywords:}

Biodiesel

Biodiesel separation

Biodiesel purification

Biodiesel upgrading

Separation and purification

\begin{abstract}
Serious environmental concerns regarding the use of fossil-based fuels have raised awareness regarding the necessity of alternative clean fuels and energy carriers. Biodiesel is considered a clean, biodegradable, and non-toxic diesel substitute produced via the transesterification of triglycerides with an alcohol in the presence of a proper catalyst. After initial separation of the by-product (glycerol), the crude biodiesel needs to be purified to meet the standard specifications prior to marketing. The presence of impurities in the biodiesel not only significantly affects its engine performance but also complicates its handling and storage. Therefore, biodiesel purification is an essential step prior to marketing. Biodiesel purification methods can be classified based on the nature of the process into equilibrium-based, affinity-based, membrane-based, reaction-based, and solid-liquid separation processes. The main adverse properties of biodiesel - namely moisture absorption, corrosiveness, and high viscosity - primarily arise from the presence of oxygen. To address these issues, several upgrading techniques have been proposed, among which catalytic (hydro)deoxygenation using conventional hydrotreating catalysts, supported metallic materials, and most recently transition metals in various forms appear promising. Nevertheless, catalyst deactivation (via coking) and/or inadequacy of product yields necessitate further research. This paper provides a comprehensive overview on the techniques and methods used for biodiesel purification and upgrading.
\end{abstract}

(C) 2017 BRTeam. All rights reserved.

* Corresponding author at: Tel.: +17405907588

E-mail address: hbateni@iastate.edu

Please cite this article as: Bateni H., Saraeian A., Able C. A comprehensive review on biodiesel purification and upgrading. Biofuel Research Journal 15 (2017) 668-690. DOI: 10.18331/BRJ2017.4.3.5 


\section{Contents}

1. Introduction

2. Biodiesel Purification

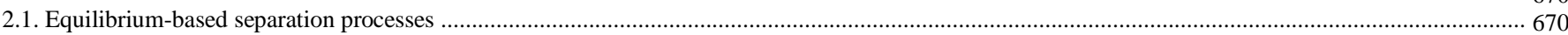

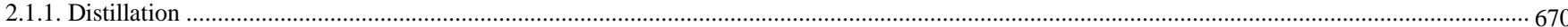

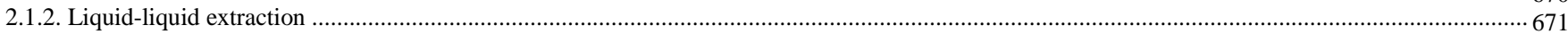

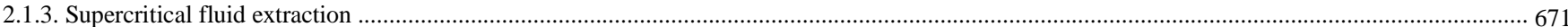

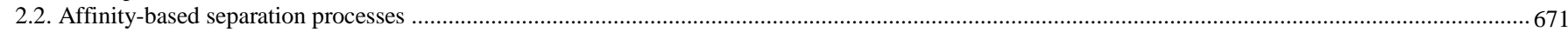

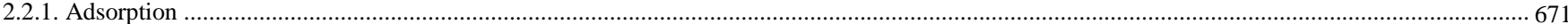

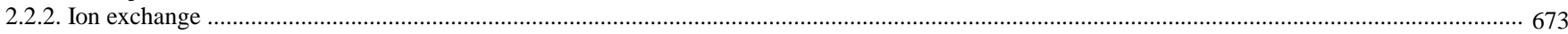

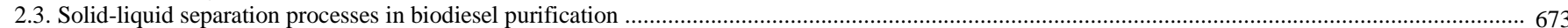

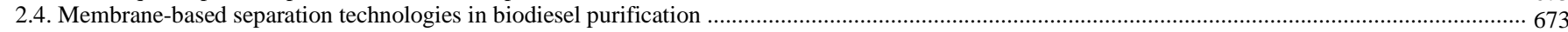

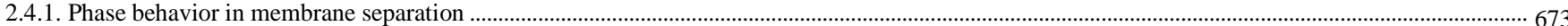

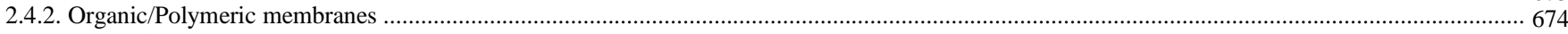

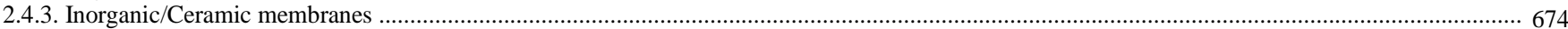

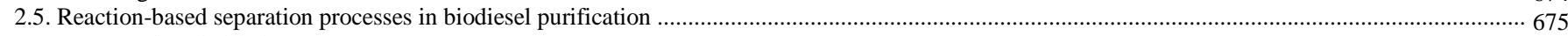

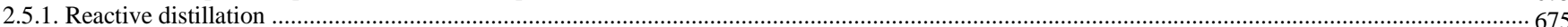

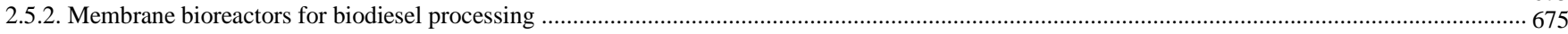

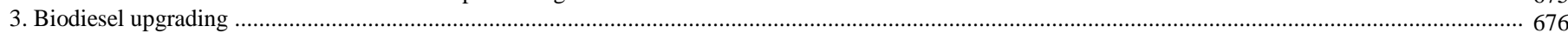

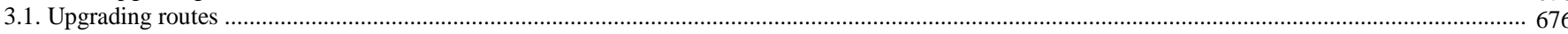

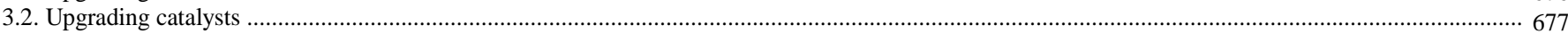

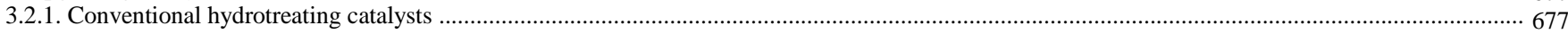

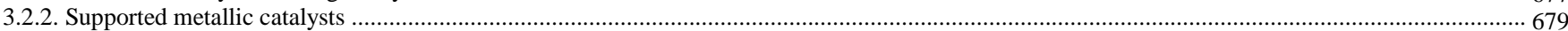

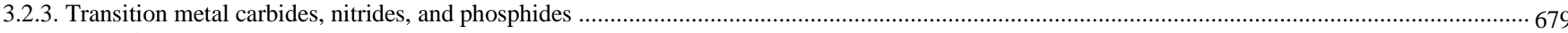

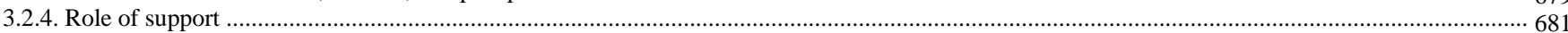

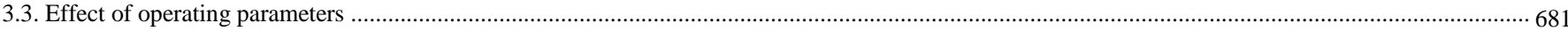

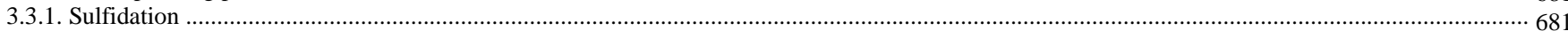

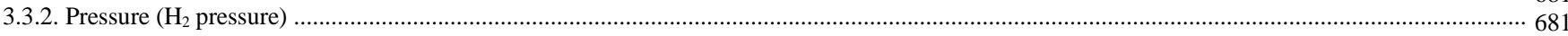

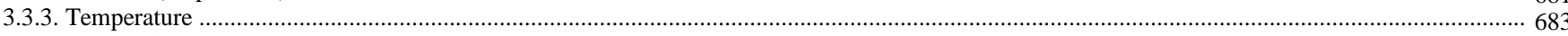

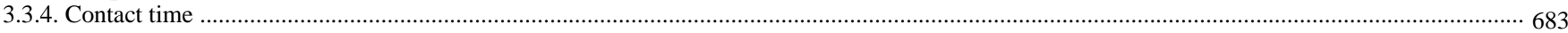

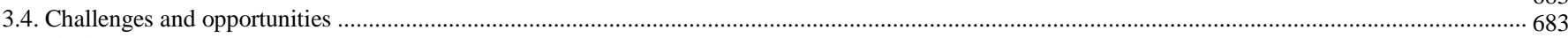

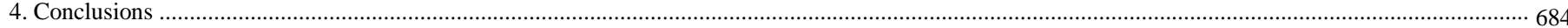

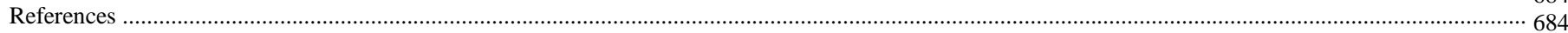

\begin{tabular}{|ll|}
\hline Abbreviations & \\
AC & Activated carbon \\
alc. & Alcohol \\
cra. & cracking/hydrocracking \\
DCO & Decarbonylation \\
DCO2 & Decarboxylation \\
DES & Deep Eutectic Solvents \\
dim. & Dimerization \\
est. & Esterification \\
FA & Fatty acid \\
FAAEs & Fatty acid alkyl esters \\
FAME & Fatty acid methyl ester \\
FFAs & Free fatty acids \\
HDO & Hydrodeoxygenation \\
IL & Ionic liquid \\
iso. & Isomerization \\
ket. & Ketonization \\
LLE & Liquid-Liquid Extraction \\
MD & Molecular distillation \\
MeOH & Methanol \\
met. & Methanation \\
NMWCO & Nominal molecular weight cutoff \\
olf. & Olefin \\
PVDF & Polyvinylidenefluoride \\
RHA & Rice husk ash \\
SA & Stearic acid \\
SCO & Spent cooking oil \\
SFE & Supercritical fluid extraction \\
SFFO & Spent fish frying oil \\
THF & Tetra hydrofurane \\
\hline & \\
\hline
\end{tabular}

\section{Introduction}

Biofuels have received a great deal of attention due to the increase in global energy demands and the necessity of alternative clean fuels and energy (Bateni et al., 2016; Samadi et al., 2017). Biodiesel is a petroleum diesel substitute and one of the most promising biofuels due to its environmental compatibility and biodegradability (Bateni and Karimi, 2016a and b; Tremblay and Montpetit, 2017). Non-edible vegetable oils as well as algae and waste oils, consisting mainly of triglycerides and free fatty acids (FFAs), are potential biorenewable feedstocks for producing biodiesel since they have hydrocarbon chains in the range of diesel fuel $\left(\mathrm{C}_{12}-\mathrm{C}_{18}\right)$ and do not raise the "food vs. fuel" conflict (Chhetri et al., 2008; Escobar et al. 2009; Greenwell et al., 2009; Srinivasan, 2009; Zhao et al., 2013). In line with that, many researchers have attempted to produce transportation fuels from these feedstocks via various methods. Thermal cracking (pyrolysis), catalytic cracking, and catalytic hydrocracking have been tested on these feedstocks (Stumborg et al., 1993; Twaiq et al., 1999; Parvizsedghy et al., 2015). The problem with these processes is the overall low energy efficiency due to considerable formation of $\mathrm{C}_{1}-\mathrm{C}_{4}$ hydrocarbons (Twaiq et al., 1999). Microemulsions of oil with solvents (and/or surfactants) such as water, methanol, ethanol, and 1-butanol have also been proposed to reduce the viscosity of bio-oils (Bora et al., 2016). However, several issues like unstable fuel properties, miscibility limitations, and heavy carbon residues during combustion have not been addressed (Ma and Hanna, 1999; Snåre et al., 2009).

Transesterification of triglycerides with short-chain alcohols (i.e., methanol or ethanol) in the presence of an alkali catalyst has been most widely used to obtain "biodiesel" or essentially fatty acid alkyl esters (FAAEs) (Ma and Hanna, 1999; Bateni and Karimi, 2016a; Bateni et al., 2017; Tremblay and Montpetit, 2017). Glycerol is an important by-product of the transesterification reaction, which needs to be separated from the biodiesel phase (Atadashi et al., 2011a; Shafiei et al., 2017). Depending on regional regulations, biodiesel needs to meet certain characterizations prior to reaching the market. Even though the densities of biodiesel and glycerol 
are distinct enough from one another to be separated via gravitational settling and centrifugation (Van Gerpen et al., 2004; Atadashi et al., 2011b), further purification is required to remove impurities (i.e., remaining vegetable oil, alcohol, catalyst, soap, and FFAs) and meet the standard specifications introduced in ASTM D6571 or EN14214. Low-quality biodiesel due to impurities can not only compromise the engine performance but also complicate the storage and transportation of the fuel (Berrios and Skelton, 2008; Demirbas, 2009). Biodiesel purification techniques include wet washing using water, acidified water, organic solvents, or ionic liquids, dry washing via adsorption and ion-exchange, and membrane separation (Jaber et al., 2015). Nevertheless, this review categorizes the biodiesel purification methods based on the nature of the process, such as equilibrium-based, affinity-based, membrane-based, solid-liquid, and reaction-based separation processes (Dechow, 1989; Huang and Ramaswamy, 2013) as shown in Figure 1. It should be noted that a proper combination of the purification methods is usually required to obtain a robust biodiesel purification technology (Venkatesan, 2013).

\section{Biodiesel Purification}

\subsection{Equilibrium-based separation processes}

Absorption and distillation, as well as supercritical fluid extraction and liquid-liquid extraction (LLE), are some of the most common equilibrium- based separation processes (Huang and Ramaswamy, 2013; Lei and Chen 2013). Absorption is commonly utilized for separating particles and impurities from a gaseous mixture (Treybal, 1980; De Haan and Bosch, 2013; Huang and Ramaswamy, 2013); therefore, it does not have a major application in biodiesel separation.

\subsubsection{Distillation}

Distillation is the most common method for separation of more volatile compounds from heavier substances in a liquid mixture (Kockmann, 2014 Nag, 2015). There are different distillation techniques including conventional distillation (ordinary, vacuum, and steam distillation), azeotropic distillation, extractive distillation, and molecular distillation (MD) (Doherty et al., 2008). Conventional distillation and evaporation are perhaps by far the most common methods used in biodiesel purification to remove remaining alcohol or water from the crude biodiesel (Atadashi et al., 2011a and b; Stojković et al., 2014). Typically, the unreacted alcohol is separated from biodiesel prior to further purification (Gomes et al., 2011; Moser, 2012; Bateni et al., 2014; Bateni and Karimi, 2016b). In molecular distillation, carried out under high-vacuum, the molecules' free path is longer than the evaporation and condenser surface distance; therefore, most of the evaporated molecules reach the condensing surface without being deflected on collision with foreign gas molecules, resulting in a higher separation yield (Erich, 1982). Wang et al. (2010) used molecular

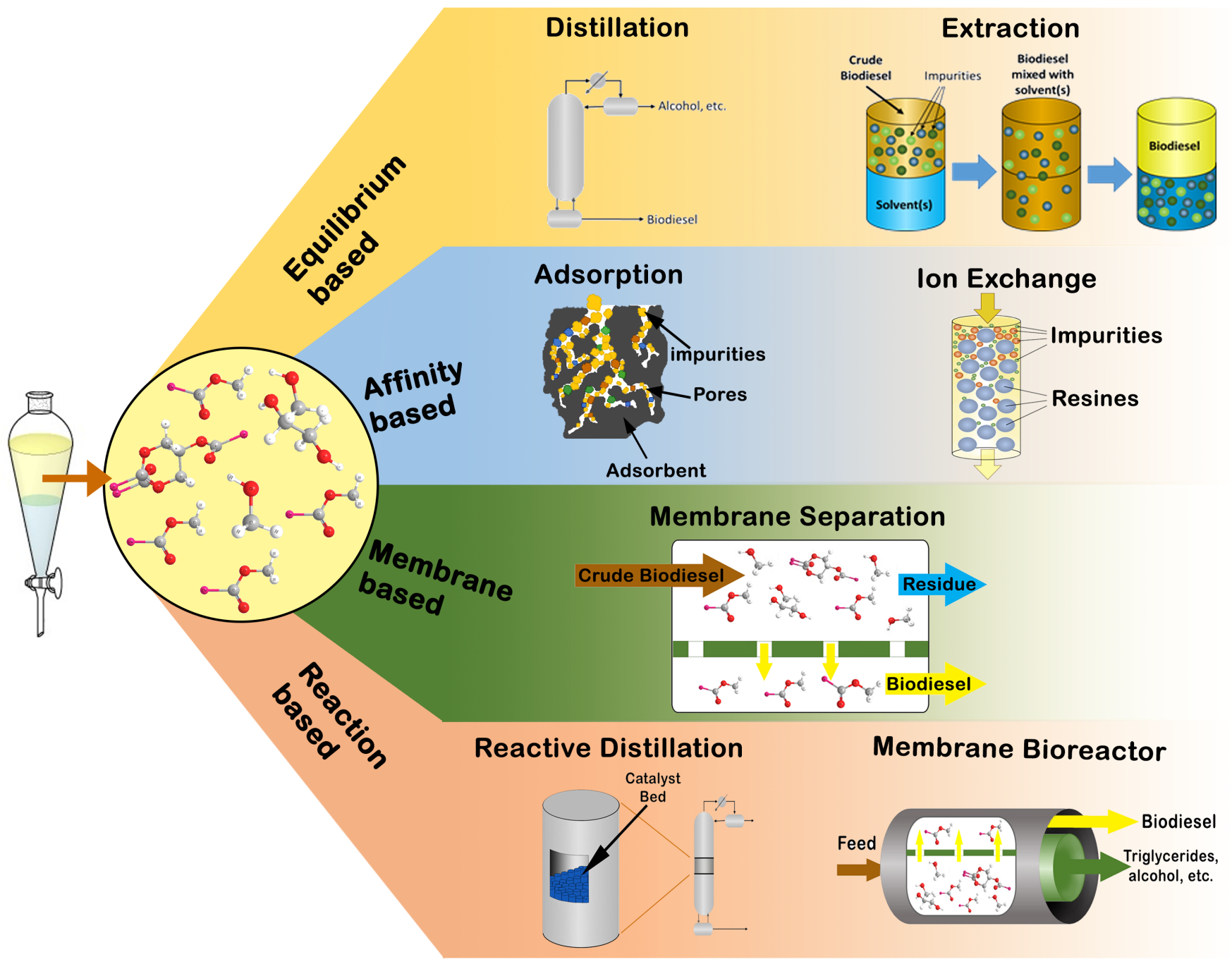

Fig.1. Biodiesel purification techniques classified based on the nature of the processes. 
distillation to purify biodiesel obtained from waste cooking oil to achieve a $98 \%$ separation yield at the evaporator temperature of $120^{\circ} \mathrm{C}$.

\subsubsection{Liquid-liquid extraction}

Liquid-liquid extraction (LLE), otherwise known as solvent extraction, is a well-established separation technique to extract desirable component(s) from a liquid feed to a specific solvent (Hanson, 1971; Kertes, 1971; Dechow, 1989; Huang and Ramaswamy, 2013). This process is the most common method used for biodiesel purification that encompasses all the techniques developed for wet washing (Berrios and Skelton, 2008; Veljković et al., 2015). The use of deionized water to remove soap, catalyst, alcohol, and other contaminants of biodiesel is one of the most common biodiesel purification methods (Atadashi et al., 2011a; Serrano et al., 2013). Water temperature and volume are the key factors in improving purification of the biodiesel phase. Higher water temperature results in higher glycerol diffusivity from biodiesel to water and higher water volume provides higher mass transfer area, leading to an elevated volumetric mass transfer coefficient. Therefore, higher glycerol mass transfer to water and consequently a superior purification is expected using higher water volume at an elevated temperature (Muniyappa et al., 1996; Atadashi et al., 2011b). It was reported that water washing using a 1:2 water/biodiesel volume ratio for $20 \mathrm{~min}$ decreased the glycerol content from $0.09331 \%$ to $0.09 \%$ while the use of $3: 1$ water/biodiesel volume ratio resulted in $0.05 \%$ glycerol (Atadashi et al., 2011b). It was also reported that the standard specification (less than $0.02 \%$ glycerol) is achieved using a multistage washing process (Ma et al., 1998; Canakci and Van Gerpen, 2003; Rahayu and Mindaryani, 2007; Atadashi et al., 2011a and b). However, increasing the water temperature can result in higher water content in the final biodiesel (Stojković et al., 2014). A gentle mixing during the water washing increases the mass transfer coefficient; however, it may result in the formation of emulsions and biodiesel losses (Atadashi et al., 2011a). An alternative method of purification via spraying water on the ester phase at low velocities was proposed to decline such a concern. Saifuddin and Chua (2004) used this technique in addition to microwave heating to accelerate the process. It is noteworthy that the use of refined vegetable oil, moderate catalyst content, and low alcohol content in transesterification could minimize the amount of required water during wet washing (Saifuddin and Chua, 2004).

More effective purification can be achieved using acidified water followed by water wash (Abbaszadeh et al., 2014; Veljković et al., 2015). According to the results presented by Coelho et al. (2011) for purification of ethyl esters of castor oil, decreasing the $\mathrm{pH}$ of water used in the washing step decreased the amount of water required for neutralization (reach $\mathrm{pH} 7$ ). The most common acids used to neutralize the homogeneous alkali catalyst prior to water washing are phosphoric acid, sulfuric acid, and hydrochloric acid (Atadashi et al., 2011a). It was reported that the use of acidified water results in the hydrolysis of soap to FFAs and subsequently decreases the tendency of emulsification (Atadashi et al., 2011a). However, Huerga et al. (2014) mentioned that this phenomenon can increase the acidity of the final product. Therefore, they used acid washing between two water washing steps to avoid soap hydrolysis (Huerga et al., 2014). Water washing does not show a promising result for the purification of biodiesel from heterogeneous processes, especially in the case of calcium-based catalysts. It was suggested that the formation of very stable calcium soaps dissolved in biodiesel can be the main reason for this deficiency (Alba-Rubio et al., 2012; Veljković et al., 2015). Organic solvents, e.g., petroleum ether and $\mathrm{n}$-hexane, were also evaluated for biodiesel purification where the crude biodiesel is dissolved in the solvent prior to further water washing (Karaosmanoğlu et al., 1996; Atadashi et al., 2011a).

It should be noted that the purified biodiesel produced using wet washing needs to be dehydrated to decrease the water content to an acceptable range (Predojević, 2008; Atadashi et al., 2011a; Serrano et al., 2013). The dehydration process (drying) can be performed via different processes, including vacuum flash evaporation, convective heat drying, anhydrous salts, hot air bubbling, and other water absorbents (Serrano et al., 2013; Stojković et al., 2014; Veljković et al., 2015).

The water washing techniques usually suffer from high water consumption, large quantity of wastewater production, and high production cost (Serrano et al., 2013; Jaber et al., 2015; Veljković et al., 2015). In fact, for each liter of biodiesel, 3-10 L of water is used resulting in an equivalent volume of wastewater that needs to be treated (Jaber et al., 2015; Veljković et al., 2015). Jaber et al. (2015) proposed a novel method to decrease the required water for biodiesel purification. The authors used microfiltration accompanied by separation with sand filtration/activated carbon (AC). They also used 70\% dilution rate with make-up water to purify the biodiesel with up to $15 \%$ lower water consumption (Jaber et al., 2015). Overall, it should be noted that the water content of biodiesel purified via a wet washing method is usually above $1000 \mathrm{ppm}$ and further reduction of water content to meet the standard specification is difficult, time-consuming, and costly (Dugan, 2007). These challenges motivated the scientists to seek out waterless methods for biodiesel purification.

Ionic liquids (ILs) have attracted a great deal of attention as green solvents owning to their non-flammable, non-volatile, and reusable properties making them excellent and safer choices for the extraction processes (Han and Row, 2010; Zhao and Baker, 2013). Many different organic, inorganic, and organometallic materials can be easily and efficiently dissolved in ILs; however, their high costs often limit their applications (Shahbaz et al., 2010). The low cost of the Deep Eutectic Solvents (DES) along with their great solvent characterizations, including biodegradability, non-toxicity, and non-reactivity with water, make them promising solvents for biodiesel purification (glycerol removal) (Shahbaz et al., 2010 and 2011). A mixture of quaternary ammonium salt with glycerol (with a 1:1 ratio) was utilized to remove the glycerol from the biodiesel where $\left[\mathrm{EtNH}_{4}\right] \mathrm{Cl},\left[\mathrm{ClEtMe}_{3} \mathrm{~N}\right] \mathrm{Cl}$, and choline chloride were the most effective salts for glycerol removal. It was reported that $51 \%$ glycerol removal was obtained when an eutectic mixture/biodiesel ratio of 1:1 was used for the eutectic mixture of choline chloride/glycerol (1:1) (Hayyan et al., 2010). Shahbaz et al. (2010) combined choline chloride with either ethylene glycol or 2,2,2-trifluoroacetamide to prepare two series of DESs for biodiesel purification. Choline chloride/ethylene glycol (1:2.5 molar ratio) and choline chloride/2,2,2-trifluracetamide (1:1.75 molar ratio) with a corresponding DES/biodiesel ratio of $2.5: 1$ and 3:1 showed effective glycerol removal from palm oil based biodiesel (Shahbaz et al., 2010). Shahbaz et al. (2011) also reported that glycerol, KOH, mono- and diglycerides from the biodiesel could be effectively removed with the DES formed using methyltriphenylphosphunium bromide and ethylene glycol.

\subsubsection{Supercritical fluid extraction}

Supercritical fluid extraction (SFE) is a mass transfer process at the operating conditions (i.e., temperature and pressure) above the critical point of the solvent. Supercritical carbon dioxide is considered a safe and green solvent in biomass processing (Steytler, 1996; Mantell et al., 2013). Wei et al. (2014) used supercritical carbon dioxide for biodiesel fractionation. A biodiesel separation yield of $99.94 \%$ was obtained at the temperature of 40 ${ }^{\circ} \mathrm{C}$, pressure of $30 \mathrm{MPa}$, and flow rate of $7 \mathrm{~mL} / \mathrm{min} \mathrm{CO}_{2}$ with a retention time of $90 \mathrm{~min}$ (Wei et al., 2014).

\subsection{Affinity-based separation processes}

Adsorption and ion exchange are the most common affinity-based separation processes, also known as dry washing methods, for biodiesel purification. In these processes, an appropriate adsorbent is used to selectively adsorb certain impurities from the liquid phase onto its surface (Huang and Ramaswamy, 2013; Atadashi, 2015).

Dry washing offers several advantages over wet washing, including ease of integration into an existing plant, shorter purification time, no water consumption and wastewater production, and smaller unit sizes (Atadash et al., 2011a). The absence of water in purification of biodiesel during dry washing results in biodiesel with acceptable water content (less than 500 ppm) based on ASTM D6751 (Dugan, 2007).

\subsubsection{Adsorption}

Adsorption is the process by which atoms, ions, or molecules, known as adsorbates, from a substance (mostly liquid or gas) adhere to a solid surface, called the adsorbent (Dechow, 1989; Venkatesan, 2013). Adsorption is not interchangeable with absorption; however, the term "sorption" refers to both processes. In the absorption process, the component penetrates or dissolves in the bulk of adsorbent while surface adhesion occurs during adsorption (Venkatesan, 2013). 
Adsorbents are natural or synthetic materials of amorphous or microcrystalline structures owning basic and acidic adsorption sites (LeVan and Carta, 2008), where polar substances such as glycerol and methanol can be adsorbed and filtered out of biodiesel (Atadashi, 2015). Adsorption loading, selectivity, regenerability, kinetics, compatibility, and cost are the most important criteria that need to be considered for adsorbent selection (Dechow, 1989; Venkatesan, 2013). A proper selection of an adsorbent can positively impact the process economy (Venkatesan, 2013).

The adsorption process for biodiesel purification can be also classified based on the type of adsorbent. Silica-based adsorbents (e.g., Magnesol and Trisyl), bio-based adsorbents such as (ligno)cellulosic substrates and activated compounds, including AC, activated fiber, and activated clay are among the most common adsorbents for this process (Atadashi et al., 2011a and Atadashi, 2015).

\section{- Silica-based absorbents}

Silica is one of the key elements in different types of industrially available adsorbents, including silica-gel, zeolites, and molecular sieves (Dechow, 1989; Venkatesan, 2013). Silica-gel is an amorphous inorganic mesoporous adsorbent produced via polymerization of silicic acid (Venkatesan, 2013). Silica-gel owns a hydrophilic surface due to the presence of hydroxyl groups which makes it a proper adsorbent for water, alcohol, and other polar molecules (Ruthven, 1984). Silica-gel showed promising potential for biodiesel purification at room temperature (Yori et al., 2007; Mazzieri et al., 2008; Manuale et al., 2011). Silica showed great potential for removal of glycerol from biodiesel synthesized from waste cooking oil (Yori et al., 2007; Predojević, 2008; Faccini et al., 2011). Yori et al. (2007) used a silica-gel bed crushed and sieved to 10-40 mesh to purify biodiesel samples with $0.1-0.2 \%$ glycerol at a space velocity of $3-11 \mathrm{~cm} / \mathrm{min}$. The full capacity of the bed $(0.13$ $\mathrm{g}$ of glycerol per $\mathrm{g}$ of silica) was used in case of using adsorbent with particle size of $1-1.5 \mathrm{~mm}$. However, mass transfer limitations in the case of industrial adsorption units (with typical 1/8 in. silica beads) limited the practical capacity of the process (Yori et al., 2007). Mazzieri et al. (2008) reported that silica-gel could effectively remove glycerol and monoglycerides from biodiesel and the presence of small amounts of water and soaps did not influence the adsorption of glycerol. However, the presence of alcohol (methanol) negatively affected glycerol adsorption and decreased the effective saturation capacity by about half due to the affinity effect of methanol on silica surface and glycerol (in liquid phase) (Mazzieri et al., 2008). The presence of water at severe conditions results in vegetable oil and glycerol hydrolysis to FFAs which need to be separated during the biodiesel refining process. Manuale et al. (2011) showed great potentials of silica-gel for separation of FFAs from the biodiesel produced from non-catalytic biodiesel production using supercritical methanol. The adsorption capacity of silica-gel was as high as $1.35 \mathrm{~g}$ per $\mathrm{g}$ of adsorbent while that value did not exceed $0.101 \mathrm{~g}$ per $\mathrm{g}$ of adsorbent for treated AC (Manuale et al., 2011).

Natural low silica content bentonite was also used for biodiesel purification. It was reported that activation of the aforementioned clay with $0.1 \mathrm{M}$ sulfuric acid at $100{ }^{\circ} \mathrm{C}$ for an hour increased its adsorption properties. Moreover, the particles within the mesh size of 120-200 had a superior performance due to accessibility of the pores and higher surface area (Leeruang and Pengprecha, 2012). Magnesol is one of the common commercially available silica-based adsorbents used for biodiesel purification (Berrios and Skelton, 2008). Magnesol is in fact an inorganic matrix of magnesium silicate and anhydrous sodium sulfate offering a great potential for selective adsorption of hydrophilic impurities of crude biodiesel (Atadashi et al., 2011a; Faccini et al., 2011). Similar to other adsorbents, biodiesel needs to be thoroughly mixed with the Magnesol powder for a certain period of time. The mixture is then subjected to filtration to separate the Magnesol from the final fuel. Faccini et al. (2011) evaluated different type of adsorbents for biodiesel purification where $1 \%$ Magnesol and 2\% silica showed promising results. The soap, methanol, and water content of the crude biodiesel were $1670 \mathrm{ppm}, 2.13 \%$, and $1300 \mathrm{mg} / \mathrm{kg}$, respectively. Those values correspondingly decreased to $60.85 \mathrm{ppm}, 0.19 \%$, and $500 \mathrm{mg} / \mathrm{kg}$ after purification by $1 \%$ Magnesol. This adsorbent also successfully decreased the free and total glycerol from 0.71 and 0.26 to 0.28 and 0.02 , respectively. The effects of Magnesol concentration and humidity of the adsorbent on the purification of biodiesel was evaluated at two different temperatures (room temperature and $60{ }^{\circ} \mathrm{C}$ ) (Berrios and Skelton, 2008). The increase in Magnesol concentration from 0.25 to $1 \%$ improved the glycerol and soap removal. Surprisingly, drying the adsorbent prior to use did not significantly affect the results. A slightly better methanol removal was observed in the case of purification at $60{ }^{\circ} \mathrm{C}$, which might be due to methanol evaporation instead of a superior adsorption process (Berrios and Skelton, 2008).

\section{- Biomass-based absorbent}

Cellulosic and lignocellulosic substrates were also found to be effective adsorbents for biodiesel purification (Manique et al., 2012; Gomes et al., 2015). These materials are abundant and inexpensive in addition to their advantages as renewable, biocompatible, and non-toxic materials (Gomes et al., 2015; Bateni et al., 2016; Noori and Karimi, 2016a and b).

This method is widely and simply used in small scale biodiesel plants and the biomass that absorbed the impurities is burned for heating after saturation and refilled with a fresh biomass.

Gomes et al. (2015) used different types of starch with various morphologies along with cellulose as a natural adsorbent for biodiesel purification. Corn starch and rice starch own a polyhedral structure while potato starch and cassava starch have ellipsoidal and semi-spherical structures, respectively. The eucalyptus bleached kraft cellulose with a tape format was also used for biodiesel purification. The dry washing was performed via admixing 1-10\% of adsorbent in biodiesel for $10 \mathrm{~min}$ at room temperature and $150 \mathrm{rpm}$ followed by filtration using filter paper. Regardless of adsorbent type and content, the acidity index decreased after purification with the aforementioned biomasses. The free glycerol content of biodiesel was about $0.13 \%$, which was completely removed using the following substrates: $5 \%$ potato starch, $1-2 \%$ cassava starch, and $1 \%$ rice starch. The purified biodiesel with $2 \%$ corn starch could also meet the standard specification for free glycerol. Turbidity, showing the presence of impurities in the biodiesel, was also significantly decreased in the case of using $5 \%$ potato starch or $1-2 \%$ cassava starch (Gomes et al., 2015).

Rice husk ash (RHA) (1-5\%) showed a promising performance in biodiesel purification. The adsorption capability of RHA is attributed to its high silica content and the presence of meso- and macropores in its structure. Although the water content of the purified biodiesel with RHA was still above the acceptable value, it was significantly lower than that of the purified biodiesel using acidified water (1\% phosphoric acid) and Magnesol 1\% (Manique et al., 2012).

\section{- Activated compounds}

AC, activated fiber (carbon fiber), and activated alumina are among the most common adsorbents in industrial applications. AC, which owns a large porous volume and high surface area, can be manufactured from any carbonaceous organics, e.g., sawdust, petroleum coke, wood, charcoal, peat, fruit nuts, bituminous coal, lignite, and coconut shells (Venkatesan, 2013). The porous structure is activated through either steam or chemica activation. In the case of steam activation, the substrate is heated at 400 $500{ }^{\circ} \mathrm{C}$ in an oxygen-free atmosphere to remove the volatile components (carbonization step), followed by oxidization using steam (or carbon dioxide) at $800-1000{ }^{\circ} \mathrm{C}$. The chemical activation is performed via impregnation of the substrate with a strong dehydration agent (e.g., phosphoric acid or zinc chloride), followed by heating to $500-800{ }^{\circ} \mathrm{C}$, washing, drying, and grinding (Yang, 2003).

Thermal dehydration of hydrated alumina and recrystallization is the most common method used to produce activated alumina. The presence of Lewis acid sites on the surface of activated alumina makes it a suitable adsorbent for polar compounds and oxygenates such as alcohols, aldehydes, ketones, and carboxylic acids (Yang, 2003; Venkatesan, 2013).

Fadhil and Dheyab (2015) compared the performance of AC prior to and after acid treatment either with sulfuric acid or hydrochloric acid for purifying biodiesel synthesized from spent cooking oil (SCO) and spent fish frying oil (SFFO). The AC purifications led to a better biodiesel yield (91.50-93.75\%) with respect to water washed product (86-89\%) on both of the feedstocks. In the case of SFFO, the modification of AC with acids improved its performance, especially in the case of the AC modified by sulfuric acid which resulted in a biodiesel yield of $93.75 \%$. On the other hand, the untreated AC led to the best purification result for SCO biodiesel (93.4\% yield) (Fadhil and Dheyab, 2015). 


\subsubsection{Ion exchange}

Ion exchange is the process of exchanging the ions between the solution and a proper solid phase (exchanger) due to a stronger affinity (electrostatic force) between the target species and the functional groups on the surface (Treybal, 1980; Dechow, 1989; LeVan and Carta, 2008; Berrios et al., 2013). Ion exchangers consist of a matrix with excess charges localized in specific sites of the structure (Grandison, 1996; Berrios et al., 2013). Ion exchangers resins are one of the most common types of exchangers typically produced via functionalization of the polymer obtained from copolymerization of styrene cross-linked with divinylbenzene. The ion exchange resins are categorized based on the functionality and yet divided according to their strength (density of the charge) to strongly acidic cation-, weakly acidic cation-, strongly basic anion-, and weakly basic anion-exchange resins (Dechow, 1989; Berrios et al., 2013). The presence of sulfonic acid groups (sulfonated polystyrene, $\mathrm{R}_{-} \mathrm{SO}_{3}{ }^{-}$ $\mathrm{H}^{+}$) in the matrix leads to the formation of strong cation exchange resin as the protons can easily be exchanged with other cations. On the other hand, carboxylic groups $\left(\mathrm{R}_{-} \mathrm{CO}_{2}{ }^{-} \mathrm{H}^{+}\right)$are usually incorporated in the exchanger's matrix to produce a weak cation exchange resins (Berrios et al., 2013). The strong anion exchange resins are usually obtained by insertion of the quaternary ammonium species into the matrix structure while the presence of radicals of secondary or tertiary amines leads to the formation of weak anion exchangers (LeVan and Carta, 2008; Berrios et al., 2013). The structural properties (e.g., degree of cross-linking, porosity, and particle size), exchange capacity, stability, type, and density of the charges (strength of the resin) need to be considered in order to choose a proper ion exchange resin (Grandison, 1996; Dechow, 1989; Berrios et al., 2013). The strong acid cation resins are the most common exchange resins used to purify biodiesel (Atadashi et al., 2011a; Faccini et al., 2011; Berrios et al., 2013). Berrios and Skelton (2008) studied the performance of PD206 and BD10 Dry ion-exchange resins (strong acid cation resins) for purification of biodiesel produced from used cooking oil and rapeseed oil. Although the resins showed promising performances for soap and glycerol removal, the methanol removal was not satisfactory (Berrios and Skelton, 2008). Lewatit GF202, on the other hand, showed a great potential for methanol removal along with its capability to decrease the soap and glycerol content in the purified biodiesel. The reusability of this resin was an additional advantage (Berrios et al., 2011). Mata et al. (2011) also used a $15 \mathrm{~cm}$ bed of Lewatit GF202 in a column with $5 \mathrm{~cm}$ diameter and $30 \mathrm{~cm}$ length to purify biodiesel with a constant flow rate of $236 \mathrm{~cm}^{3} / \mathrm{h}$. The dry washing showed a positive impact in decreasing the biodiesel acidity and viscosity compared with water washing, although the final product did not meet the specification for metal content (sodium and potassium). Wall et al. (2011) studied the mechanism of biodiesel purification using industrially available ion-exchange resins, i.e., T45BD and T45BDMP (Thermax) along with BD10 Dry (Dow Chemical). They concluded that filtration, physical adsorption, ion exchange, and soap removal by glycerol affinity are the most important factors during this process. It is noteworthy that the resins showed a better performance for sodium soap removal compared with potassium soap and decreasing the particle size further improved the process in the case of sodium soaps (Wall et al., 2011). Chen et al. (2012a) showed the great affinity of the glycerol to sodium form sulfonated resins; however, their hydrogen form owned higher adsorption capacity (Chen et al., 2012b). Dias et al. (2014) investigated the effect of resin (PD206, Purolite) content (2-40\%) on the ester and water content of the final biodiesel samples from soybean oil and waste frying oil where the purification was performed at room temperature for $1 \mathrm{~h}$. Purification of the samples using $40 \%$ resin provided the best quality products even though the ethyl ester contents were still slightly lower than the standard value reported in EN 14214 (Dias et al., 2014). Comparing the results of soybean oil biodiesel purification using $2 \%$ Purolite at room temperature (Dias et al., 2014) and $65^{\circ} \mathrm{C}$ (Faccini et al., 2011), it can be concluded that the purification at lower temperature resulted in lower water content in the final biodiesel.

It is noteworthy that the ion exchange resins can also effectively remove the metallic compounds leached out of a solid catalyst to the liquid phase (biodiesel) in the case of heterogeneous catalysis transesterification (Kouzu and Hidaka, 2013).

\subsection{Solid-liquid separation processes in biodiesel purification}

Biodiesel purification using solid-liquid separation methods is limited to filtration mostly after heterogenous transesterification or biodiesel purification by a dry washing method. However, filtration is one of the main mechanism for soap removal as mentioned earlier. Methanol acts as the co-solvent of soaps in the biodiesel; therefore, they should precipitate upon methanol removal. Therefore, filtration is considered as an effective method in the case of high concentration of soap and absence of methanol especially in the case of sodium soaps. In fact, contrary to potassium soaps which are considered soft soaps, sodium soaps are hard soaps showing the tendency to solidify and make a gel-like layer at room temperature. Therefore, sodium soaps can be separated from biodiesel more effectively (Wall et al., 2011).

\subsection{Membrane-based separation technologies in biodiesel purification}

By stark contrast to the high-water content involved in typical water washing methods (Jaber et al., 2015), membrane technology has emerged as a low or no-water alternative in the purification of crude biodiesel. As well as the cost advantages associated with a lack of wastewater, this method avoids potential emulsion in the product, facilitating two-phase separation. Microfiltration (between $0.1-10 \mu \mathrm{m}$ ), ultrafiltration (between 1 and $20 \mathrm{~nm}$ ), and nanofiltration (maximum pore size of $1 \mathrm{~nm}$ ) membranes are all used depending on the characteristics of the feedstock.

\subsubsection{Phase behavior in membrane separation}

Generally speaking, the goal of a membrane filtration system is to selectively permeate fatty acid methyl esters (FAMEs) that comprise a typical biodiesel product. Therefore, the phase behavior of other compounds typically present in a crude biodiesel feedstock (unreacted triglycerides, methanol/ethanol, glycerol and soap, among other impurities) becomes paramount in the discussion of filtration.

Glycerol can pose as a challenge in separation, due to its existence as a droplet suspension in the crude biodiesel phase - this is dependent on temperature (Saleh et al., 2011) and composition (Wang et al., 2009; Gomes et al., 2010). Both additional alcohol (Gomes et al., 2010) and saponification products (Saleh et al., 2010a and b) can prevent the glycerol droplets from reaching the necessary size for effective separation - this is due to their role as surfactants in the biodiesel phase, decreasing the surface tension in the droplets which increases overall glycerol permeability. The saponification products, specifically, can form glycerol-alkali bonds which form a "reverse-micelle" structure - this can further complicate both glycerol and saponification product separation (Wang et al., 2009).

Unreacted oils (di- and triglycerides) can also form droplets in membrane reactors - Falahati and Tremblay (2012) found that the droplets comprised a bimodal size distribution whose characteristics depended on the original oil. In their case, waste cooking oil formed larger droplets than unprocessed canola oil, allowing for ease of separation of these unreacted oils due to size exclusion.

This biodiesel phase behavior is additionally dependent on temperature - in a ternary methanol-oil-FAME system, Cheng et al. (2009) tested different distributions of these three components at three temperatures (20, 40 , and $60{ }^{\circ} \mathrm{C}$ ) in facilitating membrane separation. The two-phase region was noticeably narrower at higher temperatures according to experiments. Once the conditions for single-phase flow were met, permeate flux dramatically increased. However, this flow was not functionally different from the crude retentate in terms of composition, implying a total lack of separation beyond the two-phase region. For an initial feed of oil:FAME:MeOH of 26:54:20 wt.\%, the permeate had no triglycerides at $20{ }^{\circ} \mathrm{C}$; further increases to 40 and $60{ }^{\circ} \mathrm{C}$ produced an oil content of roughly $26 \%$. Given that the two-phase region is crucial to separation, this implies a temperature dependence of separation as well as composition dependence.

Based on the above work, the unreacted oil and methanol are themselves insoluble; however, it is the increases in FAME that can push the two-phase system into the single-phase region. Cao et al. (2007) used octanol-water coefficients to calculate the volume fractions of methanol and biodiesel that would produce heterogeneous two-phase flow. A semi-empirical model (Ho et al., 1990) noted that phase inversion would occur with volume fractions of methanol lower than 0.31 - the experiments conducted by Cao et al. (2007) found a complete lack of permeate flux at a volume fraction of 0.28 , implying that the lack of a methanol-rich phase prohibited the separation. 
The addition of water can further alter this two-phase behavior; by introducing small amounts of water between 0.06 and $0.2 \mathrm{wt} . \%$, Saleh et al. (2010b) found that glycerol readily separated from a FAME flow at percentages of water above $0.1 \%$ at temperatures of $25{ }^{\circ} \mathrm{C}$. Gomes et al. (2013) provided further insight into the effect of 10,20 , and $30 \mathrm{wt} . \%$ acidified water $(0.5 \% \mathrm{HCl})$ on phase behavior in membrane separation-10 wt.\% water was the most effective at retaining glycerol and stabilizing the permeate flux. At $20 \mathrm{wt} . \%$, the authors found that agglomerates tended to form on the membrane pores, introducing a fouling mechanism; further increases to $30 \mathrm{wt} . \%$ allowed for phase inversion where glycerol was able to permeate through the membrane.

\subsubsection{Organic/Polymeric membranes}

The organic membranes employed in biodiesel purification include polysulfone (Alicieo et al., 2002; He et al., 2006; Alves et al., 2013; Giorno et al., 2013), polyamide (Jiang et al., 2009), and polycarbonate (Cao et al., 2007), regenerated celluloses and polyvinylidenefluoride (Mah et al., 2012; Giorno et al., 2013), and polyacrylonitrile (He et al., 2006; Saleh et al., 2010b) with varying success. These organic membranes can be sorted according to their hydrophilicity or corresponding hydrophobicity. A hydrophilic membrane is less susceptible to fouling from a variety of biorefinery feeds due to the water content, but is more susceptible to deformation due to $\mathrm{pH}$ and temperature swings; a hydrophobic material is more useful for the separation of oils (Mänttäri et al., 2013).

$\mathrm{He}$ et al. (2006) directly compared polysulfone and polyacrylonitrile membranes in obtaining high purity biodiesel, as well as using water and acid washing for comparison. While all methods were able to produce high purity $(97.5 \%)$ biodiesel, only the membrane extraction method was successful in decreasing ester losses endemic to water- and acid washing methods; $10.1 \mathrm{wt} . \%$ esters were lost even at the optimum temperature of $50{ }^{\circ} \mathrm{C}$ with distilled water due to emulsification. The polysulfone and polyacrylonitrile membranes, by contrast, were able to purify biodiesel with only $8.1 \mathrm{wt} . \%$ and $10.3 \mathrm{wt} . \%$ ester losses. However, the polyacrylonitrile membrane allowed for higher water content in the final biodiesel product than any other methods, making it perhaps unsuitable for biodiesel refining. The polysulfone membrane additionally led to the highest purity of biodiesel at roughly $99 \%$ without additional steps. Later comparisons conducted between ultrafiltration poly(ether-sulfone) and microfiltration cellulose ester membranes (Alves et al., 2013) demonstrated successful separation of glycerol from the final biodiesel product; with a nominal molecular weight cutoff (NMWCO) of $10 \mathrm{kDa}$, the ultrafiltration poly(ether-sulfone) membrane alone could reach 0.02 wt.\% glycerol in the permeate, meeting international standards. Additional successes with ultrafiltration polyacrylonitrile membranes have been experienced for glycerol separation from a biodiesel product - Saleh et al. (2010b) found a 63\% reduction in glycerol content for the permeate upon adding $1 \mathrm{wt} . \%$ water by mass, reaching a level of $0.013 \mathrm{wt} . \%$ glycerol in the permeate. There are other membranes being considered for biodiesel purification, including polyimides which have been studied recently (Jiang et al., 2009) and as a membrane precursor for pervaporation (Freeman et al., 2012). However, these membranes have not been studied for the purposes of biodiesel purification. Additionally, their hydrophobicity would prove challenging to implement due to fouling from agglomeration mechanisms (Mänttäri et al., 2013).

Glycerol is difficult to separate from the final biodiesel product, but this separation is key in meeting international standards; thus, there have been extensive studies on the use of organic membranes for this very purpose (Saleh et al., 2010b). Depending on the composition, glycerol will form droplets of various sizes; Saleh et al. (2010b) found these droplets varied from $250 \mathrm{~nm}$ in pure FAME to more than $2500 \mathrm{~nm}$ in $0.06 \mathrm{wt}$ \% water. Thus, an organic membrane chosen for glycerol separation should generally have smaller pores than this to facilitate the separation of these droplets. In tests for glycerol separation, a modified hydrophilic polyacrylonitrile membrane at $100 \mathrm{kDa}$ NMWCO was able to separate glycerol more easily with higher water contents - from 3\% in pure FAME to $63 \%$ in $0.2 \mathrm{wt} \%$ water after $180 \mathrm{~min}$ of time on stream (Saleh et al., 2010b). For a poly(ether-sulfone) membrane at $10 \mathrm{kDa}$ NMWCO, small additions of water (up to $0.2 \mathrm{wt} \%$ by mass) drastically improved glycerol removal, from $0.02 \%$ to $0.009 \%$ glycerol in the permeate (Alves et al., 2013). This glycerol/water miscibility directly contributes to a two-phase flow that is crucial for separation (Wang et al., 2009; Gomes et al., 2010; Saleh et al., 2011; Alves et al., 2013). However, soap and methanol tend to complicate the mechanism of separation due to their role in increasing glycerol solubility (Saleh et al., 2010a and b). Saleh et al. (2010b) found negligible separation of glycerol in the presence of $1 \mathrm{wt} . \%$ methanol and soap and $0.06 \mathrm{wt} \%$ water for the aforementioned polyacrylonitrile membrane at $100 \mathrm{kDa}$. These authors (Saleh et al., 2010a) later employed dispersive light scattering to determine glycerol particle sizes in various concentration profiles of glycerol, soap, and methanol - they found that separation increased as particle size increased, even in homogeneous flow regimes where glycerol was unable to form said droplets.

Organic membranes could find some use in the filtration of biodiesel produced from microalgae cells (Giorno et al., 2013), whose production is traditionally limited by harvesting efficiency and triglyceride recovery from the cells themselves (Wijffels et al., 2010). Organic membranes have been employed in algal cell separation (Rossi et al., 2008) as well as protein and lipid separation from wastewater (Dumay et al., 2008). Giorno et al. (2013) utilized tested the fouling mechanisms for various organic membranes including regenerated cellulose, polysulfone and polyvinylidenefluoride (PVDF). The membranes tested were between 100 and $150 \mathrm{kDa}$ NMWCO in $20 \mathrm{~min}$ runs with $40 \mathrm{~mL}$ of the microalgae Nannochloropsis sp., and the flux was measured with water both before and after contact between the membrane and the fresh algal cells. Only the PVDF membrane lost flux after contact with the microalgae; this membrane is highly susceptible to fouling in fluctuations of $\mathrm{pH}$ and oil concentrations (Mah et al., 2012). The regenerated cellulose membrane outperformed the polysulfone membrane at similar $\mathrm{kDa}$ cutoffs; thus, a smaller $30 \mathrm{kDa}$ regenerated cellulose membrane was employed to heighten purification. The authors found that a $30 \mathrm{kDa}$ regenerated cellulose membrane could remove $89 \%$ of proteins $v s$. only $61 \%$ of proteins at $100 \mathrm{kDa}$; further sonication of the algal cells provided both higher fluxes and purities.

\subsubsection{Inorganic/Ceramic membranes}

There is a substantially less variety in inorganic membranes $v s$. their organic counterparts; they are generally focused on an alpha-alumina support structure with titanium oxide (Alicieo et al., 2002; Basso et al. 2006; Cao et al., 2008a and b; Gomes et al., 2010; Baroutian et al., 2011; Gomes et al., 2011; Gomes et al., 2013) or zirconium oxide (Cheng et al. 2009). These membranes have numerous positive qualities over organic membranes, such as increased fouling, temperature and $\mathrm{pH}$ fluctuation resistance, and a longer time-on-stream - this allows inorganic membranes to deal more effectively with the base catalysts used in transesterification reactions endemic to biodiesel production (Barredo-Damas et al., 2010; Atadashi, 2015). These increased resistances additionally lend to usefulness in a continuous process in which a FAME-rich permeate flow is separated from an unreacted retentate as transesterification occurs down the length of a membrane bioreactor (Cao et al., 2008a; Baroutian et al., 2011).

When discussing the separation of biodiesel from unwanted components, glycerol separation again becomes paramount. Thus, glycerol separation has been studied in literature from both palm and canola oil (Wang et al., 2009; Saleh et al., 2011) in pore sizes in the ultrafiltration to microfiltration range (Wang et al., 2009; Saleh et al., 2011; Atadashi et al., 2012). In these pore sizes, increases in transmembrane pressure and pore size increase the permeate flux while potentially decreasing the ability to filtrate glycerol at higher pressures (Hua et al., 2007; Gomes et al., 2010; Atadashi et al., 2012). Even though glycerol and soap will form agglomerates with rough sizes of $2.21 \mu \mathrm{m}$, increases in pore size to $0.6 \mu \mathrm{m}$ will still yield increases in glycerol permeate concentration, implying that some free glycerol still exists (Wang et al., 2009). Additionally, in time-onstream tests, larger pores and higher membrane pressures lead to fouling due to these glycerol agglomerates (Hua et al., 2007; Gomes et al., 2010). With a $0.05 \mu \mathrm{m}$ ceramic membrane at $25{ }^{\circ} \mathrm{C}$, Saleh et al. (2011) successfully met ASTM standards for glycerol in the final biodiesel product (less than 0.02 wt.\%). Increases in temperature seem to correlate positively with both permeate flux and separation - Atadashi et al. (2012) increased glycerol retention to $99.2 \%$ at temperatures up to $40{ }^{\circ} \mathrm{C}$. Additional increases have been noted at temperatures up to $60^{\circ} \mathrm{C}$ in systems lacking methanol as a component (Wang et al., 2009) - this may not be noted in systems where phase inversion can occur (Cheng et al., 2009; Saleh et al., 2011).

Cation removal is more complex and is dependent on the cation being discussed - namely, the "reverse micelle" particles formed between 
glycerol and soap are dependent on the cation in question (Wang et al., 2009). In a study by Wang et al. (2009), the authors were able to decrease the potassium and magnesium content of the permeate flow by decreasing the pore size from 0.6 to $0.1 \mu \mathrm{m}$, decreasing potassium and magnesium by $60 \%$ and $40 \%$, respectively. Sodium and calcium retention was unaffected by this decrease - leading the authors to conclude: "no trend of retention of cation with pore size was observed in this work" (Wang et al., 2009). Further work with calcium removal reflected this conclusion - however, the addition of sodium carbonate allowed for much greater calcium retention, reducing the calcium concentration in the permeate from $305 \mathrm{ppm}$ to $1.9 \mathrm{ppm}$ for a $0.1 \mu \mathrm{m}$ pore size (Ferrero et al., 2014). Given that sodium is more readily removed by a membrane than calcium, the exchange of these cations allowed for calcium to be more easily removed as calcium carbonate (Ferrero et al., 2014). If these soaps are not handled properly, they can easily foul the membrane - Gomes et al. (2011) found that a crude biodiesel product had roughly a fifth of the permeate flux of a synthetic biodiesel-glycerol-ethanol mixture $\left(12.9 \mathrm{~kg} / \mathrm{h} / \mathrm{m}^{2}\right.$ vs. $78.4 \mathrm{~kg} / \mathrm{h} / \mathrm{m}^{2}$ ). This mimics behavior as seen above with organic membranes (Saleh et al., 2010b) - however, agglomerates can be more easily removed in ceramic membranes with hexane at high flow velocities and low transmembrane pressures (Basso et al., 2006). Alcohols such as ethanol further complicate separation mechanics in ceramic membranes as well as their organic counterparts, as glycerol droplet size is modified by hydrophilic surfactants (van der Graaf et al., 2005) which decrease interfacial tension in the agglomerated particles (Y1lmaz et al., 1999; Pittia et al., 2005). With an $\alpha$ $\mathrm{Al}_{2} \mathrm{O}_{3} / \mathrm{TiO}_{2}$ membrane, Gomes et al. (2010 and 2011) found complex effects on the permeate flux, increasing from $63.1 \mathrm{~kg} / \mathrm{h} / \mathrm{m}^{2}$ at $5 \mathrm{wt} . \%$ ethanol to 78.4 $\mathrm{kg} / \mathrm{h} / \mathrm{m}^{2}$ at $10 \mathrm{wt} . \%$ ethanol, and decreasing to $59.5 \mathrm{~kg} / \mathrm{h} / \mathrm{m}^{2}$ at $20 \mathrm{wt} . \%$ ethanol. However, the effects on glycerol retention were less complex, with direct decreases as ethanol concentration increased (99.6\% at $5 \mathrm{wt} \%$ to $98.1 \%$ at 20 wt.\%, respectively) (Gomes et al., 2010).

Water has complex effects on phase behavior (Gomes et al., 2011; Gomes et al., 2013) as previously described in organic membranes (Saleh et al., $2010 \mathrm{~b}$ ). For an $\alpha-\mathrm{Al}_{2} \mathrm{O}_{3} / \mathrm{TiO}_{2}$ membrane, Gomes et al. (2011) facilitated glycerol separation with the addition of $20 \mathrm{wt} \%$ acidified water $(0.5 \% \mathrm{HCl})$, decreasing glycerol concentration in the permeate flow from $0.1 \mathrm{wt} \%$ to less than 0.02 wt. $\%$ glycerol in the permeate for transmembrane pressures between 1-3 bar (from 0.005 wt. $\%$ glycerol to 0.014 wt. $\%$ glycerol from 1 bar to 3 bar, respectively). These concentrations, however, produced much smaller steadystate permeate fluxes, reaching no higher than $10.3 \mathrm{~kg} / \mathrm{h} / \mathrm{m}^{2}$ at 3 bar transmembrane pressure, a stark decrease from $78.4 \mathrm{~kg} / \mathrm{h} / \mathrm{m}^{2}$ at 2 bar transmembrane pressure without added water (Gomes et al., 2011). Later work from these authors increased acidified water concentration to around $30 \mathrm{wt} \%$ for the same $\alpha-\mathrm{Al}_{2} \mathrm{O}_{3} / \mathrm{TiO}_{2}$ membrane (Gomes et al., 2013). While the permeate flux increased (up to $57.6 \mathrm{~kg} / \mathrm{h} / \mathrm{m}^{2}$ ), the glycerol retention was unstable, with permeate concentrations as high as $40 \mathrm{wt} . \%$ glycerol in some cases implying little retention occurred. This behavior is identical to that seen above with organic membranes (Saleh et al., 2010b) - increasing water content can allow the emulsion of droplets to coalesce in the bulk phase (Groeneweg et al., 1998). Reiterating as seen above, separation of glycerol and unreacted triglycerides from the final biodiesel product relies on a two-phase system (Cao et al., 2007; Dubé et al., 2007; Cheng et al., 2009), which is both composition and temperature dependent (Cheng et al., 2009).

\subsection{Reaction-based separation processes in biodiesel purification}

In the case of reversible reactions, the process yield is limited by the equilibrium. To overcome this limitation, a separation process should be integrated with the reaction to separate the substance (product) and keep its concentration from the equilibrium concentration. Hybrid reaction-membrane separation (e.g., membrane bioreactor), reactive distillation, and adsorptive distillation system are some of the common reaction-based separation methods (Huang and Ramaswamy, 2013).

\subsubsection{Reactive distillation}

The integration of chemical reaction and product separation (purification) in a single multifunctional process is known as reactive distillation. This integration declines the chemical equilibrium limitations, avoids the potential necessity of auxiliary solvent, and increases the selectivity (Lei et al., 2005; Kiss, 2013; Kolah et al., 2013). Therefore, reactive distillation has the potential to improve the efficiency of the process while it needs a lower capital investment, operation cost, and energy consumption (Sundmacher and Kienle, 2002). However, this process also has its own operation challenges and economic limitations especially in case of gas-liquid reactions at severe operating conditions of very slow reactions. In fact, a large column is required to provide a reasonable residence time in the case of very slow reactions which compromises the feasibility of the process (Kiss et al. 2006a and b; Kiss et al., 2007; Dimian et al., 2009; Kiss, 2010; da Silva et al., 2010; Gomez-Castro et al., 2010; Mueanmas et al., 2010; Qiu et al. 2010; Machado et al., 2011; Kolah et al., 2013; Poddar et al., 2015; PérezCisneros et al., 2016).

Wang et al. (2001) reported 10\% saving in energy consumption along with $50 \%$ higher productivity for methyl acetate hydrolysis using reactive distillation compared with the conventional process using fixed-bed reactor followed by a distillation process. Reactive distillation using acid catalysts has a potential to be used for biodiesel production or pretreatment of feedstock with high FFAs contents (Russbueldt and Hoelderich, 2009; Simasatitkul et al., 2011; Kolah et al., 2013). Therefore, various designs have been studied to maximize the reaction rate and biodiesel yield (Kolah et al., 2013). It is noteworthy that the downstream alcohol recovery step can be avoided in the case of biodiesel production using reactive distillation (Qiu et al., 2010).

\subsubsection{Membrane bioreactors for biodiesel processing}

Of the organic membranes noted above, polysulfone has alone received attention in biodiesel production and refining (Shi et al., 2016a and b) due to its temperature resistance and relative inert behavior to other organic membranes (Hao et al., 2000; Li and Wang, 2005; Li et al., 2006; Slade et al., 2012). Quarternized ammonium was grafted to polysulfone to act as a catalyst in anion exchange membrane fuel cells (Slade et al., 2012); Shi et al. (2016a) applied this concept to biodiesel production via a chloromethylated polysulfone membrane. After alkalization at an optimum synthesis time of $24 \mathrm{~h}$ and an optimum ratio of chloromethlyl ether:polysulfone of 10:1 (Hao et al., 2000), the biodiesel synthesis was performed with methanol and co-solvents (Shi et al., 2016b). Tetra hydrofurane (THF) and n-hexane both performed well as co-solvents for the reaction - the authors (Shi et al., 2016a and b) proceeded with n-hexane due to lower toxicities. The conversion increased with increasing amounts of n-hexane as a co-solvent, from $65.7 \%$ at $30 \mathrm{wt} . \% \mathrm{n}$-hexane to $95.8 \%$ at $60 \mathrm{wt} . \% \mathrm{n}$-hexane (Shi et al., 2016b). Small amounts of water in the reaction mixture had only a small negative effect - at $5 \mathrm{wt} . \%$ water, the conversion was $87.0 \%$ vs. $95.3 \%$ with no water in the mixture. Further increases in water content had sharper negative effects, decreasing to $73.9 \%$ at $6 \mathrm{wt} . \%$ water and $65.4 \%$ at 7 wt.\% water. Small amounts of FFAs in the reaction mixture had limited effect, decreasing conversion to $91.3 \%$ at 2.5 wt. $\%$ FFA vs. the aforementioned $95.3 \%$ with no FFA content. After 5 runs with $4 \mathrm{~h}$ reaction times each, the catalyst only experienced a loss of $2.1 \%$ conversion, owing to its overall stability on the polysulfone surface (Shi et al., 2016b).

Inorganic membranes have seen a larger amount of focus due to their relative stability and narrow pore distribution as noted above compared with organic membranes (Cao et al., 2007; Dubé et al., 2007; Cao et al., 2008a and b; Tremblay et al., 2008; Baroutian et al., 2011; Falahati and Tremblay, 2012). Dubé et al. (2007) employed membrane reactor technology using an inorganic carbon membrane in biodiesel production and subsequent purification. At temperatures of $65^{\circ} \mathrm{C}$ and $2 \mathrm{wt} . \%$ sulfuric acid, the authors were able to achieve up to $64 \%$ conversion; this conversion increased with increasing flow rates. A base catalyst (1 wt.\% $\mathrm{NaOH}$ ) was able to achieve $96 \%$ conversion at the same flow rate of 6.1 $\mathrm{mL} / \mathrm{min}$; however, this also allowed the saponification reaction to take place (Dubé et al., 2007).

As previously discussed, two-phase behavior is paramount in effective separation via membrane technologies; this is no less important when considering a membrane bioreactor (Cao et al., 2007; Cao et al., 2008a and b). Using a model for calculating droplet sizes based on interfacial tension for liquids of very different viscosities (DeRoussel et al., 2001), Cao et al (2007) found a minimum droplet size of $12 \mu \mathrm{m}$ for a suspension of oil droplets - thus, the authors employed no larger than $1.4 \mu \mathrm{m}$ pore sizes in their work. Additionally, at methanol volume fractions below 0.31 (Ho et 
al., 1990), phase inversion occurs - demonstrating this, the authors found a complete lack of separation at volume fractions of 0.28 for methanol (Cao et al., 2007).

In optimizing the inorganic membrane for bioreactor technology, three factors have thus far been studied - amount of catalyst (Tremblay et al., 2008; Baroutian et al., 2011), appropriate residence times for complete conversion (Tremblay et al., 2008; Falahati and Tremblay, 2012), and methanol-to-oil ratio (Cao et al., 2008a and b). Maximizing conversion is imperative for reducing the buildup of unreacted oil inside the reactor (Tremblay et al., 2008; Baroutian et al., 2011). Baroutian et al. (2011) tested potassium hydroxide catalyst loadings up to $250 \mathrm{mg} / \mathrm{cm}^{3}$ at temperatures of 50 and $70{ }^{\circ} \mathrm{C}$ in a packed bed reactor on activated carbon. For loadings of $37.5 \mathrm{mg} / \mathrm{cm}^{3}$, the conversion reached no higher than $89.3 \%$ at $70{ }^{\circ} \mathrm{C}$ - further increases to $143.75 \mathrm{mg} / \mathrm{cm}^{3}$ yielded conversions up to $93.5 \%$ at $70{ }^{\circ} \mathrm{C}$. Beyond this, the conversion dropped slightly to, at maximum, $91.5 \%$ at $250 \mathrm{mg} / \mathrm{cm}^{3}$ and $70{ }^{\circ} \mathrm{C}$ due to soap formation. The authors concluded that an optimum catalyst loading for maximum conversion was $157.04 \mathrm{mg} / \mathrm{cm}^{3}$ based on numerical optimization. For a $\mathrm{TiO}_{2}$ membrane, Tremblay et al. (2008) tested external loadings of a base catalyst $(\mathrm{NaOH})$ in a methanol/oil mixture. With a $2 \mathrm{~h}$ residence time, complete conversion could be achieved with loadings as low as $0.03 \mathrm{wt} . \%$; halving the residence time to $1 \mathrm{~h}$ required higher loadings of $0.05 \mathrm{wt} . \%$ for complete conversion. Further increases of catalyst (up to 1 wt.\%) did little to the conversion of oil fed to the reactor; however, this was useful in converting the oil already present inside the reactor, achieving $98.2 \%$ conversion of the initial oil at 1 wt. $\% \mathrm{NaOH}$ (the conversion of the oil fed alongside the $\mathrm{NaOH}$ remained at $100 \%$ ). At 0.03 wt. $\% \mathrm{NaOH}$ and a $1 \mathrm{~h}$ residence time, transmembrane pressure continued to increase without reaching steady state - by contrast, increasing the residence time to $2 \mathrm{~h}$ for complete conversion allowed the transmembrane pressure to stabilize at $30.2 \mathrm{kPa}$ (Tremblay et al., 2008). At their limit, uncontrollable increases in transmembrane pressure will foul the reactor due to the accumulation of oil droplets on the membrane pores (Hua et al., 2007). Using a $\mathrm{TiO}_{2}$ ultrafiltration membrane with a $30 \mathrm{~nm}$ pore size, Falahati and Tremblay (2012) tested residence times for canola oil conversion as low as $35 \mathrm{~min}$ for a membrane bioreactor - this work employed catalyst loadings of 0.5 and $1.4 \mathrm{wt} . \%$ and a reaction temperature of $65{ }^{\circ} \mathrm{C}$. A steady state transmembrane pressure could not be obtained for residence times of 35 min, dramatically increasing to over $350 \mathrm{kPa}$ in less than $20 \mathrm{~min}$. By increasing residence time to $60 \mathrm{~min}$, the transmembrane pressure could then stabilize for canola oil - the authors tested a variety of feedstocks at this minimum residence time, determining that higher residence times were needed for certain feedstocks to stabilize the pressure at manageable levels (65 $\mathrm{min}$ for corn oil and $80 \mathrm{~min}$ for waste cooking oil) (Falahati and Tremblay, 2012).

In the earlier work discussed above, Cao et al. (2007) employed different methanol/oil molar ratios from 11:1 to 46:1. The authors (Cao et al., 2008a and b) posited that a lower molar ratio $(6: 1)$ could be reached by recycling the methanol-rich phase. With a $\mathrm{TiO}_{2}$ membrane with a nominal molecular weight cutoff of $300 \mathrm{kDa}$, Cao et al. (2008a) tested the use of cooling for the retentate phase in order to separate methanol from biodiesel for the purposes of recycling. Even with complete recycling (100\% without purge), the FAME production was unhindered and remained between 0.0355 and $0.0423 \mathrm{~kg} / \mathrm{min}$ with no correlation with recycle amounts. However, transmembrane pressure and glycerol concentration experienced a slow buildup at recycle amounts of $100 \%$ and $75 \%$; thus, the authors (Cao et al., 2008a) recommend a 50\% recycle for the methanol-rich phase to avoid unwanted fouling of the bioreactor via glycerol agglomeration (Saleh et al., 2010b; Gomes et al., 2011). To test this concept with high FFA feedstocks, later work (Cao et al., 2008a) utilized methanol recycling to reach a 10:1 molar ratio for a variety of feedstocks, including soybean, palm and canola oil as well as yellow and brown grease. All of these runs were conducted at a reaction temperature of $65^{\circ} \mathrm{C}$ and a $0.5 \mathrm{wt} . \%$ loading of $\mathrm{NaOH}$ as a catalyst. This reaction system was able to outperform a batch reactor at similar conditions for glycerol content with water washing for both reactors, meeting ASTM standards (less than 0.24 wt.\%) - additionally, the soybean and canola products met this standard in the absence of any water washing whatsoever.

\section{Biodiesel upgrading}

Biodiesel has been blended with petroleum diesel and used successfully as transportation fuels in modified engines (Schuchardt et al., 1998; Kim et al., 2004; Demirbas, 2008). However, it still suffers from moisture absorption, corrosiveness, high viscosity, poor cold-flow properties, and low power density mainly due to high oxygen content (Srifa et al., 2015).

To address the issues associated with biodiesel, direct or indirect upgrading of triglycerides and fatty acids could be performed to produce diesel-like hydrocarbons (also known as "renewable diesel"). For a detailed discussion on terminology and historical perspectives of biodiesel and renewable diesel, see the review by Knothe (2010). In the context of this review, biodiesel upgrading refers to the conversion of vegetable oils, animal fats, bio-based triglycerides, fatty acids, and FAAEs into hydrocarbons by thermochemical and catalytic processes.

\subsection{Upgrading routes}

The main possible routes for obtaining fuels and chemicals from triglycerides, as representative molecules for bio-based oils and fats, are illustrated in Figure 2. It is imperative to understand that the deoxygenation pathways depicted in this scheme do not reveal any mechanistic information. Several studies have been performed to gain some insights into the mechanism of deoxygenation under different atmospheres. Detailed discussions about mechanisms of deoxygenation are presented in recent reviews by Gosselink et al. (2013) and Rogers and Zheng (2016).

Biodiesel consumption results in lower carbon monoxide, particulate matter, and unburned hydrocarbon emissions; however, it typically leads to higher $\mathrm{NO}_{\mathrm{x}}$ emissions, as compared with petroleum diesel (A1-Dawody and Bhatti, 2013). However, the amount of oxygen in biodiesel or its parent oil is significantly higher than its nitrogen content and much higher than oxygen content in petroleum diesel. On the other hand, any effort to remove oxygen will result in parallel removal of nitrogen (and/or sulfur) (Bezergianni et al., 2010a). Hence, effective catalytic deoxygenation of biobased oils will practically ensure obtaining a $\mathrm{NO}_{\mathrm{x}}$-free diesel. For this reason, (hydro)denitrogenation is not discussed in this review and interested readers are referred to the reviews elsewhere (Hoekman and Robbins, 2012 Yang et al., 2016).

Cracking is unattractive due to high yields of light hydrocarbons $\left(\mathrm{C}_{1}-\mathrm{C}_{4}\right)$ and short-chain alkanes $\left(\mathrm{C}_{5}-\mathrm{C}_{15}\right)$ with lower energy densities (Dupain et al., 2007; Sotelo-Boyas et al., 2010; Vinh et al., 2011). Commercial silicaalumina, zeolites, and fluid catalytic cracking catalysts are typically used for this type of reactions (Katikaneni et al., 1995; Dupain et al., 2007; Vinh et al., 2011). In contrast, deoxygenation appears promising since it produces diesel-like hydrocarbons with low oxygen content as compared with cracking and esterification processes. The fuel properties of renewable diesel (e.g., cetane number) obtained by catalytic deoxygenation of natural oils could even exceed its fossil-based counterpart (Snåre et al., 2009 Kiatkittipong et al., 2013; Phimsen et al., 2016). Furthermore, designing new catalytic systems and optimizing reaction conditions could maximize the yield of unsaturated hydrocarbons and alcohols, which can open new paths for production of higher value chemicals (Hollak et al., 2013). Note that the production of biodiesel followed by deoxygenation is possible but industrially irrelevant due to extra processing steps, which significantly increases capital and operating costs.

As concisely shown in Figure 2, two key processes for deoxygenating bio-based oils have been investigated thus far. One is deoxygenation in an inert atmosphere such as nitrogen, helium, or argon. Monometallic catalysts supported on $\mathrm{Al}_{2} \mathrm{O}_{3}, \mathrm{SiO}_{2}$, and carbon (especially carbon-supported noble metals) are the catalysts of choice for selective deoxygenation under inert atmospheres (Snåre et al., 2006; Snåre et al., 2008; Morgan et al., 2012). Nevertheless, several issues including limited deoxygenation, rapid deactivation of catalyst due to coking, and most notably high selectivity toward unwanted reactions like cracking and aromatization have hampered the advancement of this method toward larger scales (Snåre et al., 2008; Lestari et al., 2009a). As an alternative, deoxygenation in the presence of hydrogen has been proposed. The idea originally came from hydrotreating petroleum-based fuels to remove unwanted heteroatoms such as sulfur and nitrogen to improve the quality of the products and address some environmental concerns (Furimsky, 1983). Unlike the previously mentioned method, in this process deoxygenation could occur through both hydrodeoxygenation (HDO) and decarboxylation/decarbonylation (DCO) pathways. In addition, undesired reactions such as cracking, aromatization, cyclization, oligomerization, and coking are significantly hindered in the presence of $\mathrm{H}_{2}$ (Madsen et al., 2011). In principle, HDO pathway yields a 
product with one carbon atom more than that of DCO. This is advantageous from both environmental and energy efficiency viewpoints since less $\mathrm{CO}$ and $\mathrm{CO}_{2}$ are released in the product gas stream and more carbon ends up in the product liquid stream. Although it initially seems that more hydrogen is consumed in the HDO pathway as opposed to DCO, the successive methanation of $\mathrm{CO}$ and $\mathrm{CO}_{2}$ would increase the overall hydrogen consumption (Srifa et al., 2015). Saturation of double bonds also generally occurs during HDO processes. reactions such as oligomerization, cracking, and coking promoted in the absence of $\mathrm{H}_{2}$ due to inherent hydrogen deficiency of bio-based oils. Thus, co-feeding hydrogen as a reactant seems necessary to sustainably obtain a high-quality product without the frequent need for catalyst regeneration cycles. Nevertheless, the high hydrogen pressures that are sometimes required for effective deoxygenation may be a limiting factor for commercial HDO processes.

\section{Bio-based Oils and Fats}

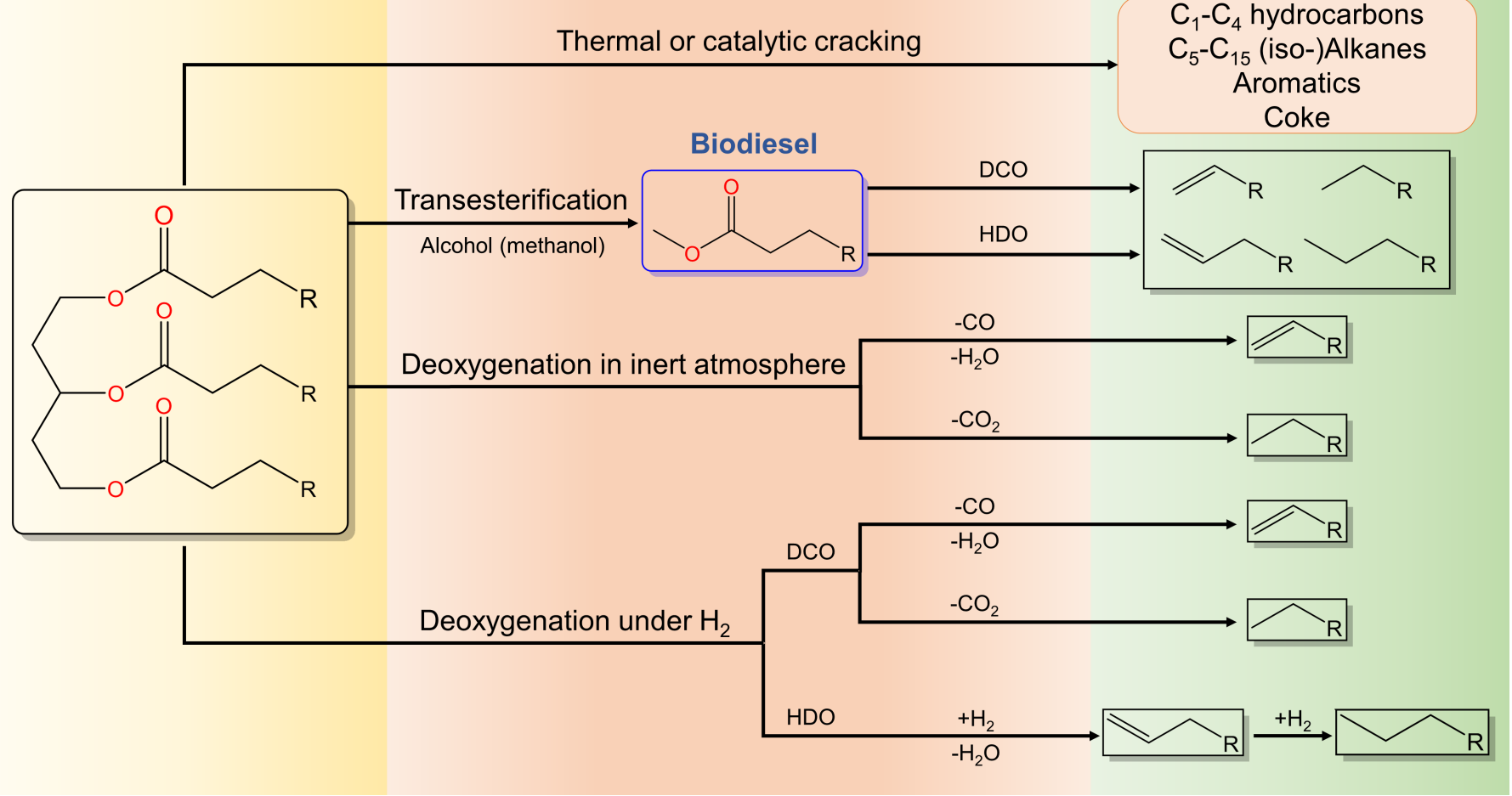

Fig.2. Possible reaction pathways for obtaining fuels and chemicals from triglycerides as representative molecules for bio-oils.

It should be noted that the hydrocarbon chain in the structure of triglycerides and/or fatty acids (i.e., -R) could be long or short, as well as saturated or unsaturated depending on the source of the triglyceride. For instance, crude palm kernel oil comprises mainly of saturated fatty acids such as lauric acid $\left(\mathrm{C}_{12}, 54.5 \%\right)$, myristic acid $\left(\mathrm{C}_{14}, 12.1 \%\right)$, and palmitic acid $\left(\mathrm{C}_{16}, 7.7 \%\right)$ (Ng et al., 2003). Rapeseed oil, on the other hand, contains primarily unsaturated $\mathrm{C}_{18}$ fatty acids: $63.7 \%$ oleic acid, $15.4 \%$ linoleic acid, and $14.3 \%$ linolenic acid, with one, two, and three double bonds, respectively (Sotelo-Boyas et al., 2010). Deoxygenation under $\mathrm{H}_{2}$ usually saturates this chain if unsaturated originally (Han et al., 2011a; Coumans and Hensen, 2017), whereas after deoxygenation under inert gases, the double bonds could remain intact (Snåre et al., 2008).

The extent of DCO and HDO routes under $\mathrm{H}_{2}$ depends on feedstock composition, reaction conditions, and the choice of catalyst (Kiatkittipong et al., 2013). The results of selected investigations for deoxygenating vegetable oils and their surrogate compounds are summarized in Tables 1-3. It is evident from these results that conventional hydrotreating catalysts have a higher selectivity for HDO than DCO reactions (Table 1). Supported noble metal catalysts, on the contrary, prefer DCO over HDO in the presence of hydrogen. Comparing deoxygenation processes in the absence and presence of hydrogen indicates the superiority of the latter. Even in the case of $\mathrm{Pd} / \mathrm{C}$ catalysts (initially believed to work identical under $\mathrm{Ar} / \mathrm{He}$ and $\mathrm{H}_{2}$ environments), hydrogen has been proven beneficial (Immer et al., 2010; Rozmysłowicz et al., 2012). For instance, higher catalyst stability and quicker kinetics were reported for stearic acid deoxygenation under $10 \% \mathrm{H}_{2}$ compared with $\mathrm{He}$ atmosphere using a 5\% Pd/C catalyst (Immer et al., 2010). This is because undesired side

\subsection{Upgrading catalysts}

Catalysts investigated to date for biodiesel upgrading can be categorized in three main groups. The first group comprises of hydrotreating catalysts including Ni- and Co-promoted Mo or W sulfides conventionally supported on silica and/or alumina materials. The second category includes supported metals with a focus on carbon-supported noble metals such as $\mathrm{Pd}$ and $\mathrm{Pt}$ Lastly, transition metal carbides, nitrides, and phosphides have been recently reported to be active for HDO reactions and selective toward longchain paraffins or olefins. Taking into account the considerable effect of support material in improving reactivity, selectivity, and stability of catalysts, it is imperative to acknowledge the role of different supports beside the active phase of upgrading catalysts.

\subsubsection{Conventional hydrotreating catalysts}

Transition metal sulfide-based catalysts were originally developed in refineries to remove heteroatoms (i.e., sulfur, nitrogen, oxygen, and metals) from distillate fuels by hydrotreating at elevated temperatures and pressures (Parkash, 2003). The presence of these heteroatoms could worsen fuel properties, corrode engines and storage units, deactivate catalysts in downstream units, and raise environmental concerns due to the emission of $\mathrm{SO}_{\mathrm{x}}$ and $\mathrm{NO}_{\mathrm{x}}$ (Parkash, 2003; Srivastava and Hancsok, 2014). Biodiesel suffers from some other problems such as low energy density and chemical stability and poor cold flow properties due to the presence of heteroatoms, 
Table 1.

Summary of some literature findings on catalytic deoxygenation using conventional hydrotreating catalysts.

\begin{tabular}{|c|c|c|c|c|c|c|c|c|c|}
\hline Entry & Feed & Catalyst & $\begin{array}{l}\mathbf{T} \\
\left({ }^{\circ} \mathbf{C}\right)\end{array}$ & $\begin{array}{l}\mathbf{P}_{\mathrm{H}_{2}} \\
\text { (bar) }\end{array}$ & $\begin{array}{l}\text { Contact time/ } \\
\text { Space velocity }\end{array}$ & Reactor & $\begin{array}{l}\text { Yield of major } \\
\text { products }^{*}\end{array}$ & Side products ${ }^{* *}$ & Reference \\
\hline 1 & Rapeseed oil & $\mathrm{NiMoS} / \gamma-\mathrm{Al}_{2} \mathrm{O}_{3}$ & 350 & 80 & $3 \mathrm{~h}$ & batch & $75 \%\left(\mathrm{C}_{13}-\mathrm{C}_{22}\right)$ & iso.- $-\mathrm{DCO}_{2}$ & Sotelo-Boyas et al. (2010) \\
\hline 2 & Rapeseed oil & $\mathrm{NiS} / \mathrm{Al}_{2} \mathrm{O}_{3}$ & 280 & 35 & $0.25 \mathrm{~h}^{-1}$ & fixed-bed & $56 \%\left(\mathrm{C}_{17}: 0\right)$ & FA $(40 \%)$ & \multirow{3}{*}{ Kubička and Kaluža (2010) } \\
\hline 3 & $"$ & $\mathrm{MoS} / \mathrm{Al}_{2} \mathrm{O}_{3}$ & $"$ & $"$ & $"$ & $"$ & $72 \%\left(C_{18}: 0\right)$ & $\mathrm{DCO}_{2}$-alc. & \\
\hline 4 & $"$ & $\mathrm{NiMoS} / \mathrm{Al}_{2} \mathrm{O}_{3}$ & $"$ & $"$ & $"$ & $"$ & $\begin{array}{l}70 \%\left(\mathrm{C}_{18}: 0\right) \\
24 \%\left(\mathrm{C}_{17}: 0\right)\end{array}$ & - & \\
\hline 5 & Rapeseed oil [a] & CoMoS/MCM-41 & 320 & 35 & $1 \mathrm{~h}^{-1}$ & fixed-bed & $53 \%(\mathrm{HCs})$ & $\begin{array}{l}\text { DCO-DCO } \\
\text { FA-FE }\end{array}$ & \multirow{2}{*}{ Kubička et al. (2010) } \\
\hline 6 & $"$ & CoMoS/MCM-41 & $"$ & 70 & $"$ & $"$ & $93 \%(\mathrm{HCs})$ & $\mathrm{DCO}-\mathrm{DCO}_{2}$ & \\
\hline 7 & Palm fatty acid distillate & $\mathrm{NiMoS} / \gamma-\mathrm{Al}_{2} \mathrm{O}_{3}$ & 375 & 40 & $1 \mathrm{~h}$ & batch & $75 \%$ (diesel) $^{[\mathrm{b}]}$ & DCO-DCO ${ }_{2}$ & \multirow[b]{2}{*}{ Kiatkittipong et al. (2013) } \\
\hline 8 & $\begin{array}{l}\text { Degummed crude palm } \\
\text { oil }\end{array}$ & $\mathrm{NiMoS} / \gamma-\mathrm{Al}_{2} \mathrm{O}_{3}$ & & & & batch & $70 \%$ (diesel) $^{[b]}$ & DCO-DCO ${ }_{2}$ & \\
\hline 9 & Palm kernel oil & $\mathrm{NiMoS} / \gamma-\mathrm{Al}_{2} \mathrm{O}_{3}$ & 330 & 50 & $1 \mathrm{~h}^{-1}$ & trickle-bed & $53 \%\left(\mathrm{C}_{10}-\mathrm{C}_{12}\right)$ & $\begin{array}{l}\text { DCO-DCO } \\
\text { met. }\end{array}$ & Itthibenchapong et al., (2017) \\
\hline 10 & Palm oil ${ }^{[c]}$ & $\mathrm{NiMoS} / \gamma-\mathrm{Al}_{2} \mathrm{O}_{3}$ & 300 & 50 & $0.25 \mathrm{~h}^{-1}$ & fixed-bed & $\begin{array}{l}54.7 \%\left(\mathrm{C}_{18}: 0\right) \\
34.3 \%\left(\mathrm{C}_{16}: 0\right)\end{array}$ & DCO-DCO ${ }_{2}$ & \multirow{4}{*}{ Srifa et al. (2014) } \\
\hline 11 & $"$ & $\mathrm{NiMoS} / \gamma-\mathrm{Al}_{2} \mathrm{O}_{3}$ & 300 & 50 & $1 \mathrm{~h}^{-1}$ & $"$ & $\begin{array}{l}47.4 \%\left(\mathrm{C}_{18}: 0\right) \\
30.7 \%\left(\mathrm{C}_{16}: 0\right)\end{array}$ & DCO-DCO ${ }_{2}$ & \\
\hline 12 & $"$ & $\mathrm{NiMoS} / \gamma-\mathrm{Al}_{2} \mathrm{O}_{3}$ & 300 & 15 & $1 \mathrm{~h}^{-1}$ & $"$ & $\begin{array}{l}43.9 \%\left(\mathrm{C}_{18}: 0\right) \\
29.3 \%\left(\mathrm{C}_{16}: 0\right)\end{array}$ & $\mathrm{DCO}-\mathrm{DCO}_{2}$ & \\
\hline 13 & $"$ & $\mathrm{NiMoS} / \gamma-\mathrm{Al}_{2} \mathrm{O}_{3}$ & 420 & 50 & $1 \mathrm{~h}^{-1}$ & $"$ & $\begin{array}{l}22.3 \%\left(\mathrm{C}_{16}: 0\right) \\
12.7 \%\left(\mathrm{C}_{18}: 0\right)\end{array}$ & $\begin{array}{l}\text { DCO-DCO } \\
\text { cra. }\end{array}$ & \\
\hline 14 & Spent coffee oil ${ }^{[\mathrm{d}]}$ & $\mathrm{NiMoS} / \gamma-\mathrm{Al}_{2} \mathrm{O}_{3}$ & 400 & 40 & $2 \mathrm{~h}$ & batch & $\begin{array}{l}34 \%\left(\mathrm{C}_{12}-\mathrm{C}_{18}\right) \\
20 \%\left(\mathrm{C}_{5}-\mathrm{C}_{11}\right)\end{array}$ & $\mathrm{DCO}-\mathrm{DCO}_{2}$ & Phimsen et al. (2016) \\
\hline 15 & Canola oil & NiMoS & 375 & 90 & $8 \mathrm{~h}$ & batch & $90 \%(\text { diesel })^{[\mathrm{e}]}$ & cra.-dim. & \multirow[b]{2}{*}{ Zhang et al. (2014) } \\
\hline 16 & $"$ & CoMoS & $"$ & $"$ & $"$ & $"$ & $78 \%(\text { diesel })^{[\mathrm{e}]}$ & $\begin{array}{l}\text { DCO-cra. } \\
\text { dim.-olf. }\end{array}$ & \\
\hline 17 & Jatropha oil $^{[\mathrm{f}]}$ & $\mathrm{NiMoS} / \mathrm{SiO}_{2}-\mathrm{Al}_{2} \mathrm{O}_{3}$ & 350 & 40 & $7.6 \mathrm{~h}^{-1}$ & fixed-bed & $\begin{array}{l}75 \%\left(\mathrm{C}_{11}-\mathrm{C}_{20}\right) \\
8 \%\left(\mathrm{C}_{5}-\mathrm{C}_{10}\right)\end{array}$ & $\begin{array}{l}\text { DCO-DCO } \\
\text { iso.-cra. }\end{array}$ & Liu et al. (2011) \\
\hline 18 & Sunflower oil ${ }^{[\mathrm{g}]}$ & $\mathrm{NiMoS} / \mathrm{Al}_{2} \mathrm{O}_{3} / \mathrm{F}$ & 350 & 40 & $1 \mathrm{~h}^{-1}$ & semi-batch & $75 \%\left(\mathrm{C}_{11}-\mathrm{C}_{21}\right)$ & iso. $(35 \%)$-cra. & Kovács et al. (2011) \\
\hline 19 & Waste cooking oil ${ }^{[\mathrm{h}]}$ & Commercial NiMoS & 330 & 83 & $1 \mathrm{~h}^{-1}$ & fixed-bed & $90 \%(\text { diesel })^{[a]}$ & DCO-DCO ${ }_{2}$ & Bezergianni et al. (2010a) \\
\hline 20 & Waste cooking oil ${ }^{[\mathrm{h}]}$ & Commercial NiMoS & 330 & 83 & $1 \mathrm{~h}^{-1}$ & fixed-bed & $91 \%\left(\mathrm{C}_{15}-\mathrm{C}_{18}\right)$ & $\begin{array}{l}\text { DCO-DCO } \\
\text { iso. }(6 \%)\end{array}$ & \multirow[b]{2}{*}{ Bezergianni et al. (2010b) } \\
\hline 21 & $"$ & Commercial NiMoS & 398 & $"$ & $"$ & $"$ & $61 \%\left(\mathrm{C}_{15}-\mathrm{C}_{18}\right)$ & $\begin{array}{l}\text { iso. }(36 \%) \\
\text { cra.( } 21 \%) \\
\operatorname{dim} .(14 \%)\end{array}$ & \\
\hline 22 & $\mathrm{C}_{18}$ fatty acids & $\mathrm{NiWS} / \mathrm{SiO}_{2}-\mathrm{Al}_{2} \mathrm{O}_{3}$ & 300 & 50 & not specified & fixed-bed & $\begin{array}{l}33 \%\left(\mathrm{C}_{18}: 0\right) \\
14 \%\left(\mathrm{C}_{17}: 0\right) \\
\end{array}$ & $\begin{array}{l}\text { DCO-DCO } \\
\text { cra. }\end{array}$ & Yang et al. (2013b) \\
\hline 23 & Methyl oleate & $\mathrm{NiMoS} / \gamma-\mathrm{Al}_{2} \mathrm{O}_{3}$ & 260 & 60 & $6.5 \mathrm{~h}^{-1}$ & fixed-bed & $\begin{array}{l}34 \%\left(\mathrm{C}_{18}: 0\right) \\
9 \%\left(\mathrm{C}_{17}: 0\right)\end{array}$ & DCO-DCO ${ }_{2}$ & Coumans and Hensen (2017) \\
\hline 24 & Methyl palmitate & $\mathrm{NiMoS} / \gamma-\mathrm{Al}_{2} \mathrm{O}_{3}$ & 260 & 15 & $2 \mathrm{~h}$ & batch & $\begin{array}{l}35 \%\left(\mathrm{C}_{15}: 0\right) \\
8 \%\left(\mathrm{C}_{16}: 0\right)\end{array}$ & $\operatorname{dim}$. & Han et al. (2012) \\
\hline 25 & Caprylic acid & $\mathrm{NiMoO} / \gamma-\mathrm{Al}_{2} \mathrm{O}_{3}$ & 360 & 17 & $6 \mathrm{~h}^{-1}$ & fixed-bed & $\begin{array}{l}12.5 \%\left(\mathrm{C}_{8}: 0\right) \\
5.6 \%\left(\mathrm{C}_{8}: 1\right) \\
\end{array}$ & iso. & Boda et al. (2010) \\
\hline 26 & Palmitic acid & $\mathrm{MoO}_{2} / \mathrm{CNT}$ & 220 & 40 & $6 \mathrm{~h}$ & batch & $92 \%\left(\mathrm{C}_{16}: 0\right)$ & DCO-DCO ${ }_{2}$ & Ding et al. (2015) \\
\hline 27 & Methyl laurate ${ }^{[f]}$ & NiMoO/SAPO-11 & 325 & 30 & $5 \mathrm{~h}^{-1}$ & fixed-bed & $\begin{array}{l}87 \%\left(\mathrm{C}_{12}: 0\right) \\
11 \%\left(\mathrm{C}_{11}: 0\right)\end{array}$ & iso. $(5 \%)$ & Chen et al. (2015) \\
\hline
\end{tabular}

*: Yields are approximate numbers and at different conversions; (Cx:y) $\mathrm{x}=$ number of carbons, $\mathrm{y}=$ number of unsaturated (double) bonds.

**: iso.=isomerization; $\mathrm{DCO}=$ decarbonylation; $\mathrm{DCO}_{2}=$ decarboxylation; $\mathrm{FA}=$ fatty acid; $\mathrm{FE}=$ fatty ester; met.=methanation; cra. $=$ cracking/hydrocracking; dim. $=$ dimerization; olf. $=$ olefin; alc. $=$ alcohol.

[a] $\mathrm{H}_{2}$ /feed molar ratio=50; [b] hydrocarbon yield in the $180-360{ }^{\circ} \mathrm{C}$ boiling range; [c] $\mathrm{H}_{2} /$ feed volume ratio=1000; [d] $\mathrm{H}_{2} /$ feed molar ratio=2; [e] hydrocarbon yield in the $200-350{ }^{\circ} \mathrm{C}$ boiling range; [f] $\mathrm{H}_{2} /$ feed volume ratio=800; [g] $\mathrm{H}_{2} /$ feed volume ratio=500; [h] $\mathrm{H}_{2} /$ feed volume ratio $=4071$. 
most noticeably oxygen. Therefore, the same principles could also apply to remove oxygen from bio-oils and bio-fats using conventional hydrotreating catalysts, although the amount of oxygen in bio-oils (28-40 wt\%) is considerably higher than the amount of oxygen $(<1 \mathrm{wt} \%)$ and sulfur $(<4 \mathrm{wt} \%)$ in petroleum-based fuels (Mortensen et al., 2011). The oxygen atoms present in the feed are able to oxidize transition metal sulfides to their less reactive oxide phase, especially in the absence of a sulfur source. Hence, a constant flow of $\mathrm{H}_{2} \mathrm{~S}$ or some other sulfur-containing compound may be required (Furimsky, 2000).

Transition metal sulfides have proven effective catalysts for HDO, but essentially inept in the absence of $\mathrm{H}_{2}$ and $\mathrm{H}_{2} \mathrm{~S}$ as expected by their deoxygenation pathway, i.e., a reverse Mars-Van Krevelen mechanism (Zhao et al., 2013). In this mechanism, $\mathrm{H}_{2}$ interacts with sulfur atoms on the $\mathrm{MoS}_{2}$ surface and forms $\mathrm{H}_{2} \mathrm{~S}$ and a coordinatively unsaturated site. This vacant site can chemisorb oxygenates, the oxygen atom of which oxidizes the catalyst while hydrocarbon products are formed with or without further hydrogenation (Romero et al., 2010). Thus, it is clear that the presence of $\mathrm{H}_{2}$ is necessary for the catalyst to proceed with deoxygenation. That is also why these catalysts are exclusively active for HDO rather than DCO pathway. Moreover, in the absence of $\mathrm{H}_{2} \mathrm{~S}$ or another sulfur source, oxygen could replace sulfur atoms, forming less active molybdenum oxide species on the surface. The results of some experiments using hydrotreating catalysts are compiled in Table 1.

The main advantages of conventional hydrotreating catalysts are as follows. Firstly, they are very active for deoxygenation and selective to HDO, which assures high hydrocarbon yields. Secondly, this class of catalysts is produced in large scales and studied comprehensively and extremely well due to their industrial presence for decades. Thus, minimal training and intellectual efforts are needed for synthesizing, characterization, and eventually commercialization (Ruddy et al., 2014). Additionally, they are robust, meaning that they are not very sensitive to other heteroatoms that may exist in biomass feedstocks.

There are several drawbacks for these catalysts, on the other hand. One of the main drawbacks is the need for continuous co-feeding of a sulfur source such as $\mathrm{H}_{2} \mathrm{~S}$ to maintain catalytic activity, which deprives the resulting biofuel from its sulfur-free nature (Badawi et al., 2011). This is particularly important as strict regulations for sulfur levels in diesel fuel are mandated by governments (Stanislaus et al., 2010). Additionally, hydrotreating is typically done at high pressures of hydrogen, requiring expensive equipment including heavy-duty compressors and special reactors, increasing both capital and operating costs. Another disadvantage is the sensitivity of these catalysts to the presence of water, a ubiquitous substance in bio-based feedstocks (Senol et al., 2005a). Last but not least, this class of catalysts is prone to coking, especially with feedstocks that have unsaturated $\mathrm{C}=\mathrm{C}$ bonds, known to be coke precursors (Furimsky and Massoth, 1999). These shortcomings in the performance of transition metal sulfide catalysts call for research on new non-sulfide materials for catalyzing deoxygenation reactions.

The same mechanistic principles can be applied to transition metal oxides. However, the oxide form of these catalysts is less reactive than the sulfide form for deoxygenation reactions (Senol et al., 2005b). Although supported molybdenum oxides have been recently found to be active for HDO of some model compounds (Boda et al., 2010; Chen et al., 2015; Ding et al., 2015), their activity seems to be inferior to the sulfide form at elevated pressures used in hydrotreating processes (Şenol et al., 2005b).

\subsubsection{Supported metallic catalysts}

To address some issues of conventional hydrotreating catalysts for bio-oil deoxygenation, supported mono- and bi-metallic catalysts gained substantial research attention (Table 2). This category of catalysts is comprised mainly of supported noble metals and base metals. These catalysts do not require cofeeding of a sulfur source, are not very sensitive to water, and are able to activate $\mathrm{H}_{2}$ at low/moderate temperatures. Therefore, they are promising candidates for converting bio-oils into liquid fuels.

Murzin's group pioneered the deoxygenation of vegetable oils and many model compounds using a variety of supported metallic catalysts (Kubičková et al., 2005; Snåre et al., 2006; Mäki-Arvela et al., 2007; Snåre et al., 2007; Lestari et al., 2008; Mäki-Arvela et al., 2008; Snåre et al., 2008; Simakova et al., 2009; Lestari et al., 2009b and c; Bernas et al., 2010; Lestari et al., 2010; Simakova et al., 2011). Their studies show that supported noble metals are generally selective to DCO and thus produce $\mathrm{C}_{\mathrm{n}-1}$ products. They suggest that HDO may proceed on bifunctional catalysts in the presence of hydrogen, where metal sites are active for hydrogenation/hydrogenolysis and the support's acidic sites are responsible for deoxygenation (via dehydration). Among monometallic catalysts, noble metals, especially Pd, have shown excellent performance for deoxygenation of various model compounds and bio-oils. Despite their effectiveness, the high price and scarcity of noble metals are important prohibitive factors for cost-effective production of bio-based fuels.

The strong affinity of these catalysts for hydrogen promotes the hydrogenation of coke precursors adsorbed on the surface and ensures a longer lifetime for the catalyst (Zhu et al., 2011). These catalysts also have a high resistance under hydrothermal conditions, which makes them excellent candidates for deoxygenation of bio-based feedstocks (Ruddy et al., 2014). However, studies suggest that leaching and sintering of the active phase might be major problems for utilization of these catalysts over extended periods (Han et al., 2011b). In addition, some works indicate their sensitivity to sulfur, nitrogen, and trace inorganic contaminants (e.g., iron) that might be present in biomass and bio-oil (Nagy et al., 2009; Ardiyant et al., 2011; Choudhary and Phillips, 2011), although the utilization of bimetallic alloys have increased their tolerance to sulfur and nitrogen (Nagy et al., 2009). This category of catalysts is not a good choice for producing alkenes/alkynes since they saturate the double/triple bonds of triglycerides, FFAs, and FAAEs prior to breaking their structures or oxygen removal (Madsen et al., 2011)

A comparison between $\mathrm{Pd} / \mathrm{C}$ and $\mathrm{NiMoS} / \gamma-\mathrm{Al}_{2} \mathrm{O}_{3}$ indicates that the former is superior, in terms of activity and selectivity to diesel-range hydrocarbons, for pure fatty acid feedstocks, but inferior in the case of biooils (Kiatkittipong et al., 2013). Despite similar observations in other studies (Boda et al., 2010; Madsen et al., 2011; Phimsen et al., 2016), there is no systematic study undertaken to address this phenomenon. Based on turnover frequencies calculated for deoxygenating oleic acid over four alumina supported monometallic catalysts, catalytic activities were found to be in the order: $\mathrm{Co}>\mathrm{Pd}>\mathrm{Pt}>\mathrm{Ni}$. It was also emphasized that $\mathrm{DCO}$ was more dominant in the case of $\mathrm{Pd}, \mathrm{Pt}$, and $\mathrm{Ni}$ catalysts, whereas the $\mathrm{Co} / \mathrm{Al}_{2} \mathrm{O}_{3}$ catalyst deoxygenates palm oil through both DCO and HDO pathways (Srifa et al., 2015). Similar results were obtained for deoxygenation of spent coffee oil using $\mathrm{Pd} / \mathrm{C}$ and $\mathrm{NiMoS} / \gamma-\mathrm{Al}_{2} \mathrm{O}_{3}$ (Phimsen et al., 2016).

At this point, supported noble metals do not seem to be an industrially relevant option mainly because of their high prices, sensitivity to contaminants, as well as leaching and sintering problems. Other monometallic catalysts such as $\mathrm{Co}$ and $\mathrm{Ni}$ have shown promise as alternatives for noble metals, but important issues such as sensitivity to trace contaminants, deactivation, and stability still remain unresolved. These issues should be addressed before any attempts can be made on industrialization of these catalysts for producing renewable diesel fuels.

\subsubsection{Transition metal carbides, nitrides, and phosphides}

Transition metals in different forms have recently emerged as effective deoxygenation catalysts (Table 3). Among them, molybdenum and tungsten have gained much attention due to their unique HDO abilities. $\mathrm{Mo}_{2} \mathrm{C}$ and $\mathrm{W}_{2} \mathrm{C}$ have shown promising results in deoxygenation of various vegetable oils and model compounds (Han et al., 2011a and b; Han et al., 2012; Sousa et al., 2012; Hollak et al., 2013; Gosselink et al., 2013; Qin et al., 2013; Wang et al., 2013; Stellwagen and Bitter, 2015). Compared with Pd and Pt catalysts, transition metal carbides exhibited higher catalytic activity, better selectivity toward HDO rather than DCO, and much higher resistance to leaching and deactivation (Han et al., 2011b). $\mathrm{Mo}_{2} \mathrm{C} / \mathrm{CNF}$ was found to be an excellent catalyst for arriving at paraffinic hydrocarbons due to its high hydrogenation ability, while $\mathrm{W}_{2} \mathrm{C} / \mathrm{CNF}$ was shown to be appropriate for producing olefins (Hollak et al., 2013). $\mathrm{Mo}_{2} \mathrm{C}$ was more stable presumably because of lower concentration of coke precursors, i.e. olefins, in the product stream. Additionally, $\mathrm{Mo}_{2} \mathrm{C}$ was less sensitive to oxidation compared with $\mathrm{W}_{2} \mathrm{C}$. The oxide phase was found to be responsible for dehydration reactions and thus producing unsaturated hydrocarbons (Stellwagen and Bitter, 2015). Hence, it seems that a tradeoff exists between catalytic activity and selectivity toward olefins.

Transition metal nitrides are studied even more extensively than carbides for hydrodesulfurization and hydrodenitrogenation (Furimsky, 2003). 
Table 2.

Summary of some literature findings on catalytic deoxygenation using supported metallic catalysts.

\begin{tabular}{|c|c|c|c|c|c|c|c|c|c|}
\hline Entry & Feed & Catalyst & $\begin{array}{c}\mathbf{T} \\
\left({ }^{\circ} \mathbf{C}\right)\end{array}$ & $\begin{array}{c}\mathbf{P} \\
(\text { bar })\end{array}$ & $\begin{array}{l}\text { Contact time/ } \\
\text { Space velocity }\end{array}$ & Reactor & $\begin{array}{l}\text { Yield of major } \\
\text { products }^{*}\end{array}$ & $\begin{array}{l}\text { Side } \\
\text { products }^{* *}\end{array}$ & Reference \\
\hline 1 & Rapeseed oil & Pt/H-ZSM-5 & 380 & $110\left(\mathrm{H}_{2}\right)$ & $3 \mathrm{~h}$ & batch & $\begin{array}{l}41 \%\left(\mathrm{C}_{5}-\mathrm{C}_{12}\right) \\
21 \%\left(\mathrm{C}_{13}-\mathrm{C}_{22}\right) \\
\end{array}$ & iso.-cra. & \multirow{2}{*}{ Sotelo-Boyas et al. (2010) } \\
\hline 2 & $"$ & $\mathrm{Pt} / \mathrm{H}-\mathrm{Y}$ & $"$ & $"$ & $"$ & $"$ & $\begin{array}{l}36 \%\left(\mathrm{C}_{13}-\mathrm{C}_{22}\right) \\
28 \%\left(\mathrm{C}_{5}-\mathrm{C}_{12}\right)\end{array}$ & iso. & \\
\hline 3 & Jatropha oil ${ }^{\text {[a] }}$ & $\mathrm{PtPd} / \mathrm{Al}_{2} \mathrm{O}_{3}$ & 350 & $30\left(\mathrm{H}_{2}\right)$ & $h^{-1}$ & fixed-bed & $\begin{array}{l}81.4 \%\left(\mathrm{C}_{17}: 0\right) \\
13.9 \%\left(\mathrm{C}_{15}: 0\right) \\
\end{array}$ & - & Gong et al. (2012) \\
\hline 4 & Spent coffee oil ${ }^{[b]}$ & $\mathrm{Pd} / \mathrm{C}$ & 400 & $40\left(\mathrm{H}_{2}\right)$ & $2 \mathrm{~h}$ & batch & $\begin{array}{l}31 \%\left(\mathrm{C}_{12}-\mathrm{C}_{18}\right) \\
17 \%\left(\mathrm{C}_{5}-\mathrm{C}_{11}\right)\end{array}$ & met. & Phimsen et al. (2016) \\
\hline 5 & $\begin{array}{l}\text { Palm fatty acid } \\
\text { distillate }\end{array}$ & $\mathrm{Pd} / \mathrm{C}$ & 375 & $40\left(\mathrm{H}_{2}\right)$ & $0.5 \mathrm{~h}$ & batch & $80 \%\left(\right.$ diesel) ${ }^{[c]}$ & - & \multirow[t]{2}{*}{ Kiatkittipong et al. (2013) } \\
\hline 6 & $\begin{array}{l}\text { Degummed crude } \\
\text { palm oil }\end{array}$ & $\mathrm{Pd} / \mathrm{C}$ & 400 & $"$ & $1 \mathrm{~h}$ & batch & $70 \%$ (diesel) $^{[c]}$ & - & \\
\hline 7 & Microalgae oil & Fe-MSN & 290 & $30\left(\mathrm{H}_{2}\right)$ & $6 \mathrm{~h}$ & batch & $51 \%\left(\mathrm{C}_{13}-\mathrm{C}_{20}\right)$ & not discussed & \multirow[b]{2}{*}{ Kandel et al. (2014) } \\
\hline 8 & Oleic acid & Fe-MSN & $"$ & $"$ & $"$ & $"$ & $\begin{array}{l}82 \%\left(\mathrm{C}_{18}: 0\right) \\
12 \%\left(\mathrm{C}_{17}: 0\right) \\
\end{array}$ & not discussed & \\
\hline 9 & Tripalmitin & $\mathrm{Pt} / \gamma-\mathrm{Al}_{2} \mathrm{O}_{3}$ & 325 & $20\left(\mathrm{H}_{2}\right)$ & $5 \mathrm{~h}$ & batch & $43 \%\left(C_{15}: 0\right)$ & - & \multirow{3}{*}{ Madsen et al. (2011) } \\
\hline 10 & Oleic acid & $\mathrm{Pt} / \gamma-\mathrm{Al}_{2} \mathrm{O}_{3}$ & - & $20\left(\mathrm{H}_{2}\right)$ & $5 \mathrm{~h}$ & - & $95 \%\left(\mathrm{C}_{17}: 0\right)$ & - & \\
\hline 11 & Oleic acid & $\mathrm{Pt} / \gamma-\mathrm{Al}_{2} \mathrm{O}_{3}$ & - & $9\left(\mathrm{H}_{2}\right)$ & $1 \mathrm{~h}$ & - & $71 \%\left(\mathrm{C}_{17}: 0\right)$ & - & \\
\hline 12 & Oleic acid & $\mathrm{Co} / \gamma-\mathrm{Al}_{2} \mathrm{O}_{3}$ & 330 & $50\left(\mathrm{H}_{2}\right)$ & $2 \mathrm{~h}^{-1}$ & trickle-bed & $\begin{array}{l}50 \%\left(\mathrm{C}_{18}: 0\right) \\
44 \%\left(\mathrm{C}_{17}: 0\right) \\
\end{array}$ & met. & \multirow{4}{*}{ Srifa et al. (2015) } \\
\hline 13 & $"$ & $\mathrm{Pd} / \gamma-\mathrm{Al}_{2} \mathrm{O}_{3}$ & $"$ & $"$ & $"$ & $"$ & $72 \%\left(\mathrm{C}_{17}: 0\right)$ & est. & \\
\hline 14 & $"$ & $\mathrm{Pt} / \gamma-\mathrm{Al}_{2} \mathrm{O}_{3}$ & $"$ & $"$ & $"$ & $"$ & $51.1 \%\left(\mathrm{C}_{17}: 0\right)$ & SA-est. & \\
\hline 15 & $"$ & $\mathrm{Ni} / \gamma-\mathrm{Al}_{2} \mathrm{O}_{3}$ & $"$ & $"$ & $"$ & $"$ & $25.5 \%\left(\mathrm{C}_{17}: 0\right)$ & SA-est. & \\
\hline 16 & Stearic acid & $\mathrm{Pd} / \mathrm{C}$ & 300 & $6(\mathrm{He})$ & $6 \mathrm{~h}$ & semi-batch & $95 \%\left(\mathrm{C}_{17}: 0\right)$ & - & \multirow{8}{*}{ Snåre et al. (2006) } \\
\hline 17 & $"$ & $\mathrm{Pt} / \mathrm{C}$ & $"$ & $"$ & $"$ & $"$ & $75 \%\left(\mathrm{C}_{17}: 0\right)$ & cra. & \\
\hline 18 & $"$ & $\mathrm{PdPt} / \mathrm{C}$ & $"$ & $"$ & $"$ & $"$ & $59.1 \%\left(\Sigma \mathrm{C}_{17}\right)$ & - & \\
\hline 19 & $"$ & $\mathrm{Rh} / \mathrm{C}$ & $"$ & $"$ & $"$ & $"$ & $15.2 \%\left(\Sigma \mathrm{C}_{17}\right)$ & dim.-cra.-ket. & \\
\hline 20 & $"$ & $\mathrm{Ru} / \mathrm{C}$ & $"$ & $"$ & $"$ & $"$ & $8.6 \%\left(\Sigma \mathrm{C}_{17}\right)$ & dim.-cra.-ket. & \\
\hline 21 & $"$ & $\mathrm{Ni} / \mathrm{SiO}_{2}$ & $"$ & $"$ & $"$ & $"$ & $10.5 \%\left(\Sigma \mathrm{C}_{17}\right)$ & cra. & \\
\hline 22 & $"$ & $\mathrm{Pd} / \mathrm{Al}_{2} \mathrm{O}_{3}$ & $"$ & $"$ & $"$ & $"$ & $10 \%\left(\Sigma \mathrm{C}_{17}\right)$ & ket.-dim. & \\
\hline 23 & $"$ & $\mathrm{Pt} / \mathrm{Al}_{2} \mathrm{O}_{3}$ & $"$ & $"$ & $"$ & $"$ & $9.2 \%\left(\Sigma \mathrm{C}_{17}\right)$ & ket.-dim. & \\
\hline 24 & Stearic acid & $\mathrm{Pd} / \mathrm{C}$ & 300 & $15(\mathrm{He})$ & $0 \mathrm{~h}$ & semi-batch & $\begin{array}{l}24.7 \%\left(\mathrm{C}_{17}: 0\right), \\
8.3 \%\left(\mathrm{C}_{17}: 1\right) \\
\end{array}$ & - & \multirow{3}{*}{ Immer et al. (2010) } \\
\hline 25 & $"$ & $\mathrm{Pd} / \mathrm{C}$ & $"$ & $15(\mathrm{He})$ & $5 \mathrm{~h}$ & $"$ & $98 \%\left(\mathrm{C}_{17}: 0\right)$ & - & \\
\hline 26 & $"$ & $\mathrm{Pd} / \mathrm{C}$ & $"$ & $\begin{array}{l}15\left(10 \% \mathrm{H}_{2-}\right. \\
\mathrm{He})\end{array}$ & $1 \mathrm{~h}$ & $"$ & $98 \%\left(\mathrm{C}_{17}: 0\right)$ & - & \\
\hline 27 & Caprylic acid & $\mathrm{Pd} / \mathrm{C}$ & 360 & $17\left(\mathrm{H}_{2}\right)$ & $6 \mathrm{~h}^{-1}$ & fixed-bed & $20.3 \%\left(\mathrm{C}_{7}: 0\right)$ & - & Boda et al. (2010) \\
\hline 28 & palmitic acid & $\mathrm{Pd} / \mathrm{CNT}$ & 280 & $40\left(\mathrm{H}_{2}\right)$ & $6 \mathrm{~h}$ & batch & $\begin{array}{l}78.3 \%\left(\mathrm{C}_{15}: 0\right) \\
12.1 \%\left(\mathrm{C}_{16}: 0\right)\end{array}$ & cra. & Ding et al. (2015) \\
\hline 29 & methyl palmitate & $\mathrm{Pd} / \mathrm{CNT}$ & 240 & $15\left(\mathrm{H}_{2}\right)$ & $2 \mathrm{~h}$ & batch & $34.5 \%\left(\mathrm{C}_{15}: 0\right)$ & not discussed & \multirow{2}{*}{ Han et al. (2011b) } \\
\hline 30 & $"$ & $\mathrm{Pt} / \mathrm{CNT}$ & $"$ & $"$ & $"$ & $"$ & $\begin{array}{l}22.4 \%\left(\mathrm{C}_{15}: 0\right) \\
3.5 \%\left(\mathrm{C}_{16}: 0\right)\end{array}$ & not discussed & \\
\hline 31 & Methyl oleate ${ }^{[d]}$ & Ni/SBA-15 & 340 & $30\left(\mathrm{H}_{2}\right)$ & $20 \mathrm{~h}^{-1}$ & fixed-bed & $\begin{array}{l}46 \%\left(\mathrm{C}_{17}: 0\right) \\
12 \%\left(\mathrm{C}_{15}: 0\right)\end{array}$ & $\begin{array}{l}\text { DCO-DCO } \\
\text { cra. }\end{array}$ & Yang et al. (2012) \\
\hline
\end{tabular}

* Yields are approximate numbers and at different conversions; (Cx:y) $\mathrm{x}=$ number of carbons, $\mathrm{y}=$ number of unsaturated (double) bonds.

**: iso.=isomerization; cra $=$ cracking $/$ hydrocracking; met. $=$ methanation; est. $=$ esterification; $\mathrm{SA}=$ stearic acid; dim. $=$ dimerization; $\mathrm{ket} .=\mathrm{ketonization} ; \mathrm{DCO}=\mathrm{dec}$ arbonylation; $\mathrm{DCO}{ }_{2}=\mathrm{dec}$ arboxylation.

[a] $\mathrm{H}_{2} /$ feed volume ratio=600; [b] $\mathrm{H}_{2} /$ feed molar ratio=2; [c] hydrocarbon yield in the $180-360{ }^{\circ} \mathrm{C}$ boiling range; [d] $\mathrm{H}_{2} /$ feed volume ratio=300 at $6 \mathrm{~h}$ on stream.

These materials are known to adsorb and activate hydrogen and can act as bifunctional catalysts with both metallic and acidic sites, which is beneficial for HDO of bio-oils (Miga et al., 1999). Nevertheless, very few studies have tested these catalysts for converting vegetable oils and model compounds into diesel-like hydrocarbons. Wang et al. (2012) examined the ability of NiMo nitride and carbide supported on ZSM-5 for hydrocracking of soybean oil. Complete conversions and high yields of hydrocarbon fuels $(\sim 50 \%)$ were obtained for both catalysts. The nitride catalyst showed a higher selectivity toward DCO and methanation, which is undesired for producing fuels. However, this might not remain true if the support material was of a less acidic nature. In another study, $\gamma-\mathrm{Al}_{2} \mathrm{O}_{3}$-supported transition metal nitrides were investigated for HDO of oleic acid and canola oil (Monnier et al. 2010). $\mathrm{Mo}_{2} \mathrm{~N} / \mathrm{Al}_{2} \mathrm{O}_{3}$ exhibited higher activity, oxygen removal, and alkane selectivity than vanadium and tungsten nitrides. Molybdenum nitride was 
very selective toward HDO, producing almost exclusively $n$-octadecane from oleic acid. A high oxygen removal of $~ 90 \%$ and diesel fuel yield of $38-48 \%$ were obtained by hydrotreating canola oil over $\mathrm{Mo}_{2} \mathrm{~N} / \mathrm{Al}_{2} \mathrm{O}_{3}$ for $450 \mathrm{~h}$ time-onstream, indicating the high stability of the catalyst.

Transition metal phosphides (Ni and Mo phosphides) have also shown promising results for deoxygenation of bio-based feedstocks (Gong et al., 2012; Yang et al., 2012; Yang et al., 2013a; Chen et al., 2014; Zarchin et al., 2015; Yang et al., 2015; Peroni et al., 2016). Alumina-supported sulfided-NiMoP and PtPd catalysts demonstrated similar extents of deoxygenation for non-edible jatropha oil, but through different pathways (Gong et al., 2012). SulfidedNiMoP maintained activity for $120 \mathrm{~h}$ time-on-stream, after which the activity reduced significantly, presumably due to the oxidation of the sulfide phase. Most recently, Peroni et al. (2016) examined the deoxygenation of palmitic acid by bulk and $\mathrm{Al}_{2} \mathrm{O}_{3}$-supported $\mathrm{Ni}_{2} \mathrm{P}$ and $\mathrm{MoP}$ catalysts in a trickle fixed-bed reactor at 40 bar $\mathrm{H}_{2}$ and $453-573 \mathrm{~K}$. The results revealed that $\mathrm{Ni}_{2} \mathrm{P}$ catalysts were intrinsically more active than MoP catalysts, although bulk MoP demonstrated the highest specific activity, meaning that its surface was more exposed to the reactants. DCO was generally more pronounced than HDO since the yields of pentadecane were higher than hexadecane. Besides these two products, hexadecanal, hexadecanol, and palmityl palmitate (esterification product) were also observed in considerable amounts. Deactivation mechanisms were not discussed in this chapter.

Considering the literature findings stated above, transition metal carbides, nitrides, and phosphides seem promising candidates for substituting transition metal sulfides for deoxygenation purposes. Nevertheless, direct comparison of these catalysts with each other and with other types of catalysts is required to understand the deficiencies and strengths of each category. Moreover, deactivation mechanisms, catalytic stability, life cycle assessment, and the economics are only some of the issues that should be addressed for designing effective commercial-scale catalytic systems.

\subsubsection{Role of support}

Support materials can play a substantial role in catalyzing biodiesel upgrading. Several support materials have been investigated for deoxygenation of bio-oils and their model compounds. Alumina and zeolite supports were conventionally used for hydrotreating petroleum fuels. Lewis acid sites on $\mathrm{Al}_{2} \mathrm{O}_{3}$ can activate oxygenated species and facilitate deoxygenation through DCO pathway (Rogers and Zheng, 2016). Nevertheless, the presence of water in bio-based feedstocks can reduce the specific surface area of $\gamma-\mathrm{Al}_{2} \mathrm{O}_{3}$ by crystallization to Boehmite (Laurent and Delmon, 1994). Brønsted acid sites on zeolites promote HDO through hydrogenation-dehydrogenation reactions, but are also responsible for cracking, isomerization, and rapid deactivation via coking (Liu et al., 2011). Silica supports are known to be inert toward deoxygenation reactions and thus are interesting materials specifically for studying the role of active sites without any interferences from the support (Liu et al., 2011). Reducible metal oxides such as $\mathrm{ZrO}_{2}, \mathrm{CeO}_{2}, \mathrm{TiO}_{2}$, and $\mathrm{Cr}_{2} \mathrm{O}_{3}$ in their reduced forms can chemisorb oxygenates through oxygen vacancies and facilitate deoxygenation.

Since its emergence, carbon in various forms has revolutionized catalysis research by its unique properties, viz., high surface area, ability to highly disperse the catalytic active phase, and inertness or functionality (RodríguezReinoso, 1998). Carbon is able to accommodate various functional groups depending on the source as well as chemical and thermal treatment techniques used to prepare it (Lam and Luong, 2014). In addition, it can be produced by simple techniques from inexpensive sources such as carbohydrates or aromatic compounds (Lam and Luong, 2014). Carbon materials have been used extensively as supports for biodiesel upgrading studies and are expected to play a crucial role in industrialization of these catalysts in the future. In a study by Snare et al. (2006), high initial rates for deoxygenation of stearic acid by carbon-supported metallic catalysts compared with alumina and silicasupported catalysts were attributed to the effect of carbon in preventing sintering and/or coking due to its structural properties. Activated carbon was responsible for a noticeable increase in the activity and selectivity of $\mathrm{Mo}_{2} \mathrm{C}$ for deoxygenating methyl stearate and methyl palmitate to $n$-octadecane and $n$ hexadecane, respectively (Table 3 entries 19-23) (Han et al., 2011a).

Mesoporous silicates (e.g., MCM-41, SBA-15, and SBA-16) have also been studied as supports for biodiesel upgrading catalysts (Wang et al., 2013). These materials are interesting because of their ability to disperse the active phase and their suitable structure for the diffusion of large molecules, such as those present in vegetable oils (Stöcker, 2008). For instance, mesoporous silica nanoparticles have been proven as effective catalyst supports for upgrading microalgae oil using iron nanoparticles (Kandel et al., 2014). Furthermore stearic acid deoxygenation on $\mathrm{Pd} / \mathrm{SBA}-15$ and $\mathrm{Pd} / \mathrm{C}$ catalysts showed a higher turnover frequency in the case of $\mathrm{Pd} / \mathrm{SBA}-15$, indicating the effectiveness of the mesoporous support (Lestari et al., 2010). These materials can also accept new active sites via ion-exchange, adsorption, or grafting techniques (Nava et al., 2009). Most importantly, the amount and strength of acid sites can be tuned by changing the structure of silicaalumina as well as the amount of aluminum (Al) incorporated into the silica framework (Si/Al ratio) (Nava et al., 2009). Mesoporous aluminum silicates could, therefore, be an excellent choice for the support of HDO catalysts as they can provide a tunable amount of weak/moderate acid sites while improving the dispersion of the active phase and facilitating the diffusion of feedstock molecules.

\subsection{Effect of operating parameters}

Studying the effect of operating parameters on conversion and yield of desired products is very important as such information is necessary for scaling up the upgrading process and evaluating the economics. The key parameters for all types of catalysts include pressure, temperature, and contact time. In addition, the influence of sulfidation on conventional hydrotreating catalysts cannot be ignored. Although the choice of reactor is of great importance, it is extremely difficult (if not impossible) to make comparisons between systems with different reactor types. This is mainly because of different geometries and sizes, as well as different operating parameters used in various studies. Hence, more data with similar operating conditions is required to enable the evaluation of the effect of reactor configuration. The chain length and degree of saturation of feedstocks are also known to affect the upgrading product yields and the extent of side reactions. However, the modifications applied due to using different feedstocks would be considered fine-tuning and would not fit into the scope of this text. Other parameters such as the choice of solvent in batch studies could also play some role in the outcome of the deoxygenation reactions for biodiesel upgrading. However, the effect of these parameters is less significant than those considered in the following sections.

\subsubsection{Sulfidation}

Conventional hydrotreating catalysts, comprising mainly of transition metal sulfides, have been the predominant choice for deoxygenation of vegetable oils. The extent of sulfidation in transition metal sulfides has been demonstrated to significantly influence the activity, selectivity, and stability of the catalyst (Kubička and Horáček, 2011; Coumans and Hensen, 2017). Thus, the amount of $\mathrm{H}_{2} \mathrm{~S}$ or other sulfiding agents co-fed into the system could be of great importance for an efficacious upgrade. The sulfiding agent is responsible for keeping the catalyst in its highly active sulfide form, otherwise changed to the less active oxide form through oxygen atoms of the bio-oil feed (Furimsky and Massoth, 1999; Kubička and Horáček, 2011). It can also compensate for the activity loss due to the inhibiting effect of water on catalysts (Şenol et al., 2007)

\subsubsection{Pressure ( $\mathrm{H}_{2}$ pressure)}

In general, pressure plays a significant role in the thermodynamics of reactions. In the context of biodiesel upgrading, higher hydrogen pressures heavily favor HDO over DCO by facilitating hydrogenolysis and hydrogenation reactions (Madsen et al., 2011; Zhao et al., 2013). Even in the case of $\mathrm{Pd} / \mathrm{C}$ catalysts that remove oxygen exclusively through DCO under either inert or hydrogen atmospheres (Snåre et al., 2007; Lestari et al., 2009b), hydrogen has been shown to influence the kinetics of deoxygenation and improve the activity and stability of the catalyst (Immer et al., 2010; Rozmysłowicz et al., 2012). Elevated hydrogen pressures ensure higher carbon yields in the diesel range by suppressing side reactions such as cracking and decarboxylation (Kandel et al., 2014). In addition, hydrogen has been found to benefit catalyst stability by preventing cokeforming oligomerization reactions through hydrogenation of coke precursors, i.e., unsaturated hydrocarbons (Do et al., 2009). The importance of hydrogen in deoxygenation of vegetable oils and model compounds has 
Table 3.

Summary of some literature findings on catalytic deoxygenation using transition metal carbide, nitride, and phosphides.

\begin{tabular}{|c|c|c|c|c|c|c|c|c|c|}
\hline Entry & Feed & Catalyst & $\begin{array}{c}\mathbf{T} \\
\left({ }^{\circ} \mathbf{C}\right)\end{array}$ & $\begin{array}{c}\mathbf{P}_{\mathrm{H}_{2}} \\
\text { (bar) }\end{array}$ & $\begin{array}{l}\text { Contact time/ } \\
\text { Space velocity }\end{array}$ & Reactor & $\begin{array}{l}\text { Yield of major } \\
\text { products }^{*}\end{array}$ & $\begin{array}{l}\text { Side } \\
\text { products }^{* *}\end{array}$ & Reference \\
\hline 1 & Maize oil & $\mathrm{Mo}_{2} \mathrm{C} / \mathrm{CNT}$ & 260 & 25 & $3 \mathrm{~h}$ & batch & $\begin{array}{l}44 \%\left(\mathrm{C}_{18}: 0\right) \\
13 \%\left(\mathrm{C}_{16}: 0\right) \\
\end{array}$ & - & \multirow{4}{*}{ Qin et al. (2013) } \\
\hline 2 & Maize oil & $\mathrm{Mo}_{2} \mathrm{C} / \mathrm{AC}$ & $"$ & $"$ & $"$ & $"$ & $\begin{array}{l}40 \%\left(\mathrm{C}_{18}: 0\right) \\
10 \%\left(\mathrm{C}_{16}: 0\right)\end{array}$ & iso. & \\
\hline 3 & Maize oil & $\mathrm{Mo}_{2} \mathrm{C} / \mathrm{CNF}$ & $"$ & $"$ & $"$ & $"$ & $\begin{array}{l}36 \%\left(\mathrm{C}_{18}: 0\right) \\
11 \%\left(\mathrm{C}_{16}: 0\right)\end{array}$ & - & \\
\hline 4 & Methyl palmitate & $\mathrm{Mo}_{2} \mathrm{C} / \mathrm{CNF}$ & $"$ & $"$ & $"$ & $"$ & $92 \%\left(\mathrm{C}_{16}: 0\right)$ & - & \\
\hline 5 & Sunflower oil & $\beta-\mathrm{Mo}_{2} \mathrm{C} / \gamma-\mathrm{Al}_{2} \mathrm{O}_{3}$ & 360 & 50 & $5 \mathrm{~h}^{-1}$ & trickle-bed & $67 \%\left(\mathrm{C}_{12}-\mathrm{C}_{18}\right)$ & $\operatorname{dim}$. & Sousa et al. (2012) \\
\hline 6 & Soybean oil & NiMoC/Al-SBA-15 & 400 & 45 & $1 \mathrm{~h}^{-1}$ & fixed-bed & $93 \%\left(\mathrm{C}_{12}-\mathrm{C}_{22}\right)$ & - & \multirow{3}{*}{ Wang et al. (2013) } \\
\hline 7 & $"$ & $\mathrm{NiMoC} / \gamma-\mathrm{Al}_{2} \mathrm{O}_{3}$ & $"$ & $"$ & $"$ & $"$ & $73 \%\left(\mathrm{C}_{12}-\mathrm{C}_{22}\right)$ & cra. & \\
\hline 8 & $"$ & NiMoC/USY & $"$ & $"$ & $"$ & $"$ & $\begin{array}{l}48 \%\left(\mathrm{C}_{12}-\mathrm{C}_{22}\right) \\
13 \%\left(\mathrm{C}_{5}-\mathrm{C}_{12}\right)\end{array}$ & cra. & \\
\hline 9 & Soybean oil & NiMoC/ZSM-5 & 450 & 45 & not specified & fixed-bed & $\begin{array}{l}13 \%\left(\mathrm{C}_{12}-\mathrm{C}_{22}\right) \\
16 \%\left(\mathrm{C}_{5}-\mathrm{C}_{12}\right)\end{array}$ & $\begin{array}{l}\text { DCO-DCO } \\
\text { cra.-met. }\end{array}$ & \multirow{2}{*}{ Wang et al. (2012) } \\
\hline 10 & $"$ & NiMoN/ZSM-5 & $"$ & $"$ & $"$ & $"$ & $\begin{array}{l}12 \%\left(\mathrm{C}_{12}-\mathrm{C}_{22}\right) \\
11 \%\left(\mathrm{C}_{5}-\mathrm{C}_{12}\right)\end{array}$ & $\begin{array}{l}\text { DCO-DCO } \\
\text { cra.-met. }\end{array}$ & \\
\hline 11 & Soybean oil & $\mathrm{Ni}_{2} \mathrm{P} / \mathrm{SiO}_{2}$ & 370 & 30 & $1 \mathrm{~h}^{-1}$ & trickle-bed & $80 \%\left(\mathrm{C}_{15}-\mathrm{C}_{18}\right)$ & DCO-dim. & \multirow{2}{*}{ Zarchin et al. (2015) } \\
\hline 12 & $"$ & $\mathrm{Ni}_{2} \mathrm{P} / \mathrm{HY}$ (20h used) & $"$ & $"$ & $"$ & $"$ & $79 \%\left(\mathrm{C}_{15}-\mathrm{C}_{18}\right)$ & DCO-cra.-iso. & \\
\hline 13 & Jatropha oil ${ }^{[a]}$ & $\mathrm{NiMoP} / \mathrm{Al}_{2} \mathrm{O}_{3}$ & 350 & 30 & $2 \mathrm{~h}^{-1}$ & fixed-bed & $\begin{array}{l}37 \%\left(\mathrm{C}_{18}: 0\right) \\
37 \%\left(\mathrm{C}_{17}: 0\right) \\
\end{array}$ & $\begin{array}{l}\mathrm{DCO}-\mathrm{DCO}_{2} \\
\text { iso. }\end{array}$ & Gong et al. (2012) \\
\hline 14 & Rapeseed oil & $\mathrm{Mo}_{2} \mathrm{C} / \mathrm{CNT}$ & 260 & 20 & $3 \mathrm{~h}$ & batch & $86 \%$ (paraffin) & iso. $(46 \%)$ & \multirow{3}{*}{ Han et al. (2011b) } \\
\hline 15 & Methyl palmitate & $\mathrm{Mo}_{2} \mathrm{C} / \mathrm{CNT}$ & 240 & 15 & $2 \mathrm{~h}$ & $"$ & $\begin{array}{l}51 \%\left(\mathrm{C}_{16}: 0\right) \\
29 \%\left(\mathrm{C}_{16}: 1\right) \\
\end{array}$ & - & \\
\hline 16 & Methyl palmitate & $\mathrm{Mo}_{2} \mathrm{C} / \mathrm{CNT}$ & 240 & 25 & $2 \mathrm{~h}$ & $"$ & $96 \%\left(\mathrm{C}_{16}: 0\right)$ & - & \\
\hline 17 & Methyl palmitate & $\mathrm{Mo}_{2} \mathrm{C} / \mathrm{OMC}$ & 260 & 15 & $5 \mathrm{~h}$ & batch & $\begin{array}{l}79 \%\left(\mathrm{C}_{16}: 0\right) \\
11 \%\left(\mathrm{C}_{16}: 1\right) \\
\end{array}$ & - & \multirow{2}{*}{ Han et al. (2012) } \\
\hline 18 & $"$ & $\mathrm{Mo}_{2} \mathrm{C} / \mathrm{AC}$ & - & - & $2 \mathrm{~h}$ & $"$ & $81 \%\left(\mathrm{C}_{16}: 0\right)$ & $\operatorname{dim}$. & \\
\hline 19 & Methyl stearate & $\mathrm{Mo}_{2} \mathrm{C}$ & 280 & 10 & $5 \mathrm{~h}$ & batch & $\begin{array}{l}28 \%\left(\mathrm{C}_{18}: 0\right) \\
4 \%\left(\mathrm{C}_{17}: 0\right)\end{array}$ & iso.-olf. & \multirow{5}{*}{ Han et al. (2011a) } \\
\hline 20 & Methyl stearate & $\mathrm{Mo}_{2} \mathrm{C} / \mathrm{AC}$ & $"$ & $"$ & $4 \mathrm{~h}$ & $"$ & $89 \%\left(\mathrm{C}_{18}: 0\right)$ & $\begin{array}{l}\text { DCO-iso. } \\
\text { olf. }\end{array}$ & \\
\hline 21 & Methyl palmitate & $\mathrm{Mo}_{2} \mathrm{C} / \mathrm{AC}$ & $"$ & $"$ & $4 \mathrm{~h}$ & $"$ & $91 \%\left(\mathrm{C}_{18}: 0\right)$ & $\begin{array}{l}\text { DCO-iso. } \\
\text { olf. }\end{array}$ & \\
\hline 22 & Ethyl stearate & $\mathrm{Mo}_{2} \mathrm{C} / \mathrm{AC}$ & $"$ & $"$ & $4 \mathrm{~h}$ & $"$ & $90 \%\left(\mathrm{C}_{18}: 0\right)$ & $\begin{array}{l}\text { DCO-iso. } \\
\text { olf. }\end{array}$ & \\
\hline 23 & Stearic acid & $\mathrm{Mo}_{2} \mathrm{C} / \mathrm{AC}$ & $"$ & $"$ & $4 \mathrm{~h}$ & $"$ & $\begin{array}{l}75 \%\left(\mathrm{C}_{18}: 0\right) \\
13 \%\left(\mathrm{C}_{17}: 0\right) \\
\end{array}$ & iso.-olf. & \\
\hline 24 & Stearic acid & $\mathrm{Mo}_{2} \mathrm{C} / \mathrm{CNF}(<3 \mathrm{~nm})$ & 350 & 30 & $5 \mathrm{~h}$ & batch & $85 \%\left(\mathrm{C}_{18}: 0\right)$ & DCO-DCO ${ }_{2}$ & \multirow{4}{*}{$\begin{array}{l}\text { Stellwagen and Bitter } \\
\text { (2015) }\end{array}$} \\
\hline 25 & $"$ & $\mathrm{Mo}_{2} \mathrm{C} / \mathrm{CNF}(10 \mathrm{~nm})$ & $"$ & $"$ & $3 \mathrm{~h}$ & $"$ & $\begin{array}{l}51 \%\left(\mathrm{C}_{18}: 0\right) \\
44 \%\left(\mathrm{C}_{17}: 0\right) \\
\end{array}$ & - & \\
\hline 26 & $"$ & $\mathrm{~W}_{2} \mathrm{C} / \mathrm{CNF}(<3 \mathrm{~nm})$ & $"$ & $"$ & $5 \mathrm{~h}$ & $"$ & $82 \%\left(C_{18}: 0\right)$ & DCO-DCO ${ }_{2}$ & \\
\hline 27 & $"$ & $\mathrm{~W}_{2} \mathrm{C} / \mathrm{CNF}(12 \mathrm{~nm})$ & $"$ & $"$ & $3 \mathrm{~h}$ & $"$ & $\begin{array}{l}60 \%\left(\mathrm{C}_{18}: 0\right) \\
30 \%\left(\mathrm{C}_{17}: 0\right) \\
\end{array}$ & est. & \\
\hline 28 & Oleic acid & $\mathrm{Mo}_{2} \mathrm{C} / \mathrm{CNF}$ & 350 & 50 & $3 \mathrm{~h}$ & batch & $84 \%\left(\mathrm{C}_{18}: 0\right)$ & alc.-ald. & \multirow[b]{2}{*}{ Hollak et al. (2013) } \\
\hline 29 & - & $\mathrm{W}_{2} \mathrm{C} / \mathrm{CNF}$ & $"$ & $"$ & $"$ & $"$ & $\begin{array}{l}43 \%\left(\mathrm{C}_{18}: 1\right) \\
25 \%\left(\mathrm{C}_{18}: 0\right)\end{array}$ & alc.-ald. & \\
\hline 30 & Oleic acid & $\mathrm{Mo}_{2} \mathrm{~N} / \gamma-\mathrm{Al}_{2} \mathrm{O}_{3}$ & 380 & 71.5 & $0.45 \mathrm{~h}^{-1}$ & fixed-bed & $\begin{array}{l}9 \%\left(\mathrm{C}_{18}: 0\right) \\
4 \%\left(\mathrm{C}_{10}: 0\right) \\
\end{array}$ & $\begin{array}{l}\text { DCO-DCO } \\
\text { cra. }\end{array}$ & Monnier et al. (2010) \\
\hline 31 & Methyl oleate ${ }^{[b]}$ & $\mathrm{Ni}_{2} \mathrm{P} / \mathrm{SBA}-15$ & 340 & 30 & $20 \mathrm{~h}^{-1}$ & fixed-bed & $\begin{array}{l}68 \%\left(\mathrm{C}_{17}: 0\right) \\
14 \%\left(\mathrm{C}_{18}: 0\right)\end{array}$ & - & \multirow{2}{*}{ Yang et al. (2015) } \\
\hline 32 & $"$ & $\mathrm{Ni}_{2} \mathrm{P} / \mathrm{SBA}-15$ & 250 & $"$ & $"$ & $"$ & $\begin{array}{l}5 \%\left(\mathrm{C}_{18}: 0\right) \\
3 \%\left(\mathrm{C}_{17}: 0\right) \\
\end{array}$ & - & \\
\hline 33 & Methyl laurate $^{[c]}$ & $\mathrm{Ni}_{2} \mathrm{P} / \mathrm{SiO}_{2}$ & 340 & 30 & $14 \mathrm{~h}^{-1}$ & fixed-bed & $\begin{array}{l}85 \%\left(\mathrm{C}_{11}: 0\right) \\
12 \%\left(\mathrm{C}_{12}: 0\right) \\
\end{array}$ & - & \multirow{3}{*}{ Chen et al. (2014) } \\
\hline 34 & $"$ & $\mathrm{NiMoP} / \mathrm{SiO}_{2}$ & $"$ & $"$ & $"$ & $"$ & $\begin{array}{l}66 \%\left(\mathrm{C}_{11}: 0\right) \\
32 \%\left(\mathrm{C}_{12}: 0\right)\end{array}$ & - & \\
\hline 35 & $"$ & $\mathrm{MoP} / \mathrm{SiO}_{2}$ & $"$ & $"$ & $"$ & $"$ & $\begin{array}{l}75 \%\left(\mathrm{C}_{12}: 0\right) \\
7 \%\left(\mathrm{C}_{11}: 0\right)\end{array}$ & - & \\
\hline
\end{tabular}

Please cite this article as: Bateni H., Saraeian A., Able C. A comprehensive review on biodiesel purification and upgrading. Biofuel Research Journal 15 (2017) 668-690. DOI: 10.18331/BRJ2017.4.3.5 
Table 3.

(continued).

\begin{tabular}{|c|c|c|c|c|c|c|c|c|c|}
\hline Entry & Feed & Catalyst & $\begin{array}{c}\mathbf{T} \\
\left({ }^{\circ} \mathbf{C}\right)\end{array}$ & $\begin{array}{l}\mathbf{P}_{\mathrm{H}_{2}} \\
\text { (bar) }\end{array}$ & $\begin{array}{l}\text { Contact time/ } \\
\text { Space velocity }\end{array}$ & Reactor & $\begin{array}{l}\text { Yield of major } \\
\text { products }^{*}\end{array}$ & $\begin{array}{l}\text { Side } \\
\text { products }^{* *}\end{array}$ & Reference \\
\hline 36 & Methyl laurate ${ }^{[c]}$ & $\mathrm{Ni}_{2} \mathrm{P} / \mathrm{SiO}_{2}$ & 340 & 20 & $10 \mathrm{~h}^{-1}$ & fixed-bed & $\begin{array}{l}82 \%\left(\mathrm{C}_{11}: 0\right) \\
15 \%\left(\mathrm{C}_{12}: 0\right)\end{array}$ & - & \multirow{3}{*}{ Yang et al. (2013a) } \\
\hline 37 & $"$ & $\mathrm{Ni}_{2} \mathrm{P} / \mathrm{MCM}-41$ & $"$ & $"$ & $"$ & $"$ & $\begin{array}{l}86 \%\left(\mathrm{C}_{11}: 0\right) \\
12 \%\left(\mathrm{C}_{12}: 0\right) \\
\end{array}$ & - & \\
\hline 38 & $"$ & $\mathrm{Ni}_{2} \mathrm{P} / \mathrm{SBA}-15$ & $"$ & $"$ & $"$ & $"$ & $\begin{array}{l}87 \%\left(\mathrm{C}_{11}: 0\right) \\
13 \%\left(\mathrm{C}_{12}: 0\right) \\
\end{array}$ & - & \\
\hline 39 & Methyl oleate ${ }^{[b]}$ & $\mathrm{Ni}_{2} \mathrm{P} / \mathrm{SBA}-15$ & 340 & 30 & $20 \mathrm{~h}^{-1}$ & fixed-bed & $\begin{array}{l}71 \%\left(\mathrm{C}_{17}: 0\right) \\
11 \%\left(\mathrm{C}_{18}: 0\right)\end{array}$ & - & Yang et al. (2012) \\
\hline 40 & Palmitic acid & $\mathrm{MoP}$ & 300 & 40 & $1 \mathrm{~h}^{-1}$ & trickle-bed & $\begin{array}{l}47 \%\left(\mathrm{C}_{15}: 0\right) \\
22 \%\left(\mathrm{C}_{16}: 0\right)\end{array}$ & alc. & \multirow{2}{*}{ Peroni et al. (2016) } \\
\hline 41 & $"$ & $\mathrm{Ni}_{2} \mathrm{P} / \gamma-\mathrm{Al}_{2} \mathrm{O}_{3}$ & $"$ & $"$ & $"$ & $"$ & $\begin{array}{l}76 \%\left(\mathrm{C}_{15}: 0\right) \\
22 \%\left(\mathrm{C}_{16}: 0\right)\end{array}$ & - & \\
\hline
\end{tabular}

* Yields are approximate numbers and at different conversions; $(\mathrm{Cx}: \mathrm{y}) \mathrm{x}=$ number of carbons, $\mathrm{y}=$ number of unsaturated (double) bonds

** iso.=isomerization; dim. $=$ dimerization; cra. $=$ cracking/hydrocracking; $\mathrm{DCO}=$ decarbonylation; $\mathrm{DCO}_{2}=$ decarboxylation; met. $=$ methanation; olf. $=$ olefins; est. $=$ esterification; alc. $=$ alcohols; ald.=aldehydes.

[a] $\mathrm{H}_{2} /$ feed volume ratio=600; [b] $\mathrm{H}_{2} /$ feed volume ratio $=300$ at $6 \mathrm{~h}$ on stream; [c] $\mathrm{H}_{2} /$ feed molar ratio $=50$.

been confirmed by exploring the effect of hydrogen pressure (Donnis et al., 2009; Kubička et al., 2009; Kandel et al., 2014), $\mathrm{H}_{2}$ partial pressure in mixtures with He (Do et al., 2009; Immer et al., 2010), and hydrogen donor solvents (Mäki-Arvela et al., 2007). High pressures of hydrogen are required not only to obtain higher extent of deoxygenation, but also to prolong catalyst activity. However, the expensive compressors and leak-proof reactors that are required for increasing the pressure and maintaining it at those levels make it economically unfeasible. Therefore, new reactor configurations and catalytic systems would have to be designed and employed to lower the operating pressures while effectively deoxygenating bio-oils.

\subsubsection{Temperature}

The effect of temperature on kinetics and thermodynamics of reactions is unquestionable. Higher temperature almost always translates into faster kinetics and thus, the production of final products at a higher rate. However, this is not necessarily equivalent to better economics since increasing the temperature requires extra energy. More importantly, faster kinetics do not always correspond to better results as temperature also influences the selectivity of the products. In another word, one can obtain the products at a higher rate by raising the temperature, but the products obtained might not be the ones desired. This is in fact the case for deoxygenation processes. As the temperature rises, the reaction proceeds faster and the degree of deoxygenation increases significantly, both of which are favorable (Senol et al., 2005a; Bezergianni et al., 2010a). Nevertheless, high temperatures (typically $>400{ }^{\circ} \mathrm{C}$ ) give rise to undesired cracking $\left(\mathrm{C}_{4}-\mathrm{C}_{14}\right)$ and heavy $\left(\mathrm{C}_{19}-\mathrm{C}_{30}\right)$ products and reduce the yields of diesel fuel in the product stream (Bezergianni et al., 2010b; Kiatkittipong et al., 2013; Phimsen et al., 2016). They also increase the isomerization products that can improve the cold flow properties of diesel fuel at the expense of cetane number (Bezergianni et al., 2010b). It has been found in some works that higher temperatures also increase the DCO to HDO ratio, resulting in lower carbon yields (Kubička and Kaluža, 2010; Yang et al., 2013b; Itthibenchapong et al., 2017). Therefore, temperature should be controlled carefully to obtain high yields of products at a high rate without compromising carbon efficiency and fuel properties. The effect of operating temperature on catalyst coking and stability has yet to be examined.

\subsubsection{Contact time}

Contact time is an important parameter in determining the kinetics of a reaction. The effect of time on conversion and yields could provide useful information for optimizing and scaling up a process. The effect of time, particularly in batch and semi-batch reactors, is typically evaluated to obtain useful information about deoxygenation pathways as well as product evolution (Foraita et al., 2017). Reaction pathways are interesting because they enable scientists to rationally design new catalytic systems, while product evolution over time may indicate an opportunity to maximize the yield of some products (Stellwagen and Bitter, 2015). Although longer reaction times guarantee higher conversions and normally the production of saturated compounds under $\mathrm{H}_{2}$ atmosphere (Immer et al., 2010; Foraita et al., 2017; Hollak et al., 2013), they could also result in lower overall diesel yields due to excessive cracking and DCO reactions (Kiatkittipong et al., 2013 Phimsen et al., 2016). In continuous systems, activity and selectivity over reaction time or time-on-stream is indicative of the catalyst's deactivation, stability, and surface/structure changes (Do et al., 2009; Lestari et al., 2009a; Kubička and Horáček, 2011; Kovács et al., 2011), whereas space velocity can regulate the contact time between feed and catalyst, determining the feed's conversion and product selectivity (Kubička et al., 2010; Kubička and Kaluža, 2010).

\subsection{Challenges and opportunities}

The primary challenge for producing renewable diesel is to secure the availability of feedstocks that do not compete with food production and make optimal use of land, water, and fertilizers (Escobar et al., 2009; Srinivasan, 2009). This is particularly imperative for developing countries and regions of the world that suffer from drought or harsh climates. Regarding biodiesel upgrading, the leading challenge is to design a catalyst with high resistance to water, coke, and minor minerals present in vegetable oils and animal fats, while being active for their conversion and selective toward HDO rather than DCO. This is a non-trivial challenge since numerous parameters play roles in the outcome. The trade-off between ignition properties (i.e., cetane number) and cold flow properties (cloud point and freezing point) of $n$-alkanes and iso-alkanes presents a major challenge for direct production of a petro-diesel substitute from bio-based feedstocks. In another word, the resulting product stream will not be able to replace petro-diesel if it only contains long-chain $n$-alkanes; rather, it acts as a cetane enhancer. Thus, isomerization ability of the upgrading catalyst should also be taken into consideration if feasible one-step production of renewable diesel is the ultimate goal. Another challenge is the use of more representative model compounds to obtain information about the performance of catalysts using real feedstocks as discussed in detail in a review by Gosselink et al. (2013).

Despite the above-mentioned challenges, the commercial production of renewable diesel fuels during recent years, with fuel properties exceeding petroleum diesel (Satyarthi et al., 2013; Phimsen et al., 2016), bodes well for a prosperous future in large-scale production of green diesel. NExBTL was introduced in 2005 as the first renewable diesel by the Finnish company, Neste Oil (Rantanen et al., 2005). Since then, several commercial plants have been built by Neste Oil, UOP/Eni, Petrobras/H-Bio, British Petroleum, Conoco Philips/Tyson, and Dynamic Fuels/Syntroleum/Tyson (Aslam et al., 2015). Currently, these commercial plants are mainly built 
adjacent to the existing refineries to avoid high capital costs of constructing a completely new plant. However, improving the economics of biorefineries by integrating processes such as HDO and steam reforming, and even making use of light hydrocarbons and acid gases may increase the feasibility of stand-alone units. As far as fuel quality, an initial (hydro)-deoxygenation step followed by a (hydro)-isomerization process ensures a high cetane number, excellent cold flow properties, and environmental friendliness of the obtained renewable diesel compared with petroleum diesel and biodiesel (Table 4).

Table 4.

Summary of chemical characteristics of petroleum diesel, biodiesel, and Honeywell Green Diesel (UOP, 2017).

\begin{tabular}{llll}
\hline Parameter & $\begin{array}{l}\text { Petroleum } \\
\text { ultra-low sulfur diesel }\end{array}$ & $\begin{array}{l}\text { Biodiesel } \\
\text { (fatty acid methyl ester) }\end{array}$ & $\begin{array}{l}\text { Renewable } \\
\text { diesel }\end{array}$ \\
\hline Oxygen (\%) & 0 & 11 & 0 \\
\hline $\begin{array}{l}\text { Cetane number } \\
\text { Energy density }\end{array}$ & $40-55$ & $50-65$ & $75-90$ \\
$(\mathrm{MJ} / \mathrm{kg})$ & 43 & 38 & 44 \\
\hline Sulfur (ppm) & $<10$ & $<2$ & $<2$ \\
\hline Cold flow properties & Baseline & Poor & Excellent \\
\hline Oxidative stability & Baseline & Poor & Excellent \\
\hline & & &
\end{tabular}

Aside from renewable diesel production, another opportunity is to produce commodity chemicals by tuning the surface characteristics of catalysts and optimizing the reaction conditions maximizing the yield of mono- or polyunsaturated hydrocarbons (linear alpha/internal olefins). The smaller olefins can be used as precursors for polymeric materials, while the bigger olefins can be utilized as building blocks of important lubricants, surfactants, and even ecofriendly drilling fluids (Gee et al., 1996; Vora et al., 2009). The challenge here is the tradeoff between the olefin concentration in the product stream and the deactivation rate of the catalysts due to coking as explained in Section 3.2.3. Therefore, designing new catalytic systems that are able to produce unsaturated hydrocarbons from bio-based feedstocks without rapid deactivation may be an interesting venue for future research. Practically speaking, the need for biofuels may not allow for utilization of vegetable oils for olefin production, yet there is a use for this research since olefins are produced as side products, especially from highly unsaturated feedstocks.

\section{Conclusions}

Biodiesel has been introduced as a clean, biodegradable, and biocompatible diesel substitute produced via transesterification of fresh vegetable oil, animal fats, waste cooking oil, and microalgae oil. In efforts to obtain an alternative method for purifying biodiesel, multiple methods have been studied in addition to the traditional water washing methods - washing with ionic liquids or supercritical carbon dioxide, adsorbents such as silica or biomass, ion exchange techniques and organic and inorganic membranes are covered in this work. These methods must successfully minimize the presence of total and free glycerol, water, and cations (either free or in soaps) within the crude biodiesel to produce a finished biodiesel product that meets ASTM and EN standards. In most cases, these methods are employed in conjunction with one another to produce a truly clean product; an equilibrium-based method will have different strengths in purification than an affinity-based or filtration-based method. Additionally, the effectiveness of these methods is dependent on the feedstock.

The stability and compatibility issues of biodiesel fuels have compelled scientists to search for effective upgrading processes. The deoxygenation of vegetable oils and animal fats to produce hydrocarbons in the range of diesel fuel has thus become an attractive alternative. Several catalytic systems have been tested for this task, but the future trend is expected to go toward nonsulfided catalysts ideally with high activity and stability in $\mathrm{H}_{2}$-moderate environments, reduced sensitivity to water and trace contaminants, and selectivity to HDO. The presence of hydrogen could lead to the dominance of HDO over DCO, improving carbon efficiency. In addition, hydrogen appears to reduce the extent of undesired side reactions (i.e., cracking and coking).
The optimization of HDO processes poses a great challenge to the largescale production of renewable diesel due to insufficient industrially relevant information in the field. Besides, the current commercial approach comprises of a two-step process (HDO followed by hydroisomerization) to produce high-quality diesel fuel. The integration of these two steps could be very appealing from economics perspective, although the price of catalysts also plays a key role in economic evaluations.

In sum, despite academic and industrial efforts and achievements, further development of deoxygenation technologies to feasibly produce biorenewable diesel fuels depends heavily on the price of fossil fuels as well as governmental mandates and regulations (i.e., incentives and tax reductions). Hence, a future deprived from fossil-based fuels and/or filled with environmental awareness in political administrations would guarantee major achievements in the production of renewable diesel fuels.

\section{References}

[1] Abbaszadeh, A., Ghobadian, B., Najafi, G., Yusaf, T., 2014. An experimental investigation of the effective parameters on wet washing of biodiesel purification. Int. J. Automot. Mech. Eng. 9, 1525 .

[2] Al-Dawody, M.F., Bhatti, S.K., 2013. Optimization strategies to reduce the biodiesel NOx effect in diesel engine with experimental verification. Energy Convers. Manage. 68, 96-104.

[3] Alba-Rubio, A.C., Castillo, M.A., Albuquerque, M.C.G., Mariscal, R., Cavalcante, C.L., Granados, M.L., 2012. A new and efficient procedure for removing calcium soaps in biodiesel obtained using $\mathrm{CaO}$ as a heterogeneous catalyst. Fuel. 95, 464-470.

[4] Alicieo, T.V.R., Mendes, E.S., Pereira, N.C., Lima, O.M., 2002. Membrane ultrafiltration of crude soybean oil. Desalination. 148(1) 99-102.

[5] Alves, M.J., Nascimento, S.M., Pereira, I.G., Martins, M.I., Cardoso, V.L., Reis, M., 2013. Biodiesel purification using micro and ultrafiltration membranes. Renew. Energy. 58, 15-20.

[6] Ardiyanti, A.R., Gutierrez, A., Honkela, M.L., Krause, A.O.I., Heeres, H.J., 2011. Hydrotreatment of wood-based pyrolysis oil using zirconia-supported mono-and bimetallic (Pt, Pd, Rh) catalysts Appl. Catal., A. 407(1), 56-66.

[7] Aslam, M., Kothiyal, N.C., Sarma, A.K., 2015. True boiling point distillation and product quality assessment of biocrude obtained from Mesua ferrea L. seed oil via hydroprocessing. Clean Technol. Environ. Policy. 17(1), 175-185

[8] Atadashi, I.M., 2015. Purification of crude biodiesel using dry washing and membrane technologies. Alexandria Eng. J. 54(4), 1265 1272.

[9] Atadashi, I.M., Aroua, M.K., Aziz, A.A., Sulaiman, N.M.N., 2012. High quality biodiesel obtained through membrane technology. J. Membr. Sci. 421-422, 154-164

[10] Atadashi, I.M., Aroua, M.K., Aziz, A.A., Sulaiman, N.M.N., 2011a Refining technologies for the purification of crude biodiesel. Appl. Energy. 88(12), 4239-4251

[11] Atadashi, I.M., Aroua, M.K., Aziz, A.A., 2011b. Biodiesel separation and purification: a review. Renew. Energy. 36(2), 437-443.

[12] Badawi, M., Paul, J.F., Cristol, S., Payen, E., Romero, Y., Richard F., Brunet, S., Lambert, D., Portier, X., Popov, A., Kondratieva, E., 2011. Effect of water on the stability of Mo and CoMo hydrodeoxygenation catalysts: a combined experimental and DFT study. J. Catal. 282(1), 155-164.

[13] Baroutian, S., Aroua, M.K., Raman, A.A.A., Sulaiman, N.M., 2011 A packed bed membrane reactor for production of biodiesel using activated carbon supported catalyst. Bioresour. Technol. 102(2), 1095-1102.

[14] Barredo-Damas, S., Alcaina-Miranda, M.I., Bes-Piá, A., Iborra-Clar M.I., Iborra-Clar, A., Mendoza-Roca, J.A., 2010. Ceramic membrane behavior in textile wastewater ultrafiltration. Desalination. 250(2), 623-628.

[15] Basso, R.C., Viotto, L.A., Gonçalves, L.A.G., 2006. Cleaning process in ceramic membrane used for the ultrafiltration of crude soybean oil. Desalination. 200(1-3), 85-86. 
[16] Bateni, H., Bateni, F., Able, C., Noori, M.S., 2017. Biorefinery of safflower seeds in a sequential process for effective use of The substrate for biofuel production. Waste Biomass Valorization. 1-11.

[17] Bateni, H., Bateni, F., Karimi, K., 2016. Effects of oil extraction on ethanol and biogas production from Eruca sativa seed cake. Waste Biomass Valorization. 1-9.

[18] Bateni, H., Karimi, K., 2016. Biodiesel production from castor plant integrating ethanol production via a biorefinery approach. Chem. Eng. Res. Des. 107, 4-12.

[19] Bateni, H., Karimi, K., 2016. Biorefining of Eruca sativa plant for efficient biofuel production. RSC Adv. 6(41), 34492-34500.

[20] Bateni, H., Karimi, K., Zamani, A., Benakashani, F., 2014. Castor plant for biodiesel, biogas, and ethanol production with a biorefinery processing perspective. Appl. Energy. 136, 14-22.

[21] Bernas, H., Eränen, K., Simakova, I., Leino, A.R., Kordás, K., Myllyoja, J., Mäki-Arvela, P., Salmi, T., Murzin, D.Y., 2010. Deoxygenation of dodecanoic acid under inert atmosphere. Fuel. 89(8), 2033-2039.

[22] Berrios, M., Martín, M.A., Chica, A.F., Martín, A., 2011. Purification of biodiesel from used cooking oils. Appl. Energy. 88(11), 3625-3631.

[23] Berrios, M., Siles, J., Martín, M., Martín, A., 2013. Ion exchange, in: Ramaswamy, S., Huang, H.J., Ramarao, B.V. (Eds.), Separation and purification technologies in biorefineries. John Wiley and Sons, Chichester, United Kingdom.

[24] Berrios, M., Skelton, R.L., 2008. Comparison of purification methods for biodiesel. Chem. Eng. J. 144(3), 459-465.

[25] Bezergianni, S., Dimitriadis, A., Kalogianni, A., Pilavachi, P.A., 2010. Hydrotreating of waste cooking oil for biodiesel production. Part I: effect of temperature on product yields and heteroatom removal. Bioresour. Technol. 101(17), 6651-6656.

[26] Bezergianni, S., Dimitriadis, A., Sfetsas, T., Kalogianni, A., 2010. Hydrotreating of waste cooking oil for biodiesel production. Part II: effect of temperature on hydrocarbon composition. Bioresour. Technol. 101(19), 7658-7660.

[27] Boda, L., Onyestyák, G., Solt, H., Lónyi, F., Valyon, J., Thernesz, A., 2010. Catalytic hydroconversion of tricaprylin and caprylic acid as model reaction for biofuel production from triglycerides. Applied Catal., A. 374(1-2), 158-169.

[28] Bora, P., Boro, J., Konwar, L.J., Deka, D., 2016. Formulation of microemulsion based hybrid biofuel from waste cooking oil-a comparative study with biodiesel. J. Energy Inst. 89(4), 560-568.

[29] Canakci, M., Van Gerpen, J., 2003. A pilot plant to produce biodiesel from high free fatty acid feedstocks. Trans. ASAE. 46, 945-954.

[30] Cao, P., Dubé, M.A., Tremblay, A.Y., 2008. High-purity fatty acid methyl ester production from canola, soybean, palm, and yellow grease lipids by means of a membrane reactor. Biomass Bioenergy. 32(11), $1028-1036$

[31] Cao, P., Dubé, M.A., Tremblay, A.Y., 2008. Methanol recycling in the production of biodiesel in a membrane reactor. Fuel. 87(6), 825-833.

[32] Cao, P., Tremblay, A.Y., Dubé, M.A., Morse, K., 2007. Effect of membrane pore size on the performance of a membrane reactor for biodiesel production. Ind. Eng. Chem. Res. 46(1), 52-58.

[33] Chen, B., Wang, W., Liu, X., Xue, W., Ma, X., Chen, G., Yu, Q., Li, R., 2012. Adsorption study of glycerol in biodiesel on the sulfonated adsorbent. Ind. Eng. Chem. Res. 51(39), 12933-12939.

[34] Chen, B., Wang, W., Ma, X., Wang, C., Li, R., 2012. Adsorption behaviors of glycerol from biodiesel on sulfonated polystyrenedivinylbenzene resins in different forms. Energy Fuels. 26(11), 70607067.

[35] Chen, J., Yang, Y., Shi, H., Li, M., Chu, Y., Pan, Z., Yu, X., 2014. Regulating product distribution in deoxygenation of methyl laurate on silica-supported Ni-Mo phosphides: effect of Ni/Mo ratio. Fuel, 129, 110.

[36] Chen, N., Gong, S., Qian, E.W., 2015. Effect of reduction temperature of $\mathrm{NiMoO}_{3-X} / \mathrm{SAPO}-11$ on its catalytic activity in hydrodeoxygenation of methyl laurate. Appl. Catal., B. 174-175, 253-263.

[37] Cheng, L.H., Cheng, Y.F., Yen, S.Y., Chen, J., 2009. Ultrafiltration of triglyceride from biodiesel using the phase diagram of oil-FAME-MeOH. J. Membr. Sci. 330(1-2), 156-165.

[38] Chhetri, A.B., Watts, K.C., Islam, M.R., 2008. Waste cooking oil as an alternate feedstock for biodiesel production. Energies. 1(1), 3-18.
[39] Choudhary, T.V., Phillips, C.B., 2011. Renewable fuels via catalytic hydrodeoxygenation. Applied Catal., A. 397(1-2), 1-12.

[40] Coêlho, D.G., Almeida, A.P., Soletti, J.I., De Carvalho, S.H., 2011 Influence of variables in the purification process of castor oi biodiesel. Chem. Eng. Trans. 24, 829-834.

[41] Coumans, A.E., Hensen, E.J.M., 2017. A model compound (methyl oleate, oleic acid, triolein) study of triglycerides hydrodeoxygenation over alumina-supported NiMo sulfide. Appl. Catal., B. 201, 290-301.

[42] Coumans, A.E., Hensen, E.J.M., 2017. A model compound (methyl oleate, oleic acid, triolein) study of triglycerides hydrodeoxygenation over alumina-supported NiMo sulfide. Appl. Catal., B. 201, 290-301.

[43] Da Silva, N.D.L., Santander, C.M.G., Batistella, C.B., Maciel Filho, R., Maciel, M.R.W., 2010. Biodiesel production from integration between reaction and separation system: reactive distillation process. Appl. Biochem. Biotechnol. 161(1-8), 245-254.

[44] De Haan, A.B., Bosch, H., 2013. Industrial Separation Processes: Fundamentals. Walter de Gruyter. Berlin, Germany.

[45] Dechow, F.J., 1989. Separation and Purification Techniques in Biotechnology. Noyes Publications, Park Ridge, United State.

[46] Demirbas, A., 2008. Comparison of transesterification methods for production of biodiesel from vegetable oils and fats. Energy Convers. Manage. 49(1), 125-130.

[47] Demirbas, A., 2009. Progress and recent trends in biodiesel fuels. Energy Convers. Manage. 50(1), 14-34

[48] DeRoussel, P., Khakhar, D.V., Ottino, J.M., 2001. Mixing of viscous immiscible liquids. Part 2: overemulsification-interpretation and use. Chem. Eng. Sci. 56(19), 5531-5537.

[49] Dias, J.M., Santos, E., Santo, F., Carvalho, F., Alvim-Ferraz, M.C.M., Almeida, M.F., 2014. Study of an ethylic biodiesel integrated process: raw-materials, reaction optimization and purification methods. Fuel Process. Technol. 124, 198-205.

[50] Dimian, A.C., Bildea, C.S., Omota, F., Kiss, A.A., 2009. Innovative process for fatty acid esters by dual reactive distillation. Comput. Chem. Eng. 33(3), 743-750.

[51] Ding, R., Wu, Y., Chen, Y., Liang, J., Liu, J., Yang, M., 2015. Effective hydrodeoxygenation of palmitic acid to diesel-like hydrocarbons over $\mathrm{MoO}_{2} /$ CNTs catalyst. Chem. Eng. Sci. 135, 517 525.

[52] Do, P.T., Chiappero, M., Lobban, L.L., Resasco, D.E., 2009 Catalytic deoxygenation of methyl-octanoate and methyl-stearate on $\mathrm{Pt} / \mathrm{Al}_{2} \mathrm{O}_{3}$. Catal. Lett. 130(1-2), 9-18.

[53] Doherty, M.F., Fidkowski, Z.T., Malone, M.F., Taylor, R., 2008 Section 13. Distillation, in: Green, D.W., Perry, R.H. (Eds.), Perry's Chemical Engineers'handbook, eighth ed. Mcgraw-Hill, New York, United States.

[54] Donnis, B., Egeberg, R.G., Blom, P., Knudsen, K.G., 2009. Hydroprocessing of bio-oils and oxygenates to hydrocarbons. Understanding the reaction routes. Top. Catal. 52(3), 229-240.

[55] Dubé, M.A., Tremblay, A.Y., Liu, J., 2007. Biodiesel production using a membrane reactor. Bioresour. Technol. 98(3), 639-647.

[56] Dugan, J., Magazine, B., 2007. A dry wash approach to biodiesel purification. Biodiesel Magazine.

[57] Dumay, J., Radier, S., Barnathan, G., Berge, J.P., Jaouen, P., 2008. Recovery of valuable soluble compounds from washing waters generated during small fatty pelagic surimi processing by membrane processes. Environ. Technol. 29(4), 451-461.

[58] Dupain, X., Costa, D.J., Schaverien, C.J., Makkee, M., Moulijn, J.A., 2007. Cracking of a rapeseed vegetable oil under realistic FCC conditions. Appl. Catal., B. 72(1-2), 44-61.

[59] Erich, K., 1982. Separating processes, in: Erich, K. (Ed.), Handbook of Laboratory Distillation with an Introduction to Pilot Plant Distillation. Elsevier, New York, United State.

[60] Escobar, J.C., Lora, E.S., Venturini, O.J., Yáñez, E.E., Castillo, E.F., Almazan, O., 2009. Biofuels: environment, technology and food security. Renew. Sust. Energy Rev. 13(6-7), 1275-1287.

[61] Faccini, C.S., Cunha, M.E.D., Moraes, M.S.A., Krause, L.C., Manique, M.C., Rodrigues, M.R.A., Benvenutti, E.V., Caramão, E.B., 2011. Dry washing in biodiesel purification: a comparative study of adsorbents. J. Braz. Chem. Soc. 22(3), 558-563. 
[62] Fadhil, A.B., Dheyab, M.M., 2015. Purification of biodiesel fuels produced from spent frying oils over activated carbons. Energy Sour. Part A. 37(2), 149-155.

[63] Falahati, H., Tremblay, A.Y., 2012. The effect of flux and residence time in the production of biodiesel from various feedstocks using a membrane reactor. Fuel. 91(1), 126-133.

[64] Ferrero, G.O., Almeida, M.F., Alvim-Ferraz, M.C.M., Dias, J.M., 2014. Water-free process for eco-friendly purification of biodiesel obtained using a heterogeneous Ca-based catalyst. Fuel Process. Technol. 121, 114-118.

[65] Foraita, S., Liu, Y., Haller, G.L., Baráth, E., Zhao, C., Lercher, J.A., 2017. Controlling hydrodeoxygenation of stearic acid to $n$-heptadecane and $\mathrm{n}$-octadecane by adjusting the chemical properties of $\mathrm{Ni} / \mathrm{SiO}_{2}-\mathrm{ZrO}_{2}$ catalyst. ChemCatChem. 9(1), 195-203.

[66] Freeman, B.D., Paul, D.R., Czenkusch, K., Ribeiro, C.P., Ba, C., 2012. Thermally rearranged ( $\mathrm{Tr}$ ) polymers as membranes for ethanol dehydration. U.S. Patent 20120305484 A.

[67] Furimsky, E., 1983. Chemistry of catalytic hydrodeoxygenation. Catal. Rev. Sci. Eng. 25(3), 421-458.

[68] Furimsky, E., 2000. Catalytic hydrodeoxygenation. Appl. Catal., A. 199(2), 147-190.

[69] Furimsky, E., 2003. Metal carbides and nitrides as potential catalysts for hydroprocessing. Appl. Catal., A. 240(1-2), 1-28.

[70] Furimsky, E., Massoth, F.E., 1999. Deactivation of hydroprocessing catalysts. Catal. Today. 52(4), 381-495.

[71] Gee, J.C., Lawrie, C.J., Williamson, R.C., 1996. Drilling fluids comprising mostly linear olefins. U.S. Patent 5589442 A.

[72] Giorno, F., Mazzei, R., Giorno, L., 2013. Purification of triacylglycerols for biodiesel production from nannochloropsis microalgae by membrane technology. Bioresour. Technol. 140, 172-178.

[73] Gomes, M.C.S., Arroyo, P.A., Pereira, N.C., 2011. Biodiesel production from degummed soybean oil and glycerol removal using ceramic membrane. J. Membr. Sci. 378(1-2), 453-461.

[74] Gomes, M.C.S., Arroyo, P.A., Pereira, N.C., 2013. Influence of acidified water addition on the biodiesel and glycerol separation through membrane technology. J. Membr. Sci. 431, 28-36.

[75] Gomes, M.C.S., Pereira, N.C., De Barros, S.T.D., 2010. Separation of biodiesel and glycerol using ceramic membranes. J. Membr. Sci. 352(12), 271-276.

[76] Gomes, M.G., Santos, D.Q., De Morais, L.C., Pasquini, D., 2015. Purification of biodiesel by dry washing, employing starch and cellulose as natural adsorbents. Fuel. 155, 1-6.

[77] Gomez-Castro, F.I., Rico-Ramirez, V., Segovia-Hernandez, J.G., Hernandez, S., 2010. Feasibility study of a thermally coupled reactive distillation process for biodiesel production. Chem. Eng. Process. Process Intensif. 49(3), 262-269.

[78] Gong, S., Shinozaki, A., Shi, M., Qian, E.W., 2012. Hydrotreating of jatropha oil over alumina based catalysts. Energy Fuels. 26(4), 23942399.

[79] Gosselink, R.W., Hollak, S.A., Chang, S.W., Van Haveren, J., De Jong, K.P., Bitter, J.H., Van Es, D.S., 2013. Reaction pathways for the deoxygenation of vegetable oils and related model compounds. ChemSusChem. 6(9), 1576-1594.

[80] Grandison, A.S., 1996. Ion-exchange and electrodialysis, in: Grandison, A.S., Lewis, M.J. (Eds.), Separation Processes in the Food and Biotechnology Industries. Woodhead Publishing, Cambridge, United Kingdom.

[81] Greenwell, H.C., Laurens, L.M.L., Shields, R.J., Lovitt, R.W., Flynn, K.J., 2009. Placing microalgae on the biofuels priority list: a review of the technological challenges. J. Royal Soc. Interface. 7, 703-726.

[82] Groeneweg, F., Agterof, W.G.M., Jaeger, P., Janssen, J.J.M., Wieringa, J.A., Klahn, J.K., 1998. On the mechanism of the inversion of emulsions. Chem. Eng. Res. Des. 76(1), 55-63.

[83] Han, D., Row, K.H., 2010. Recent applications of ionic liquids in separation technology. Molecules. 15(4), 2405-2426.

[84] Han, J., Duan, J., Chen, P., Lou, H., Zheng, X., 2011. Molybdenum carbide-catalyzed conversion of renewable oils into diesel-like hydrocarbons. Adv. Synth. Catal. 353(14-15), 2577-2583.

[85] Han, J., Duan, J., Chen, P., Lou, H., Zheng, X., Hong, H., 2011. Nanostructured molybdenum carbides supported on carbon nanotubes as efficient catalysts for one-step hydrodeoxygenation and isomerization of vegetable oils. Green Chem. 13(9), 2561-2568.

[86] Han, J., Duan, J., Chen, P., Lou, H., Zheng, X., Hong, H., 2012. Carbon-supported molybdenum carbide catalysts for the conversion of vegetable oils. ChemSusChem. 5(4), 727-733.

[87] Hanson, C., 1971. Solvent extraction: the current position, in: Hanson, C. (Ed.), Recent Advances in Liquid-Liquid Extraction. Pergamon Press, Oxford, United Kingdom.

[88] Hao, J.H., Chen, C., Li, L., Yu, L., Jiang, W., 2000. Preparation of solvent-resistant anion-exchange membranes. Desalination. 129(1), $15-22$.

[89] Hayyan, M., Mjalli, F.S., Hashim, M.A., Alnashef, I.M., 2010. A Novel technique for separating glycerine from palm oil-based biodiesel using ionic liquids. Fuel Process. Technol. 91(1), 116-120.

[90] He, H.Y., Guo, X., Zhu, S.L., 2006. Comparison of membrane extraction with traditional extraction methods for biodiesel production. J. Am. Oil Chem. Soc. 83(5), 457-460.

[91] Ho, R.M., Wu, C.H., Su, A.C., 1990. Morphology of plastic/rubber blends. Polym. Eng. Sci. 30(9), 511-518.

[92] Hoekman, S.K., Robbins, C., 2012. Review of the effects of biodiese on NOx emissions. Fuel Process. Technol. 96, 237-249.

[93] Hollak, S.A., Gosselink, R.W., Van Es, D.S., Bitter, J.H., 2013. Comparison of tungsten and molybdenum carbide catalysts for the hydrodeoxygenation of oleic acid. ACS Catal. 3(12), 2837-2844.

[94] Hua, F.L., Tsang, Y.F., Wang, Y.J., Chan, S.Y., Chua, H., Sin, S.N., 2007. Performance study of ceramic microfiltration membrane for oily wastewater treatment. Chem. Eng. J. 128(2-3), 169-175.

[95] Huang, H.J., Ramaswamy, S., 2013. Overview of biomass conversion processes and separation and purification technologies in biorefineries, in: Ramaswamy, S., Huang, H.J., Ramarao, B.V (Eds.), Separation and Purification Technologies in Biorefineries. John Wiley and Sons, Chichester, United Kingdom.

[96] Huerga, I.R., Zanuttini, M.S., Gross, M.S., Querini, C.A., 2014 Biodiesel production from jatropha curcas: integrated process optimization. Energy Convers. Manage. 80, 1-9.

[97] Immer, J.G., Kelly, M.J., Lamb, H.H., 2010. Catalytic reaction pathways in liquid-phase deoxygenation of $\mathrm{C} 18$ free fatty acids. Appl. Catal., A. 375(1), 134-139.

[98] Itthibenchapong, V., Srifa, A., Kaewmeesri, R., Kidkhunthod, P., Faungnawakij, K., 2017. Deoxygenation of palm kernel oil to jet fuellike hydrocarbons using $\mathrm{Ni}-\mathrm{MoS}_{2} / \gamma-\mathrm{Al}_{2} \mathrm{O}_{3}$ catalysts. Energy Convers. Manage. 134, 188-196.

[99] Jaber, R., Shirazi, M.M.A., Toufaily, J., Hamieh, A.T., Noureddin, A., Ghanavati, H., Ghaffari, A., Zenouzi, A., Karout, A., Ismail, A.F., Tabatabaei, M., 2015. Biodiesel wash-water reuse using microfiltration: toward zero-discharge strategy for cleaner and economized biodiesel production. Biofuel Res. J. 2(1), 148-151.

[100] Jiang, L.Y., Wang, Y., Chung, T.S., Qiao, X.Y., Lai, J.Y., 2009 Polyimides membranes for pervaporation and biofuels separation. Prog. Polym. Sci. 34(11), 1135-1160.

[101] Kandel, K., Anderegg, J.W., Nelson, N.C., Chaudhary, U., Slowing, I.I., 2014. Supported iron nanoparticles for the hydrodeoxygenation of microalgal oil to green diesel. J. Catal. 314, 142-148.

[102] Karaosmanoğlu, F., Cığızoğlu, K.B., Tüter, M., Ertekin, S., 1996. Investigation of the refining step of biodiesel production. Energy Fuels. 10(4), 890-895.

[103] Katikaneni, S.P., Adjaye, J.D., Bakhshi, N.N., 1995. Catalytic conversion of canola oil to fuels and chemicals over various cracking catalysts. Can. J. Chem. Eng. 73(4), 484-497.

[104] Kertes, A.S., 1971. The chemistry of solvent extraction, in: Hanson, C. (Ed.), Recent Advances in Liquid-Liquid Extraction. Pergamon Press, Oxford, United Kingdom.

[105] Kiatkittipong, W., Phimsen, S., Kiatkittipong, K., Wongsakulphasatch, S., Laosiripojana, N., Assabumrungrat, S., 2013. Diesel-like hydrocarbon production from hydroprocessing of relevant refining palm oil. Fuel Process. Technol. 116, 16-26.

[106] Kim, H.J., Kang, B.S., Kim, M.J., Park, Y.M., Kim, D.K., Lee, J.S., Lee, K.Y., 2004. Transesterification of vegetable oil to biodiesel using heterogeneous base catalyst. Catal. Today. 93-95, 315-320. 
[107] Kiss, A.A., 2010. Separative reactors for integrated production of bioethanol and biodiesel. Comput. Chem. Eng. 34(5), 812-820.

[108] Kiss, A.A., 2013. Advanced Distillation Technologies: Design, control and applications. John Wiley and Sons, Chichester, United Kingdom.

[109] Kiss, A.A., Dimian, A.C., Rothenberg, G., 2006. Solid acid catalysts for biodiesel production-towards sustainable energy. Adv. Synth. Catal. 348(1-2), 75-81.

[110] Kiss, A.A., Dimian, A.C., Rothenberg, G., 2007. Biodiesel by catalytic reactive distillation powered by metal oxides. Energy Fuels. 22(1), 598604.

[111] Kiss, A.A., Omota, F., Dimian, A.C., Rothenberg, G., 2006. The heterogeneous advantage: biodiesel by catalytic reactive distillation. Top. Catal. 40(1-4), 141-150.

[112] Knothe, G., 2010. Biodiesel and renewable diesel: a comparison. Prog. Energy Combust. Sci. 36(3), 364-373.

[113] Kockmann, N., 2014. History of distillation, in: Górak, A., Sorensen, E. (Eds.), Distillation: Fundamentals and Principles. Academic Press, Boston, United State.

[114] Kolah, A.K., Lira, C.T., Miller, D.J., 2013. Reactive distillation for the biorefinery, in: Ramaswamy, S., Huang, H.J., Ramarao, B.V. (Eds.), Separation and Purification Technologies in Biorefineries. John Wiley and Sons, Chichester, United Kingdom.

[115] Kouzu, M., Hidaka, J.S., 2013. Purification to remove leached $\mathrm{CaO}$ catalyst from biodiesel with the help of cation-exchange resin. Fuel. 105, 318-324.

[116] Kovács, S., Kasza, T., Thernesz, A., Horváth, I.W., Hancsók, J., 2011. Fuel production by hydrotreating of triglycerides on $\mathrm{NiMo} / \mathrm{Al}_{2} \mathrm{O}_{3} / \mathrm{F}$ catalyst. Chem. Eng. J. 176, 237-243.

[117] Kubička, D., Bejblová, M., Vlk, J., 2010. Conversion of vegetable oils into hydrocarbons over CoMo/MCM-41 catalysts. Top. Catal. 53(3-4), $168-178$.

[118] Kubička, D., Horáček, J., 2011. Deactivation of HDS catalysts in deoxygenation of vegetable oils. Appl. Catal., A. 394(1-2), 9-17.

[119] Kubička, D., Kaluža, L., 2010. Deoxygenation of vegetable oils over sulfided Ni, Mo and NiMo catalysts. Appl. Catal., A. 372(2), 199-208.

[120] Kubička, D., Šimáček, P., Žilková, N., 2009. Transformation of vegetable oils into hydrocarbons over mesoporous-alumina-supported CoMo catalysts. Top. Catal. 52(1-2), 161-168.

[121] Kubičková, I., Snåre, M., Eränen, K., Mäki-Arvela, P., Murzin, D.Y., 2005. Hydrocarbons for diesel fuel via decarboxylation of vegetable oils. Catal. Today. 106(1-4), 197-200.

[122] Lam, E., Luong, J.H., 2014. Carbon materials as catalyst supports and catalysts in the transformation of biomass to fuels and chemicals. ACS Catal. 4(10), 3393-3410.

[123] Laurent, E., Delmon, B., 1994. Influence of water in the deactivation of a sulfided NiMo $-\mathrm{Al}_{2} \mathrm{O}_{3}$ catalyst during hydrodeoxygenation. J. Catal. 146(1), 281288-285291.

[124] Leeruang, U., Pengprecha, S., 2012. Purification of biodiesel by adsorption with activated low silica bentonite. Int. Conf. Chem. Process. Environ. Issues. 15-16.

[125] Lei, Z., Chen, B., 2013. Distillation, in: Ramaswamy, S., Huang, H.J., Ramarao, B.V. (Eds.), Separation and Purification Technologies in Biorefineries. John Wiley and Sons, Chichester, United Kingdom.

[126] Lei, Z., Chen, B., Ding, Z., 2005. Special Distillation Processes. Elsevier, Amesterdame, Netherlands.

[127] Lestari, S., Maki-Arvela, P., Bernas, H., Simakova, O., SjöHolm, R., Beltramini, J., Lu, G.M., Myllyoja, J., Simakova, I., Murzin, D.Y., 2009. Catalytic deoxygenation of stearic acid in a continuous reactor over a mesoporous carbon-supported Pd catalyst. Energy Fuels. 23(8), 38423845.

[128] Lestari, S., Mäki-Arvela, P., Eränen, K., Beltramini, J., Lu, G.M., Murzin, D.Y., 2010. Diesel-like hydrocarbons from catalytic deoxygenation of stearic acid over supported Pd nanoparticles on SBA15 catalysts. Catal. Lett. 134(3-4), 250-257.

[129] Lestari, S., Mäki-Arvela, P., Simakova, I., Beltramini, J., Lu, G.M., Murzin, D.Y., 2009. Catalytic deoxygenation of stearic acid and palmitic acid in semibatch mode. Catal. Lett. 130(1-2), 48-51.

[130] Lestari, S., Mäki-Arvela, P., Beltramini, J., Lu, G.Q., Murzin, D.Y., 2009. Transforming triglycerides and fatty acids into biofuels. ChemSusChem. 2(12), 1109-1119.
[131] Lestari, S., Simakova, I., Tokarev, A., Mäki-Arvela, P., Eränen, K., Murzin, D.Y., 2008. Synthesis of biodiesel via deoxygenation of stearic acid over supported Pd/C catalyst. Catal. Lett. 122(3-4), 247251.

[132] LeVan, M.D., Carta, G., 2008. Section 16. Adsorption and ion exchange, in: Green, D.W., Perry, R.H. (Eds.), Perry's Chemical Engineers' Handbook, $8^{\text {th }}$ ed. Mcgraw-Hill, New York, United States.

[133] Li, L., Wang, Y., 2005. Quaternized polyethersulfone cardo anion exchange membranes for direct methanol alkaline fuel cells. J. Membr. Sci. 262(1-2), 1-4.

[134] Li, M., Zhang, H., Shao, Z.G., 2006. Quaternized poly (phthalazinone ether sulfone ketone) membrane doped with $\mathrm{H}_{3} \mathrm{PO}_{4}$ for hightemperature PEMFC operation. Electrochem. Solid State Lett. 9(2), A60-A63.

[135] Liu, Y., Sotelo-Boyás, R., Murata, K., Minowa, T., Sakanishi, K., 2011. Hydrotreatment of vegetable oils to produce bio-hydrogenated diesel and liquefied petroleum gas fuel over catalysts containing sulfided Ni-Mo and solid acids. Energy Fuels, 25(10), 4675-4685.

[136] Ma, F., Clements, L.D., Hanna, M.A., 1998. Biodiesel fuel from animal fat. ancillary studies on transesterification of beef tallow. Ind. Eng. Chem. Res. 37(9), 3768-3771.

[137] Ma, F., Hanna, M.A., 1999. Biodiesel production: a review. Bioresour. Technol. 70(1), 1-15.

[138] Machado, G.D., Aranda, D.A., Castier, M., Cabral, V.F., CardozoFilho, L.C., 2011. Computer simulation of fatty acid esterification in reactive distillation columns. Ind. Eng. Chem. Res. 50(17), 1017610184

[139] Madsen, A.T., Christensen, C.H., Fehrmann, R., Riisager, A., 2011. Hydrodeoxygenation of waste fat for diesel production: study on model feed with Pt/alumina catalyst. Fuel. 90(11), 3433-3438.

[140] Mah, S.K., Leo, C.P., Wu, T.Y., Chai, S.P., 2012. A feasibility investigation on ultrafiltration of palm oil and oleic acid removal from glycerin solutions: flux decline, fouling pattern, rejection and membrane characterizations. J. Membr. Sci. 389, 245-256.

[141] Mäki-Arvela, P., Kubickova, I., Snåre, M., Eränen, K., Murzin, D.Y. 2007. Catalytic deoxygenation of fatty acids and their derivatives. Energy Fuels. 21(1), 30-41.

[142] Mäki-Arvela, P., Snåre, M., Eränen, K., Myllyoja, J., Murzin, D.Y. 2008. Continuous decarboxylation of lauric acid over Pd/C catalyst. Fuel. 87(17-18), 3543-3549.

[143] Manique, M.C., Faccini, C.S., Onorevoli, B., Benvenutti, E.V. Caramão, E.B., 2012. Rice husk ash as an adsorbent for purifying biodiesel from waste frying oil. Fuel. 92(1), 56-61.

[144] Mantell, C., Casas, L., Rodriguez, M., De La Ossa, E.M., 2013. Supercritical fluid extraction, in: Ramaswamy, S., Huang, H.J. Ramarao, B.V. (Eds.), Separation and Purification Technologies in Biorefineries. John Wiley and Sons, Chichester, United Kingdom.

[145] Mänttäri, M., Van Der Bruggen, B., Nyström, M., 2013. Nanofiltration, in: Ramaswamy, S., Huang, H.J., Ramarao, B.V. (Eds.), Separation and Purification Technologies in Biorefineries. John Wiley and Sons, Chichester, United Kingdom.

[146] Manuale, D.L., Mazzieri, V.M., Torres, G., Vera, C.R., Yori, J.C. 2011. Non-catalytic biodiesel process with adsorption-based refining. Fuel. 90(3), 1188-1196.

[147] Mata, T.M., Cardoso, N., Ornelas, M., Neves, S., Caetano, N.S., 2011. Evaluation of two purification methods of biodiesel from beef tallow, pork lard, and chicken fat. Energy Fuels. 25(10), 4756-4762.

[148] Mazzieri, V.A., Vera, C.R., Yori, J.C., 2008. Adsorptive properties of silica gel for biodiesel refining. Energy Fuels. 22(6), 4281-4284.

[149] Miga, K., Stanczyk, K., Sayag, C., Brodzki, D., Djéga-Mariadassou, G., 1999. Bifunctional behavior of bulk $\mathrm{MoO}_{\mathrm{x}} \mathrm{N}_{\mathrm{y}}$ and nitrided supported NiMo catalyst in hydrodenitrogenation of indole. J. Catal. 183(1), 63-68.

[150] Monnier, J., Sulimma, H., Dalai, A., Caravaggio, G., 2010 Hydrodeoxygenation of oleic acid and canola oil over aluminasupported metal nitrides. Appl. Catal., A. 382(2), 176-180.

[151] Morgan, T., Santillan-Jimenez, E., Harman-Ware, A.E., Ji, Y., Grubb, D., Crocker, M., 2012. Catalytic deoxygenation of triglycerides to hydrocarbons over supported nickel catalysts. Chem. Eng. J. 189-190, 346-355. 
[152] Mortensen, P.M., Grunwaldt, J.D., Jensen, P.A., Knudsen, K.G., Jensen, A.D., 2011. A review of catalytic upgrading of bio-oil to engine fuels. Appl. Catal., A. 407(1-2), 1-19.

[153] Moser, B.R., 2012. Preparation of fatty acid methyl esters from hazelnut, high-oleic peanut and walnut oils and evaluation as biodiesel. Fuel, 92(1), 231-238.

[154] Mueanmas, C., Prasertsit, K., Tongurai, C., 2010. Transesterification of triolein with methanol in reactive distillation column: simulation studies. Int. J. Chem. Reactor Eng. 8(1).

[155] Muniyappa, P.R., Brammer, S.C., Noureddini, H., 1996. Improved conversion of plant oils and animal fats into biodiesel and co-product. Bioresour. Technol. 56(1), 19-24.

[156] Nag, A., 2015. Distillation \& Hydrocarbon Processing Practices, Pennwell Corporation. Tulsa, United State.

[157] Nagy, G., Pölczmann, G., Kalló, D., Hancsók, J., 2009. Investigation of hydrodearomatization of gas oils on noble metal/support catalysts. Chem. Eng. J. 154(1-3), 307-314.

[158] Nava, R., Pawelec, B., Castaño, P., Álvarez-Galván, M.C., Loricera, C.V., Fierro, J.L.G., 2009. Upgrading of bio-liquids on different mesoporous silica-supported CoMo catalysts. Appl. Catal., B. 92(1-2), 154-167.

[159] Ng, W.K., Lim, P.K., Boey, P.L., 2003. Dietary lipid and palm oil source affects growth, fatty acid composition and muscle $\alpha$-tocopherol concentration of African catfish, Clarias gariepinus. Aquaculture. 215(14), 229-243.

[160] Noori, M.S., Karimi, K., 2016. Chemical and structural analysis of alkali pretreated pinewood for efficient ethanol production. RSC Adv. 6(70), 65683-65690.

[161] Noori, M.S., Karimi, K., 2016. Detailed study of efficient ethanol production from elmwood by alkali pretreatment. Biochem. Eng. J. 105, 197-204.

[162] Parkash, S., 2003. Refining Process Handbook. Gulf Professional Publishing, Burlington, United State.

[163] Parvizsedghy, R., Sadrameli, S.M., Towfighi Darian, J., 2015. Upgraded biofuel diesel production by thermal cracking of castor biodiesel. Energy Fuels. 30(1), 326-333.

[164] Pérez-Cisneros, E.S., Mena-Espino, X., Rodríguez-López, V., SalesCruz, M., Viveros-García, T., Lobo-Oehmichen, R., 2016. An integrated reactive distillation process for biodiesel production. Comput. Chem. Eng. 91, 233-246.

[165] Peroni, M., Mancino, G., Baráth, E., Gutiérrez, O.Y., Lercher, J.A., 2016. Bulk and $\gamma-\mathrm{Al}_{2} \mathrm{O}_{3}$-supported $\mathrm{Ni}_{2} \mathrm{P}$ and $\mathrm{MoP}$ for hydrodeoxygenation of palmitic acid. Appl. Catal., B. 180, 301-311.

[166] Phimsen, S., Kiatkittipong, W., Yamada, H., Tagawa, T., Kiatkittipong, K., Laosiripojana, N., Assabumrungrat, S., 2016. Oil extracted from spent coffee grounds for bio-hydrotreated diesel production. Energy Convers. Manage. 126, 1028-1036.

[167] Pittia, P., Mastrocola, D., Nicoli, M., 2005. Effect of colloidal properties of oil-in-water emulsions on ethanol liquid-vapour partition. Food Res. Int. 38(5), 585-595.

[168] Poddar, T., Jagannath, A., Almansoori, A., 2015. Biodiesel production using reactive distillation: a comparative simulation study. Energy Procedia. 75, 17-22.

[169] Predojević, Z.J., 2008. The production of biodiesel from waste frying oils: a comparison of different purification steps. Fuel. 87(17-18), 35223528.

[170] Qin, Y., Chen, P., Duan, J., Han, J., Lou, H., Zheng, X., Hong, H., 2013. Carbon nanofibers supported molybdenum carbide catalysts for hydrodeoxygenation of vegetable oils. RSC Adv. 3(38), 17485-17491.

[171] Qiu, Z., Zhao, L., Weatherley, L., 2010. Process intensification technologies in continuous biodiesel production. Chem. Eng. Process. Process Intensif. 49(4), 323-330.

[172] Rahayu, S.S., Mindaryani, A., 2007. Optimization of biodiesel washing by water extraction. Proc. World Congr. Eng. Comput. Sci. 24-26.

[173] Rantanen, L., Linnaila, R., Aakko, P., Harju, T., 2005. NExBTLbiodiesel fuel of the second generation. SAE Technical Paper, 2005-013771 .

[174] Rodríguez-Reinoso, F., 1998. The role of carbon materials in heterogeneous catalysis. Carbon. 36(3), 159-175.
[175] Rogers, K.A., Zheng, Y., 2016. Selective deoxygenation of biomassderived bio-oils within hydrogen-modest environments: a review and new insights. ChemSusChem. 9(14), 1750-1772.

[176] Romero, Y., Richard, F., Brunet, S., 2010. Hydrodeoxygenation of 2 ethylphenol as a model compound of bio-crude over sulfided mobased catalysts: promoting effect and reaction mechanism. Appl. Catal., B. 98(3-4), 213-223.

[177] Rozmysłowicz, B., Maki-Arvela, P., Tokarev, A., Leino, A.R., EräNen, K., Murzin, D.Y., 2012. Influence of hydrogen in catalytic deoxygenation of fatty acids and their derivatives over $\mathrm{Pd} / \mathrm{C}$. Ind Eng. Chem. Res. 51(26), 8922-8927.

[178] Ruddy, D.A., Schaidle, J.A., Ferrell Iii, J.R., Wang, J., Moens, L. Hensley, J.E., 2014. Recent advances in heterogeneous catalysts for bio-oil upgrading via "ex situ catalytic fast pyrolysis": catalyst development through the study of model compounds. Green Chem. 16(2), 454-490.

[179] Russbueldt, B.M., Hoelderich, W.F., 2009. New sulfonic acid ionexchange resins for the preesterification of different oils and fats with high content of free fatty acids. Appl. Catal. A. 362(1-2), 47-57.

[180] Ruthven, D.M., 1984. Principles of Adsorption and Adsorption Processes. John Wiley and Sons, New York, United State.

[181] Saifuddin, N., Chua, K.H., 2004. Production of ethyl ester (biodiesel) from used frying oil: optimization of transesterification process using microwave irradiation. Malaysian J. Chem. 6(1), 77-82.

[182] Saleh, J., Dubé, M.A., Tremblay, A.Y., 2010. Effect of soap, methanol, and water on glycerol particle size in biodiesel purification. Energy Fuels. 24(11), 6179-6186

[183] Saleh, J., Dubé, M.A., Tremblay, A.Y., 2011. Separation of glycero from FAME using ceramic membranes. Fuel Process. Technol. 92(7), 1305-1310.

[184] Saleh, J., Tremblay, A.Y., Dubé, M.A., 2010. Glycerol removal from biodiesel using membrane separation technology. Fuel. 89(9), 22602266.

[185] Samadi, S., Karimi, K., Behnam, S., 2017. Simultaneous biosorption and bioethanol production from lead-contaminated media by mucor indicus. Biofuel Res. J. 4(1), 545-550.

[186] Satyarthi, J.K., Chiranjeevi, T., Gokak, D.T., Viswanathan, P.S. 2013. An overview of catalytic conversion of vegetable oils/fats into middle distillates. Catal. Sci. Technol. 3(1), 70-80.

[187] Schuchardt, U., Sercheli, R., Vargas, R.M., 1998. Transesterification of vegetable oils: a review. J. Braz. Chem. Soc. 9(3), 199-210.

[188] Şenol, O., Ryymin, E.M., Viljava, T.R., Krause, A., 2007. Effect of hydrogen sulphide on the hydrodeoxygenation of aromatic anc aliphatic oxygenates on sulphided catalysts. J. Mol. Catal. A: Chem. 277(1-2), 107-112.

[189] Şenol, O., Viljava, T.R., Krause, A.O.I., 2005. Hydrodeoxygenation of aliphatic esters on sulphided $\mathrm{NiMo} / \gamma-\mathrm{Al}_{2} \mathrm{O}_{3}$ and $\mathrm{CoMo} / \gamma-\mathrm{Al}_{2} \mathrm{O}$ catalyst: the effect of water. Catal. Today. 106(1-4), 186-189.

[190] Şenol, O.I., Viljava, T.R., Krause, A.O.I., 2005. Hydrodeoxygenation of methyl esters on sulphided $\mathrm{NiMo} / \gamma-\mathrm{Al}_{2} \mathrm{O}_{3}$ and $\mathrm{CoMo} / \gamma-\mathrm{Al}_{2} \mathrm{O}_{3}$ catalysts. Catal. Today. 100(3-4), 331-335.

[191] Serrano, M., Bouaid, A., Martínez, M., Aracil, J., 2013. Oxidation stability of biodiesel from different feedstocks: influence of commercial additives and purification step. Fuel. 113, 50-58.

[192] Shafiei, A., Rastegari, H., Ghaziaskar, H.S., Yalpani, M., 2017 Glycerol transesterification with ethyl acetate to synthesize acetins using ethyl acetate as reactant and entrainer. Biofuel Res. J. 4(1), 565 570 .

[193] Shahbaz, K., Mjalli, F.S., Hashim, M.A., Alnashef, I.M., 2011. Eutectic solvents for the removal of residual palm oil-based biodiesel catalyst. Sep. Purif. Technol. 81(2), 216-222.

[194] Shahbaz, K., Mjalli, F.S., Hashim, M.A., Al-Nashef, I.M., 2010 Using deep eutectic solvents for the removal of glycerol from palm oil-based biodiesel. J. Appl. Sci.10(24), 3349-3354.

[195] Shi, W., Li, H., Su, Y., Liu, J., 2016. Biodiesel production by quaternized polysulfone membrane: experimental and kinetics model. Energy Procedia. 104, 402-406.

[196] Shi, W., Li, H., Zhou, R., Zhang, H., Du, Q., 2016. Biodiese production from soybean oil by quaternized polysulfone alkalicatalyzed membrane. Bioresour. Technol. 210, 43-48. 
[197] Simakova, I., Rozmysłowicz, B., Simakova, O., Mäki-Arvela, P., Simakov, A., Murzin, D.Y., 2011. Catalytic deoxygenation of C18 fatty acids over mesoporous Pd/C catalyst for synthesis of biofuels. Top. Catal. 54(8-9), 460-466.

[198] Simakova, I., Simakova, O., Mäki-Arvela, P., Simakov, A., Estrada, M., Murzin, D.Y., 2009. Deoxygenation of palmitic and stearic acid over supported Pd catalysts: effect of metal dispersion. Appl. Catal., A. 355(12), 100-108.

[199] Simasatitkul, L., Siricharnsakunchai, P., Patcharavorachot, Y., Assabumrungrat, S., Arpornwichanop, A., 2011. Reactive distillation for biodiesel production from soybean oil. Korean J. Chem. Eng. 28(3), 649655.

[200] Slade, R.C., Kizewski, J.P., Poynton, S.D., Zeng, R., Varcoe, J.R. 2012. Alkaline membrane fuel cells, in: Meyers, R.A. (Ed.), Encyclopedia of Sustainability Science and Technology. Springer, New York, United States.

[201] Snåre, M., Kubičková, I., Mäki-Arvela, P., Chichova, D., Eränen, K., Murzin, D.Y., 2008. Catalytic deoxygenation of unsaturated renewable feedstocks for production of diesel fuel hydrocarbons. Fuel. 87(6), 933945.

[202] Snåre, M., Kubickova, I., Mäki-Arvela, P., Eränen, K., Murzin, D.Y., 2006. Heterogeneous catalytic deoxygenation of stearic acid for production of biodiesel. Ind. Eng. Chem. Res. 45(16), 5708-5715.

[203] Snåre, M., Kubičková, I., Mäki-Arvela, P., Eränen, K., Wärnå, J., Murzin, D.Y., 2007. Production of diesel fuel from renewable feeds: kinetics of ethyl stearate decarboxylation. Chem. Eng. J. 134(1-3), 29-34.

[204] Snåre, M., Mäki-Arvela, P., Simakova, I.L., Myllyoja, J., Murzin, D.Y., 2009. Overview of catalytic methods for production of next generation biodiesel from natural oils and fats. Russ. J. Phys. Chem. B. 3(7), 10351043.

[205] Sotelo-Boyas, R., Liu, Y., Minowa, T., 2010. Renewable diesel production from the hydrotreating of rapeseed oil with Pt/Zeolite and $\mathrm{NiMo} / \mathrm{Al}_{2} \mathrm{O}_{3}$ catalysts. Ind. Eng. Chem. Res. 50(5), 2791-2799.

[206] Sousa, L.A, Zotin, J.L., Da Silva, V.T., 2012. Hydrotreatment of sunflower oil using supported molybdenum carbide. Appl. Catal., A. 449, 105-111.

[207] Srifa, A., Faungnawakij, K., Itthibenchapong, V., Assabumrungrat, S., 2015. Roles of monometallic catalysts in hydrodeoxygenation of palm oil to green diesel. Chem. Eng. J. 278, 249-258.

[208] Srifa, A., Faungnawakij, K., Itthibenchapong, V., Viriya-Empikul, N., Charinpanitkul, T., Assabumrungrat, S., 2014. Production of biohydrogenated diesel by catalytic hydrotreating of palm oil over $\mathrm{NiMoS}_{2} /$ $\gamma-\mathrm{Al}_{2} \mathrm{O}_{3}$ catalyst. Bioresour. Technol.158, 81-90.

[209] Srinivasan, S., 2009. The food v. fuel debate: a nuanced view of incentive structures. Renew. Energy. 34(4), 950-954.

[210] Srivastava, S.P., Hancsok, J., 2014. Fuels and Fuel-Additives. John Wiley and Sons, New Jersey, United State.

[211] Stanislaus, A., Marafi, A., Rana, M.S., 2010. Recent advances in the science and technology of ultralow sulfur diesel (ULSD) production. Catal. Today. 153(1-2), 1-68.

[212] Stellwagen, D.R., Bitter, J.H., 2015. Structure-performance relations of molybdenum-and tungsten carbide catalysts for deoxygenation. Green Chem. 17(1), 582-593.

[213] Steytler, D., 1996. Supercritical fluid extraction and its application in the food industry, in: Grandison, A.S., Lewis, M.J. (Eds.), Separation Processes in The Food and Biotechnology Industries. Woodhead Publishing, Cambridge, United Kingdom.

[214] Stöcker, M., 2008. Biofuels and biomass-to-liquid fuels in the biorefinery: catalytic conversion of lignocellulosic biomass using porous materials. Angew. Chem. Int. Ed. 47(48), 9200-9211.

[215] Stojković, I.J., Stamenković, O.S., Povrenović, D.S., Veljković, V.B., 2014. Purification technologies for crude biodiesel obtained by alkalicatalyzed transesterification. Renew.Sust. Energy Rev.32, 1-15.

[216] Stumborg, M., Soveran, D., Craig, W., Robinson, W., 1993. Catalytic conversion of vegetable oils to diesel additives. Energy Biomass Wastes. $16,721-721$.

[217] Sundmacher, K., Kienle, A., 2002. Reactive Distillation: Status and Future Directions. Weinheim, Germany, Wiley-VCH.

[218] Tremblay, A.Y., Cao, P., Dubé, M.A., 2008. Biodiesel production using ultra low catalyst concentrations. Energy Fuels. 22(4), 2748-2755.
[219] Tremblay, A.Y., Montpetit, A., 2017. The in-process removal of sterol glycosides by ultrafiltration in biodiesel production. Biofuel Res. J. 4(1), 559-564.

[220] Treybal, R.E., 1980. Mass Transfer Operations, third Ed. McgrawHill, New York, United State.

[221] Twaiq, F.A., Zabidi, N.A., Bhatia, S., 1999. Catalytic conversion of palm oil to hydrocarbons: performance of various zeolite catalysts. Ind. Eng. Chem. Res. 38(9), 3230-3237.

[222] UOP, Honeywell Green Diesel, 2017.

[223] Van Der Graaf, S., Schroën, C.G.P.H., Boom, R.M., 2005. Preparation of double emulsions by membrane emulsification-a review. J. Membr. Sci. 251(1-2), 7-15.

[224] Van Gerpen, J., Shanks, B., Pruszko, R., Clements, D., Knothe, G., 2004. Biodiesel production technology. August 2002-January 2004 National Renew. Energy Lab. NREL/SR-510-36244.

[225] Veljković, V.B., Banković-Ilić, I.B., Stamenković, O.S., 2015. Purification of crude biodiesel obtained by heterogeneouslycatalyzed transesterification. Renew. Sust. Energy Rev. 49, 500-516.

[226] Venkatesan, S., 2013. Adsorption, in: Ramaswamy, S., Huang, H.J. Ramarao, B.V. (Eds.), Separation and Purification Technologies in Biorefineries. John Wiley and Sons, Chichester, United Kingdom.

[227] Vinh, T.Q., Loan, N.T.T., Yang, X.Y., Su, B.L., 2011. Preparation of bio-fuels by catalytic cracking reaction of vegetable Oil sludge. Fuel. 90(3), 1069-1075.

[228] Vora, B.P., Peterson, G.A., Sohn, S.W., Riley, M.G., 2009. Detergent alkylate and detergent olefins production. Handbook of Detergents, Part F: Production. CRC Press, Taylor and Francis Group, LLC, Boca Raton, United State. 39-45

[229] Wall, J., Van Gerpen, J., Thompson, J., 2011. Soap and glycerin removal from biodiesel using waterless processes. Trans. ASABE. $54(2), 535-541$

[230] Wang, H., Yan, S., Salley, S.O., Ng, K.S., 2012. Hydrocarbon fuels production from hydrocracking of soybean Oil using transition metal carbides and nitrides supported on ZSM-5. Ind. Eng. Chem. Res. 51(30), 10066-10073

[231] Wang, H., Yan, S., Salley, S.O., Ng, K.S., 2013. Support effects on hydrotreating of soybean oil over NiMo carbide catalyst. Fuel. 111 81-87.

[232] Wang, J., Ge, X., Wang, Z., Jin, Y., 2001. Experimental studies on the catalytic distillation for hydrolysis of methyl acetate. Chem. Eng. Technol. 24(2), 155-159.

[233] Wang, Y., Nie, J., Zhao, M., Ma, S., Kuang, L., Han, X., Tang, S. 2010. Production of biodiesel from waste cooking oil via a two-step catalyzed process and molecular distillation. Energy Fuels. 24(3), 2104-2108.

[234] Wang, Y., Wang, X., Liu, Y., Ou, S., Tan, Y., Tang, S., 2009. Refining of biodiesel by ceramic membrane separation. Fuel Process. Technol. 90(3), 422-427.

[235] Wei, C.Y., Huang, T.C., Yu, Z.R., Wang, B.J., Chen, H.H., 2014 Fractionation for biodiesel purification using supercritical carbon dioxide. Energies. 7(2), 824-833.

[236] Wijffels, R.H., Barbosa, M.J., Eppink, M.H., 2010. Microalgae for the production of bulk chemicals and biofuels. Biofuels, Bioprod. Biorefin. 4(3), 287-295.

[237] Yang, C., Li, R., Cui, C., Liu, S., Qiu, Q., Ding, Y., Wu, Y., Zhang, B., 2016. Catalytic hydroprocessing of microalgae-derived biofuels a review. Green Chem. 18(13), 3684-3699.

[238] Yang, R.T., 2003. Adsorbents: Fundamentals and Applications. John Wiley \& Sons, New Jersey, United State.

[239] Yang, Y., Chen, J., Shi, H., 2013. Deoxygenation of methyl laurate as a model compound to hydrocarbons on $\mathrm{Ni}_{2} \mathrm{P} / \mathrm{SiO}_{2}, \mathrm{Ni}_{2} \mathrm{P} / \mathrm{MCM}-41$, and $\mathrm{Ni}_{2} \mathrm{P} / \mathrm{SBA}-15$ catalysts with different dispersions. Energy Fuels. 27(6), 3400-3409.

[240] Yang, Y., Ochoa-Hernández, C., De La Peña O'shea, V.A. Coronado, J.M., Serrano, D.P., 2012. $\mathrm{Ni}_{2} \mathrm{P} / \mathrm{SBA}-15$ as a hydrodeoxygenation catalyst with enhanced selectivity for the conversion of methyl oleate into n-octadecane. ACS Catal. 2(4), 592 598.

[241] Yang, y., Ochoa-hernández, C., Pizarro, P., Víctor, A., Coronado, J.M., Serrano, D.P., 2015. Influence of the Ni/P ratio and metal 
loading on the performance of $\mathrm{Ni}_{\mathrm{x}} \mathrm{P}_{\mathrm{y}} / \mathrm{SBA}-15$ catalysts for the hydrodeoxygenation of methyl oleate. Fuel. 144, 60-70.

[242] Yang, Y., Wang, Q., Zhang, X., Wang, L., Li, G., 2013. Hydrotreating of $\mathrm{C}_{18}$ fatty acids to hydrocarbons on sulphided $\mathrm{Niw} / \mathrm{SiO}_{2}-\mathrm{Al}_{2} \mathrm{O}_{3}$. Fuel Process. Technol. 116, 165-174.

[243] Yilmaz, G., Jongboom, R.O.J., Van Soest, J.J.G., Feil, H., 1999. Effect of glycerol on the morphology of starch-sunflower oil composites. Carbohydr. Polym. 38(1), 33-39.

[244] Yori, J.C., D'ippolito, S.A., Pieck, C.L., Vera, C.R., 2007. Deglycerolization of biodiesel streams by adsorption over silica beds. Energy Fuels. 21(1), 347-353.

[245] Zarchin, R., Rabaev, M., Vidruk-Nehemya, R., Landau, M.V., Herskowitz, M., 2015. Hydroprocessing of soybean oil on nickelphosphide supported catalysts. Fuel. 139, 684-691.
[246] Zhang, H., Lin, H., Zheng, Y., 2014. The role of cobalt and nickel in deoxygenation of vegetable oils. Appl. Catal., B. 160, 415-422.

[247] Zhao, C., Brück, T., Lercher, J.A., 2013. Catalytic deoxygenation of microalgae oil to green hydrocarbons. Green Chem. 15(7), 17201739.

[248] Zhao, H., Baker, G.A., 2013. Ionic liquids and deep eutectic solvents for biodiesel synthesis: a review. J. Chem. Technol. Biotechnol. 88(1), 3-12.

[249] Zhu, X., Lobban, L.L., Mallinson, R.G., Resasco, D.E., 2011 Bifunctional transalkylation and hydrodeoxygenation of anisole over a Pt/Hbeta catalyst. J. Catal. 281(1), 21-29. 